\title{
LONGITUDINAL, NATURALISTIC STUDY OF TRAINING AND SUPPORT FOR IMPLEMENTATION OF EVIDENCE-BASED YOUTH MENTAL HEALTH PRACTICES AMONG COMMUNITY PROVIDERS
}

\author{
A Dissertation \\ presented to \\ the faculty of the Graduate School \\ at the University of Missouri-Columbia \\ In Partial Fulfillment \\ Of the Requirements for the Degree \\ Doctor of Philosophy \\ by \\ BRIGID R. MARRIOTT \\ Dr. Kristin M. Hawley, Dissertation Supervisor
}

JULY 2021 
The undersigned, appointed by the dean of the Graduate School, have examined the dissertation entitled

LONGITUDINAL, NATURALISTIC STUDY OF TRAINING AND SUPPORT FOR IMPLEMENTATION OF EVIDENCE-BASED YOUTH MENTAL HEALTH PRACTICES AMONG COMMUNITY PROVIDERS

presented by Brigid R. Marriott

a candidate for the degree of doctor of philosophy

and hereby certify that, in their opinion, it is worthy of acceptance.

Professor Kristin M. Hawley

Professor Charles M. Borduin

Professor Keith C. Herman

Professor Todd R. Schachtman 


\section{DEDICATION}

I dedicate this dissertation to my parents, Duncan and Margaret Marriott. 


\section{ACKNOWLEDGEMENTS}

I am tremendously grateful to the many individuals who have played a role in my professional development and training. I wish to express my deepest gratitude to my advisor, Dr. Kristin Hawley, for her mentorship and support throughout the preparation of this dissertation and throughout graduate school over the last five years. I would also like to thank Dr. Charles Borduin, Dr. Keith Herman, and Dr. Todd Schachtman for their valuable advice, guidance, and helpful feedback. My appreciation also extends to my lab mates, Jack Andrews, Evelyn Cho, and Siena Tugendrajch, for their assistance in coding the qualitative interviews as well as for their support and encouragement throughout graduate school. Thank you also to the Boone County Children's Services Fund for funding the training initiative and the University of Missouri's Psychological Sciences Graduate Research Fund for support for my dissertation project. Lastly, I would like to thank my parents, two sisters, and my partner, Joel, for their constant support, love, encouragement, and understanding. 


\section{TABLE OF CONTENTS}

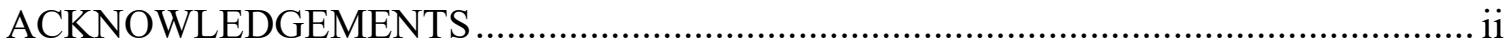

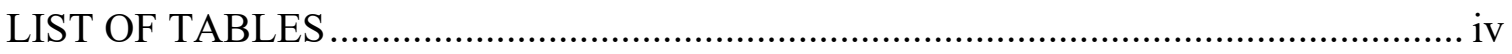

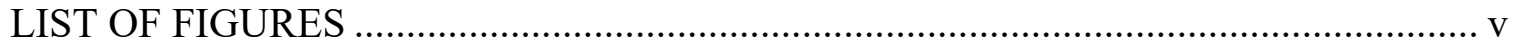

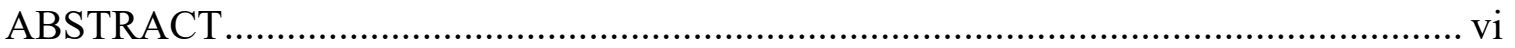

Chapter

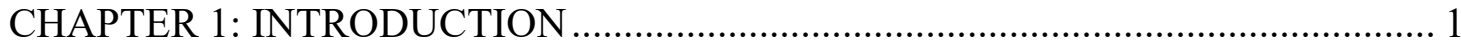

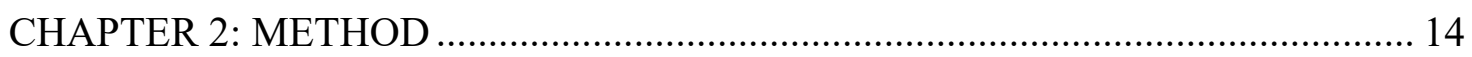

CHAPTER 3: STATISTICAL ANALYSIS PLAN................................................ 25

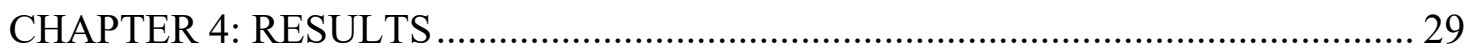

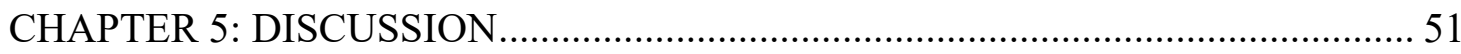

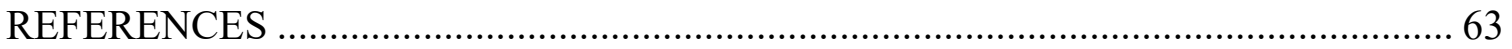

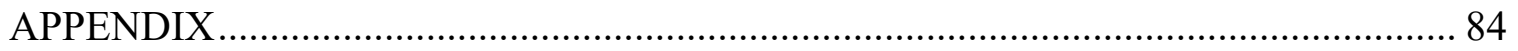

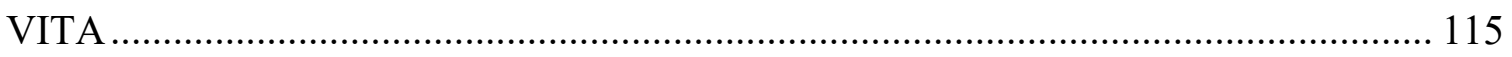




\section{LIST OF TABLES}

Table

Page

1. Workshops and Topics $(\mathrm{N}=62)$....... .84

2. Mental Health Provider Demographic and Practice Characteristics $(\mathrm{N}=717) \ldots . .85$

3. Training Activity Participation $(\mathrm{N}=717)$

4. Negative Binomial Regression Variables Associated with Training Engagement among Mental Health Providers

5. Zero-Inflated Negative Binomial Regression Variables Associated with Anxiety Workshop Registration among Mental Health Providers

6. Zero-Inflated Negative Binomial Regression Variables Associated with Anxiety Workshop Attendance among Mental Health Providers

7. Zero-Inflated Poisson Regression Variables Associated with Depression Workshop Registration among Mental Health Providers

8. Zero-Inflated Poisson Regression Variables Associated with Depression Workshop Attendance among Mental Health Providers

9. Zero-Inflated Negative Binomial Regression Variables Associated with Disruptive Behavior Workshop Registration among Mental Health Providers.....94

10. Zero-Inflated Negative Binomial Regression Variables Associated with Disruptive Behavior Workshop Attendance among Mental Health Providers

11. Model 1: Multilevel Model for Knowledge of Evidence-Based Services $(n=285)$

12. Model 2: Multilevel Model for Specific Evidence-Based Strategy Use ( $n=317) 97$

13. Model 3: Multilevel Model for Common Evidence-Based Strategy Use ( $\mathrm{n}=317)$

14. Model 4: Multilevel Model for Other Therapy Strategy Use $(n=319)$

15. Model 5: Multilevel Model for Confidence in One's Effectiveness in Treating Youth with Anxiety, Depression, Disruptive Behavior, and Trauma $(\mathrm{n}=319) . .100$

16. Model 6: Multilevel Model for Attitudes towards Evidence-Based Practices ( $\mathrm{n}=$ 317) 101

17. Qualitative Questions and Themes .102 


\section{LIST OF FIGURES}

Figure

Page

1. Interaction Effect between Trainee Status and Ongoing Support Activity Participation in Model 1: Predicting Impact of the Training Initiative on

Knowledge 105

2. Interaction Effect between Number of Training Hours, Ongoing Support Activity Participation, and Trainee Status in Model 3: Predicting Impact of the Training Initiative on Common EB Therapy Strategy Use 106

3. Interaction Effect between Trainee Status and Ongoing Support Activity Participation in Model 3: Predicting Impact of the Training Initiative on Common Evidence-Based Therapy Strategy Use.

4. Interaction Effect between Number of Training Hours and Ongoing Support Activity Participation in Model 3: Predicting Impact of the Training Initiative on Common Evidence-Based Therapy Strategy Use....

5. Interaction Effect between Number of Training Hours and Ongoing Support Activity Participation in Model 4: Predicting Impact of the Training Initiative on Other Therapy Strategy Use.

6. Interaction Effect between Trainee Status and Ongoing Support Activity Participation in Model 5: Predicting Impact of the Training Initiative on Provider Self-Reported Confidence 


\begin{abstract}
Ongoing training and implementation support for mental health $(\mathrm{MH})$ providers may help to bridge the often-noted research-to-practice gap in community $\mathrm{MH}$ care. However, $\mathrm{MH}$ providers typically have limited ability to access training or implementation support in evidence-based practices (EBPs). To address this need, the current study describes the reach and impact of a county-wide youth $\mathrm{MH}$ initiative aimed at increasing youths' and families' access to effective youth MH services by providing free EBP training and implementation support to $\mathrm{MH}$ service providers. Specifically, the initiative offered 1) formal workshops focused on specific EBPs, 2) a biweekly learning community, 3) individual case consultation or supervision, and 4) a confidential online session-bysession clinical feedback system. To evaluate the training initiative, we employed a mixed methods approach within a naturalistic, longitudinal design. Providers $(N=717)$ were asked to complete an initial web-based assessment in order to register for trainings and on a yearly basis thereafter ( $n=255$ completed at least one follow-up assessment). Measures included demographics, clinical practice information, self-reported confidence in treating youths with various problem types, organizational implementation climate, and EBP knowledge, attitudes, and practices. Additionally, we completed individual, semi-structured, qualitative interviews with a stratified purposeful sampling of providers $(n=13)$ based on level of participation in the training. While the training initiative had high reach, far fewer providers ultimately engaged in training. Results suggested providers who were trainees, who had higher baseline knowledge of EBPs, who used common evidence-based strategies more extensively, and who used other therapy strategies less extensively, engaged in more training. A provider's stage of career (i.e.,
\end{abstract}


being a pre-service trainee or post-graduate provider) consistently showed differences in training outcomes, with trainees having greater knowledge of EBPs, using common evidence-based strategies and other therapy strategies less extensively, and self-reporting less confidence in their effectiveness than post-graduate providers. Contrary to hypotheses, quantity and method of training were less consistently associated with change in training outcomes. Rapid qualitative analysis of semi-structured interviews complemented and expanded upon the quantitative results, illuminating provider, organizational, system, practical, and training activity-specific barriers and facilitators to training engagement and EBP implementation. Implications for future research and training initiatives are discussed in light of these findings. 


\section{CHAPTER 1: INTRODUCTION}

\section{Implementation Science}

Decades of research have demonstrated the efficacy and effectiveness of many treatments for youth mental health (MH) problems (e.g., Weisz et al., 2013, 2017). In addition to efficacy and effectiveness, evidence-based treatments have also been shown to be more cost-effective (Borduin \& Dopp, 2015; Dopp, Borduin, Wagner, \& Sawyer, 2014; Dopp, Schaeffer, Swenson, \& Powell, 2018). However, these evidence-based treatments still remain underutilized in community MH care (e.g., Cho et al., 2019; Garland, Bickman, \& Chorpita, 2010). Implementation science, which is the scientific study of strategies and methods to increase the uptake or integrate evidence-based treatments into everyday clinical practice, aims to close this research-to-practice gap (Eccles \& Mittman, 2006). For example, implementation strategies (e.g., conducting ongoing training, accessing funding, or mandating change) can be employed within an implementation effort to enhance the uptake of evidence-based practices (EBPs) into community MH care (Powell et al., 2015). While the specific implementation strategies that should be selected and used for a given implementation effort often depends on the context and circumstances, training (e.g., conducting ongoing training, providing ongoing consultation) has been identified as a necessary, though likely not sufficient, strategy for successful implementation and sustainment of EBPs (Frank, Becker-Haimes, \& Kendall, 2020; Okamura et al., 2018; Powell et al., 2015).

\section{Training in EBPs}

Even though training strategies may help to address this research-to-practice gap, a chasm remains between evidence-based training recommendations and training-as-usual 
(Frazier, Bearman, Garland, \& Atkins, 2014; Lim, Nakamura, Higa-McMillan, Shimabukuro, \& Slavin, 2012). Training-as-usual typically consists of didactic presentations or lectures with little to no ongoing support (Beidas \& Kendall, 2010); these didactic, single-shot workshops tend to be characteristic of continuing education for MH providers. Reviews of the training literature have found training-as-usual to alter attitudes and improve declarative knowledge, but workshops in isolation result in minimal behavior change (Beidas \& Kendall, 2010; Davis, Thomson, Oxman, \& Haynes, 1992, 1995; Dave Davis et al., 1999; Frank et al., 2020; Herschell, Kolko, Baumann, \& Davis, 2010; Lyon, Stirman, Kerns, \& Bruns, 2011).

Ongoing support (e.g., consultation, supervision) is thought to be critical to producing behavior change (Beidas \& Kendall, 2010; Frank et al., 2020; Herschell et al., 2010). For example, consultation following initial training results in improved knowledge, attitudes, and greater treatment integrity (e.g., Bearman, Schneiderman, \& Zoloth, 2017; Martino et al., 2016). However, the lasting impact of ongoing supports (e.g., consultation) is unclear, with some studies indicating that change may not be sustained after these supports are removed (Wiltsey-Stirman et al., 2012). Active, behaviorally-oriented learning strategies (e.g., behavioral rehearsal, supervision, feedback) rather than passive learning strategies (e.g., lectures) have been shown to be the most effective at creating behavior change (Beidas \& Kendall, 2010; Herschell et al., 2010). Furthermore, multi-component training packages that include several training components (e.g., treatment manual, workshop, consultation) have demonstrated improved treatment outcomes, including change in skills, knowledge, and client outcomes (Frank et al., 2020; Herschell et al., 2010). In fact, the gold standard of training, often used within efficacy trials, entails an initial workshop, 
a detailed treatment manual, and ongoing supervision or consultation (Sholomskas et al., 2005).

Most of the training literature has focused on how various training methods impact training outcomes within post-graduate provider continuing education. Little research, however, has examined the impact of training and education methods during graduate school (i.e., pre-service training) and how a provider's stage of career (i.e., pre-service trainee vs. post-graduate professional) may influence training outcomes (Becker-Haimes et al., 2019). One reason for this dearth of research is pre-service trainees and postgraduate providers are believed to have differing implementation challenges (BeckerHaimes et al., 2019). Nevertheless, Meyer et al. (2019) found similar perceived practice and training resource barriers to implementation among clinical educators, practitioners, and trainees. Thus, additional research is needed to evaluate training and education methods among post-graduate providers and pre-service trainees (i.e., those enrolled in MH graduate programs).

Beyond training and implementation outcomes, several training studies have shown intensive, effective trainings to also result in improved client outcomes (Campos-Melady, Smith, Meyers, Godley, \& Godley, 2017; Schoenwald, Sheidow, \& Letourneau, 2004; Simons et al., 2010). Implementation outcomes (e.g., adoption, fidelity, sustainability) are proposed to precede client outcomes (Proctor et al., 2011), with client outcomes posited to improve through these implementation outcomes, such as therapist adoption of and fidelity to EBPs. A recent review of the training literature (Frank et al., 2020) found studies of in-person workshop followed by ongoing consultation (Brookman-Frazee, Drahota, \& Stadnick, 2012; Frank et al., 2020; Lu et al., 2012; Simons et al., 2010), 
online training with ongoing support (Jones et al., 2015; Kobak, Wolitzky-Taylor, Craske, \& Rose, 2017), train-the-trainer (Southam-Gerow et al., 2014), and intensive, multi-component training (Karlin et al., 2012; Smith et al., 2017; Walser, Karlin, Trockel, Mazina, \& Barr Taylor, 2013) demonstrated improvement in client outcomes (i.e., symptom improvement, high rates of parent involvement) following training. Therefore, effective, competency-based trainings that can change providers' behaviors and lead to fidelity to EBPs are critical, as EBP adoption and fidelity have been linked to client outcomes (e.g., Hogue et al., 2008; Hukkelberg \& Ogden, 2013; Schoenwald, Carter, Chapman, \& Sheidow, 2008).

\section{Barriers to EBP Training}

Nevertheless, numerous barriers have been associated with these empirically supported, competency-based trainings. Limited opportunity to access effective, affordable training in EBPs is one often-cited roadblock to the implementation of EBPs (Cook, Biyanova, \& Coyne, 2009). Significant time (e.g., multi-day workshops) and financial cost (e.g., cost of the workshop, travel, and lodging) have been identified as roadblocks to obtaining EBP training and resources (Herschell, Reed, Mecca, \& Kolko, 2014; Meyer et al., 2019; Stewart, Chambless, \& Baron, 2012). Providers have also noted competing work demands (e.g., meeting billable hours) as a barrier to attending trainings (Herschell, Reed, et al., 2014). Additionally, an absence of opportunities to refine skills, such as through ongoing supervision or consultation, is also a barrier to EBP use (Cook et al., 2009); for example, consultation requires the availability of a consultant and the provider (Herschell et al., 2010). While web-based trainings may be one potential solution for improving access to effective, affordable trainings in EBPs, limited follow- 
through and completion has also been found for web-based trainings (McMillen, Hawley, \& Proctor, 2016).

Although licensure requirements require continuing education credits every 1-3 years, there are no stipulations that continuing education trainings demonstrate a positive impact on providers' knowledge, attitudes, practices, or fidelity. This is critical as over $40 \%$ of $\mathrm{MH}$ providers in a national survey of professional guild members and $70 \%$ of $\mathrm{MH}$ providers in a statewide survey of Medicaid-billing providers indicated their current practice is most influenced by continuing education (Marriott, Cho, Tugendrajch, \& Hawley, manuscript in preparation). Thus, there is a need to identify effective, feasible, and accessible training strategies, especially training strategies that can be integrated into continuing education for $\mathrm{MH}$ providers.

\section{Training Mechanisms}

Unfortunately, the mechanisms through which training strategies (e.g., workshops, consultation) produce change in training outcomes (e.g., knowledge, skill) have been understudied to date (McLeod et al., 2018). Illuminating the pathways through which trainings produce change can help advance the field's understanding of what different training strategies can accomplish. One proposed process model of change is the Knowledge, Attitude, and Practice (KAP) model, which proposes that a provider first learns about a practice, then forms a positive attitude toward the practice, and then subsequently initiates or starts using the practice (Chaffe \& Roser, 1986; Valente \& Rogers, 1995; Valente \& Saba, 1998). KAP was developed based on social learning theory (Bandura, 1986) and the diffusion of innovations theory (Rogers, 2003), and has been studied and supported for health education and communication (e.g., Rav-Marathe, 
Wan, \& Marathe, 2016). While the KAP model has not been directly tested in the context of MH providers delivering EBPs, provider attitudes, knowledge, self-efficacy, and motivation have been identified as factors that can impact training outcomes and the implementation of EBPs (Lim et al., 2012; McLeod et al., 2018). More research studying behavior change models and the mechanisms of change within the context of implementing EBPs is needed to close the research-to-practice gap (McLeod et al., 2018; Williams, 2016).

\section{Implementation Frameworks}

Even though EBP implementation is a high priority for many $\mathrm{MH}$ providers (e.g., Meyer et al., 2019), there are many factors that influence (e.g., organization climate, external policies and incentives, cost of the intervention) and impact a providers' ability to engage in EBP training and implement EBPs into their clinical practice. Understanding the context in which a provider delivers $\mathrm{MH}$ services is critical to identifying barriers and facilitators to achieving successful implementation and sustainment. While training may be necessary for successful implementation, it is likely not sufficient on its own, as other determinants may play a role and need to be addressed for EBP implementation and sustainment. Implementation determinant frameworks provide a framework of determinants (e.g., barriers, facilitators) that may influence the implementation process.

As one example, the Consolidated Framework for Implementation Research (CFIR) is a comprehensive, multi-level (e.g., individual, organization, and system-level) implementation determinant framework created to guide implementation research (Damschroder et al., 2009). The CFIR was developed by organizing constructs from previous theories, models, frameworks, and syntheses (e.g., Glisson \& Schoenwald, 
2005; Greenhalgh, Robert, Macfarlane, Bate, \& Kyriakidou, 2004; Mendel, Meredith, Schoenbaum, Sherbourne, \& Wells, 2008) and compiling these into a consolidated framework. The CFIR consists of 39 constructs organized into five main domains: intervention characteristics, outer setting, inner setting, characteristics of individuals involved, and implementation process. The intervention characteristics domain entails provider's perceptions of the intervention; for example, the adaptability of an EBP to be able to be adapted to fit a provider's practice and the cost of implementing the EBP may influence a provider's implementation of the intervention. The inner setting domain consists of organizational-level factors, such as the implementation climate or quality of communication within an organization, that might influence implementation, while the outer setting domain includes system-level factors that might affect implementation including the political context and external policies and regulations. The characteristics of individuals domain describes individual characteristics (e.g., a provider's attitudes or self-efficacy related to an intervention) that may influence the implementation of an intervention. Lastly, the implementation process domain identifies four common activities involved in the implementation process (e.g., engaging providers in the implementation of an intervention). The CFIR has been used across a wide range of studies and settings (Kirk et al., 2015), including studies examining the implementation of EBPs within community MH care for both youth and adults (e.g., Beidas et al., 2019; Marques et al., 2016).

\section{MH Provider Interest and Engagement in EBP Trainings}

Powell and colleagues (2013) administered a web-based survey to therapists to identify what motivates or prevents therapists from seeking training; therapists reported 
seeking trainings that taught advanced skills, fit with their clients, and provide continuing education credit. While providers indicated these factors motivated them to seek trainings, training studies have found providers to have low engagement in EBP training, such as low attendance at workshops, on consultation calls, or low rates of completing training cases (e.g., Jensen-Doss et al., 2019; McMillen et al., 2016). Therefore, it is critical to understand the individual and inner context factors that predict providers' engagement in EBP trainings, and in particular, those factors that are malleable. Moreover, only a handful of studies (e.g., Skriner et al., 2018) have explored which individuals choose to engage in EBP trainings or initiatives.

McMillen and colleagues (2016) investigated predictors of clinician engagement in various training activities in a largely web-based trauma-focused cognitive-behavioral therapy (TF-CBT) training study. Findings revealed that older clinicians, professional counselors, and clinicians with greater attitudes about learning an EBP if it would help with job security participated in more training activities. Another study (Skriner, Wolk, et al., 2018) examined therapist characteristics that predicted participation in a systemsponsored EBP initiative, including therapist demographics, burnout, attitudes towards EBPs, EBP knowledge, and self-reported use of therapy strategies. Only number of years spent at the organization was found to be predictive of EBP initiative participation, with a greater number of years at the organization associated with more EBP initiative participation. Jensen-Doss et al. (2019) explored individual and organizational-level predictors of engagement in a community-based learning collaborative for TF-CBT. Interestingly, implementation leadership, attitudes towards EBPs, and professional burnout were not predictive of engagement. Viewing their own practice as more trauma- 
informed and self-reported higher use of TF-CBT components at baseline were predictive of higher engagement in different learning collaborative training requirements, while stronger implementation climate was predictive of lower engagement. Given the mixed findings among these studies, more research is needed to better understand the determinants to engaging in EBP trainings for $\mathrm{MH}$ providers.

\section{Training-Practice Gap}

In addition to the different barriers and facilitators related to engaging in EBP trainings, various determinants influencing the implementation of EBPs into practice exist for MH providers. Attending trainings is often not sufficient on its own for implementation and sustainment. Many providers fail to implement what they learned in trainings into their routine clinical practice, referred to as the training-practice gap (Beidas \& Kendall, 2010; Herschell et al., 2010; Marques, Dixon, Valentine, Borba, Simon, \& Wiltsey Stirman, 2016). Regarding provider characteristics that influence EBP implementation, previous studies have found positive attitudes towards EBPs (Locke et al., 2019; Nelson \& Steele, 2007), less clinical experience (L. Brookman-Frazee, Haine, Baker-Ericzén, Zoffness, \& Garland, 2010), treatment manual use (Becker, Smith, \& Jensen-Doss, 2013; Tugendrajch, Cho, Proctor, McMillen, \& Hawley, 2019) and type of discipline (Higa-McMillan, Nakamura, Morris, Jackson, \& Slavin, 2015; Jensen-Doss \& Hawley, 2011) to be related to providers' implementation of EBPs.

Inner setting, or organizational context factors, have also been shown to be related to the implementation and sustainment of EBPs (e.g., Becker-Haimes, Williams, Okamura, \& Beidas, 2019; Beidas et al., 2019; Glisson et al., 2008). For example, implementation leadership, which is defined as "strategically focused leader behaviors 
that reflect the leader's commitment to, support for, and perseverance during EBP implementation" (Williams, Wolk, Becker-Haimes, \& Beidas, 2020), and implementation climate, or the shared perceptions members of an organization have that the implementation of EBPs is rewarded, supported, and expected in their organization (Ehrhart, Schneider, \& Macey, 2013; Williams et al., 2020), have been identified as organizational context variables that affect EBP implementation. A recent study longitudinally examined the influence of implementation leadership and EBP implementation climate on clinicians' use of EBPs across a five-year span (Williams et al., 2020). Findings revealed that when first-level leaders (i.e., leaders who directly supervise clinicians) increased their use of implementation leadership behaviors (e.g., support EBP implementation, demonstrate and role model EBP implementation), this led to improvements in EBP implementation climate within the organization, which in turn led to an increase in clinicians' use of EBPs in their practice. However, the role of inner setting factors has not been consistent across studies, with some studies finding implementation leadership and climate to not be predictive of EBP implementation (Locke et al., 2019). Additional research is needed to understand these mixed findings and elucidate the role of provider characteristics and inner setting factors as well as the interaction of provider-level and inner setting factors on providers' implementation and sustainment of EBPs.

\section{Current Study}

In sum, training has been identified as a necessary strategy for the implementation of EBPs (Okamura et al., 2018; Powell et al., 2015). The training literature to date indicates that training with little to no ongoing support following initial training does not yield 
adherent providers (e.g., Beidas \& Kendall, 2010), while intensive training approaches (e.g., multi-component training packages, ongoing support and feedback) have been shown to yield adherent providers (e.g., Bearman et al., 2017; Martino et al., 2016). Providers, however, have limited opportunity to access these more intensive, effective trainings (Cook et al., 2009; Herschell, Reed, et al., 2014; Stewart et al., 2012). Thus, more accessible and effective ongoing provider training in EBPs is needed.

To address this need, we designed a suite of training activities to try to approximate these more intensive trainings but in a more accessible and acceptable way to $\mathrm{MH}$ providers. This training initiative grew out of a county-wide effort to improve youths' and families' access to effective youth MH services and is supported by a voter-approved sales tax (Herman, Reinke, Thompson, \& Hawley, 2019). This local quarter-cent sales tax on purchases created the Boone County Children's Services Fund, which supports a range of services to support the wellbeing of youth and families in the county. A review and synthesis of existing county-level reports and several community input sessions to determine areas that should be targeted by the initiative revealed 1) the need for continued professional development among $\mathrm{MH}$ providers in EBPs and 2) the prohibitive expense associated with continuing professional development in EBPs (Schumacher, Arment, \& Meyers, 2014). Thus, the training initiative aimed to improve access to effective youth MH services by increasing the availability of providers trained in EBPs. The initiative provided EBP training and implementation support at no charge to $\mathrm{MH}$ service providers (e.g., school counselors, case managers, social workers, psychologists, professional counselors, medical personnel, educators). Through this project, $\mathrm{MH}$ providers could attend workshops on specific EBPs, individual case consultation, weekly 
individual and group supervision, a biweekly learning community, and/or use a confidential online session-by-session clinical feedback system - all services were free to the clinician. The training initiative began in 2015 and has been ongoing for over four years.

The current study was an evaluation of this voluntary, community-based, EBP training initiative. We employed a mixed methods approach within a longitudinal, naturalistic design. Qualitative data were compared with and expanded upon the quantitative findings for each aim below to better understand $\mathrm{MH}$ provider engagement and implementation of EBPs in the training initiative. The study was guided by the following aims and hypotheses:

Aim 1) Determine the reach of the training initiative. We hypothesized that the training initiative will reach a majority of the agencies and providers in the county (Heck, Saunders, \& Smith, 2015; McMillen et al., 2016). We further hypothesized that workshops will show the greatest reach, as evidenced by more providers attending formal workshops than consultation, supervision, the learning community, or using the online clinical feedback system (McMillen et al., 2016).

Aim 2) Examine provider characteristics and organizational factors (e.g., discipline, attitudes, knowledge, organizational climate) as predictors of participation, or engagement, in training. Given only a few studies have explored this question (e.g., Jensen-Doss et al., 2019; Skriner et al., 2018) and there has been mixed findings, this aim is exploratory and no a priori hypotheses were posited.

Aim 3) Explore providers' interest and engagement in specific workshops. We hypothesized that providers will register for and attend workshops that advance their 
existing skill set, as evidenced by providers being more likely to register and attend workshops covering topics they (1) self-reported greater confidence in treating and (2) about which they showed more pre-attendance knowledge (Jensen-Doss et al., 2019; Powell et al., 2013). We also hypothesized that more extensive pre-attendance evidencebased (EB) strategy use would predict greater registration and attendance of workshops (Jensen-Doss et al., 2019; Powell et al., 2013).

Aim 4) Examine the effectiveness of the training initiative in changing provider training outcomes over time including: (a) provider knowledge of EBPs, (b) attitudes regarding the efficacy and feasibility of EBPs, (c) confidence in their own efficacy in treating youths, and (d) use of EB strategies in their clinical practice. It is hypothesized that providers who only attended workshops will have a significant increase in knowledge and attitudes but will not significantly change their confidence or practices (i.e., use of EB strategies), while those who attended ongoing support activities would demonstrate change across all four training outcomes (Beidas \& Kendall, 2010; Davis et al., 1992, 1995; Davis et al., 1999; Frank et al., 2020; Herschell et al., 2010; Lyon et al., 2011).

Aim 5) Compare with and expand upon the quantitative findings in the first four aims using qualitative methods to better understand provider engagement and implementation of EBPs in the training initiative. 


\section{CHAPTER 2: METHOD}

\section{Participants and Eligibility}

Community providers and trainees across $\mathrm{MH}$ disciplines (e.g., psychology, counseling, social work) who serve youth in Boone County were eligible to participate in EBP trainings at no charge (i.e., workshops, learning community, individual consultation or weekly individual and group supervision, online clinical feedback system). Providers were recruited via email to participate in EBP trainings. Emails contained information on upcoming workshops and other training opportunities. At the beginning of the project, emails of community providers were collected through websites and contact information found online. After the initial creation of the email list, providers could self-select to sign

up for the training announcements via the web-based registration survey described below. In addition, providers could learn about training opportunities through the initiative's website: http://youthmentalhealth.missouri.edu/providerservices.html. Participants consisted of 717 community $\mathrm{MH}$ providers and trainees.

\section{Procedure}

Quantitative. Providers received emails about training opportunities. Providers wanting to participate in any of the EBP trainings were asked to complete a web-based registration survey via Qualtrics to register. This web-based survey consisted of several measures described below and took approximately 15-30 minutes to complete. Providers created an account with their own username and password to access the survey and to register for trainings. Providers were initially asked to complete the registration survey prior to registering for any trainings and subsequently, every 8-14 months thereafter in order to register for additional trainings. We also emailed a selected subset of providers at 
two different time points (December $2017[n=90] \& 2018[n=243]$ ) offering a $\$ 20$ incentive to complete the survey a second time, to get a more representative sample of providers beyond just those who continued to be interested in attending trainings. We specifically emailed providers who had not yet completed the survey for a second time and it had been over eight months since their first survey completion. We had a $24.44 \%$ response rate $(n=22$ out of 90$)$ in December 2017 and $33.33 \%$ response rate $(n=81$ out of 243) in December 2018. Overall, some 717 providers have completed the registration survey once, 255 have completed it twice, 85 have completed a third assessment point, 20 have completed the survey four times, and 4 have completed a fifth assessment point across the last four years, with an average of 398.82 days $(S D=179.97$, range $=12$ to 1063 days) between surveys.

Qualitative. A subset of providers $(N=47)$ was selected to participate in a semistructured qualitative interview to better understand provider engagement and implementation of EBPs. Providers were selected using stratified purposeful sampling (Palinkas et al., 2015), based on the types of training activities they participated in (e.g., from all four activities to none) and number of workshops they attended (e.g., none, 1-5, $6-10,11+$ workshops), to capture variation among providers. Selected providers $(N=47)$ were emailed a request to participate in an in-person individual interview at a location convenient for them. Of those contacted, 15 (31.91\%) providers responded indicating interest, and $13(27.66 \%)$ providers ultimately participated in an interview. 


\section{Training Activities}

Four training activities were offered at no charge to $\mathrm{MH}$ providers: workshops, individual case consultation and/or weekly individual and group supervision, biweekly learning community, and online clinical feedback system.

Workshops. The workshops $(N=62)$ covered numerous topics and primarily focused on the four common MH problems found in youth - e.g., anxiety, depression, behavior problems, trauma (see Table 1 for all the content covered in workshops). The content of these workshops was based on the core components of evidence-based treatments for a given problem type (e.g., CBT + exposure for anxiety), rather than focusing on name brand protocols (e.g., Coping Cat for anxiety). More specifically, workshops on anxiety emphasized exposure as well as other cognitive-behavioral treatment strategies (e.g., relaxation); depression workshops focused on behavioral activation and cognitive-behavioral treatment strategies; disruptive behavior workshops concentrated on behavior parent training strategies and cognitive-behavioral treatment strategies for older youth; and lastly, trauma workshops highlighted trauma narrative and cognitive processing of the trauma and cognitive-behavioral treatment strategies. We integrated active, behaviorally-oriented learning strategies, such as discussion, role-play, and feedback, into the workshops in addition to didactics. To reduce barriers to participation in workshops, all workshops were provided locally with no charge for participation, and $\mathrm{MH}$ providers were surveyed to determine the optimal length, day of the week, and time of day to hold the workshops. In addition, continuing education credits, required for maintenance of professional licensure, were provided for participants. 
Biweekly learning community (LC). The ongoing LC entailed biweekly meetings of MH providers and an EBP expert, a clinical psychologist at the University of Missouri. LCs consisted of professional development; learning about research supported practices for children, adolescents, young adults, and parents; consultation on $\mathrm{MH}$ providers' cases; and peer consultation and support among MH providers to provide the best possible care. Seventy-seven LC meetings were held from 05/10/2016 to 08/27/2019.

Consultation and Supervision. Individual case consultation between an EBP expert (i.e., the consultant) and MH provider to support the implementation of EBPs in a provider's ongoing practice was offered to interested MH providers. Consultation is described as external support and a non-hierarchical, collaborative relationship between the consultant and consultee; the consultant seeks information or help with a professional problem or topic, treatment planning for a client(s), and application of therapy techniques (Knotek \& Hylander, 2014; Nadeem, Gleacher, \& Beidas, 2013). If a MH provider was interested in receiving consultation, the provider could either (a) contact the consultant directly, or (b) complete a request for consultation on the online registration survey. The consultant was an EBP expert who is a clinical psychologist at the University of Missouri.

In addition, individual and group supervision-consultation were provided to trainee $\mathrm{MH}$ providers who were participating in a youth evidence-based treatment practicum as part of the training initiative. The supervisors were EBP experts who are licensed health service provider psychologists and faculty at the University of Missouri. Supervision usually entails internal support and is an ongoing, evaluative, and often 
hierarchical relationship between a supervisee (e.g., more junior professional) and supervisor (e.g., more senior professional) as part of their work, with the purpose of developing professional competence, gatekeeping, and ensuring service quality (Falender et al., 2004; Nadeem et al., 2013). Trainee MH providers who participated in the practicum attended weekly one-hour individual and two-hour group supervisionconsultation.

Online clinical feedback system. The online clinical feedback system was a confidential online session-by-session measurement feedback system. It provided MH providers with formal, written feedback and helped them with ongoing self-evaluation and improvement of client outcomes. Providers as well as youth clients and their caregivers would fill out an online questionnaire after each session appointment. In the questionnaire, providers, clients, and caregiver(s) reported on therapy session activities, youth $\mathrm{MH}$ symptoms, and youth and parent working alliance with providers through the online system. Based on the submitted questionnaire, providers were emailed individualized feedback reports on how well their approach fit the "research evidence" for treating the most common youth referral problems and how the youth was progressing in treatment in terms of their internalizing and externalizing symptoms and their selfidentified top problems.

Provider, youth client, and caregiver report of therapy session activities was measured via the 22-item Cognitive Behavioral Therapy Adherence Measure (Hawley, 2019), which assesses core components of evidence-based cognitive-behavioral therapy for youth anxiety, depression, disruptive behavior, and trauma. Youth MH symptoms were assessed via a standardized symptom measure and an idiographic measure. The 
Symptoms and Functioning Severity Scale (SFSS; Bickman et al., 2010) is a 26-item (27item for providers) standardized measure of the most commonly reported youth symptoms of emotional and behavioral problems; the SFSS has two short forms that are each 13-items and can be alternated. The two alternating short forms are used in the clinical feedback system. On the SFSS, respondents rate how often the youth experienced internalizing and externalizing symptoms on a 5-point Likert scale of "Never" to "Very Often." The SFSS has demonstrated good to excellent reliability, construct validity, and convergent validity (Bickman et al., 2010). The Top Problems Assessment (TPA; Weisz et al., 2011) is a 3-item idiographic measure of the three most important problems that the provider and family are working on in therapy. These problems are generated by the family and provider and are rated on a scale of 0 to 10 from "not at all a problem" to "a huge problem." The TPA has shown high test-retest reliability, convergent validity, discriminant validity, sensitivity to change, and slope reliability (Weisz et al., 2011).

\section{Registration Survey Measures}

The web-based registration survey included several measures which were administered in the order below.

\section{Provider Demographics form (Cho et al., 2019; Weersing, Weisz \& Geri, \&}

Donenberg, 2002). This form was based on prior MH provider surveys and questionnaires about personal demographics. The form asked for gender, age, race, degree level, primary mental health discipline, and licensure status. All providers were administered the demographics form.

Practice Characteristics form (Cho et al., 2019; Weersing et al., 2002). Similar to the Provider Demographics form, this form was based on previous surveys about 
practice characteristics and inquired about MH services provided, years of experience, current employment setting, and years with current employer. In addition, this form asked providers about treatment manual use; general use of research supported strategies; and ongoing assessment use at intake, throughout treatment, at last session, and after the last session in their current practice using a 7-point Likert scale from "never (with none of my cases)" to "always (with all of my cases)." Only providers who indicated they provided mental or behavioral health services were administered this form.

Confidence in Treating Youth (developed in house). This 17-item survey measures how confident a provider feels about their effectiveness in treating children and adolescents with a number of problems and concerns (e.g., fears or anxiety, depression or mood, autism spectrum). Providers rated their level of confidence on a 6-point Likert scale from "not at all confident" to "extremely confident" in treating 17 problems or concerns. Similar to the practice characteristics form, only providers who indicated they provided mental or behavioral health services completed this form.

\section{Evidence-Based Practice Attitudes Scale-50 (EBPAS-50; Aarons, Cafri,}

Lugo, \& Sawitzky, 2012). EPBAS-50 is a 50-item measure that assesses providers' attitudes toward evidence-based practices by rating the extent to which they agree with statements using a 5-point Likert scale of "Not at all" to "To a Very Great Extent." This measure has demonstrated high internal consistency (Aarons, 2004; Aarons et al., 2012) and has 12 subscales: Openness, Burden, Divergence, Balance, Feedback, Limit, Organizational Support, Job Security, Fit, Appeal, and Requirements. In the current study, internal consistency ranged from questionable to excellent: Openness (Cronbach's $\alpha=0.83)$, Divergence $(\alpha=.74)$, Appeal $(\alpha=.85)$, Requirements $(\alpha=.94)$, Fit $(\alpha=.92)$, 
Limitations $(\alpha=.95)$, Monitoring ( $\alpha=.89)$, Balance $(\alpha=.60)$, Burden $(\alpha=.86)$, Job Security $(\alpha=.88)$, Organizational Support $(\alpha=.84)$, and Feedback $(\alpha=.89)$. All providers were administered the EBPAS-50.

Evidence-Based Behavioral Strategies Scale (EBBSS; Cho et al., 2019) and Cognitive Behavioral Therapy Adherence Measure (CBTAM; Hawley, 2019). To assess evidence-based practice use and adherence, items from the EBBSS and CBTAM were used. First, providers were asked to think back on their recently completed youth cases (aged 0-19) and select a case that was representative of their typical practice and answer questions about this selected case. From the EBBSS, providers were asked to provide demographic information (e.g., gender, age, race, ethnicity, income level, and funding source) and the primary and any secondary presenting problems or concerns (e.g., fears or anxiety, disruptive behavior or conduct problems) about the selected case. In addition, providers indicated whether they used a treatment manual, whether the youth was on psychiatric medication, caregiver level of involvement in the treatment, and the location of treatment (e.g., home, school) for the selected case. Providers also selfreported on how much improvement the youth experienced and the degree of therapeutic alliance for the selected case. Lastly, providers rated their use of 35 therapy strategies on 6-point Likert scales from "Not at all (e.g., I never used this strategy with this case)" to "A lot (e.g., I used this strategy extensively; it was a very big part of the treatment for this case)." The therapy strategies included "common" EB strategies for anxiety, depression, trauma, and behavior problems, which are strategies with research support across problem types (e.g., relaxation, psychoeducation), "specific" EB strategies, which are strategies with research support for specific problem types (e.g., exposure for anxiety, 
activity scheduling for depression), and "other" strategies, which are strategies without research support for a given problem type (e.g., gaining insight, exposure for disruptive behavior disorder; Cho et al., 2019). We calculated three scores: common EB strategies, specific EB strategies, and other therapy strategies score. Strategies were categorized based on the youth's primary and secondary problems noted by the provider. Only providers who reported they currently provide therapy or therapy supervision for children, adolescents, or young adults (up to 19 years) were administered the evidencebased strategy use survey.

\section{Implementation Climate Scale (ICS; Ehrhart, Aarons, \& Farahnak, 2014).}

To measure organizational context, or inner setting, variables, the ICS was used. The 18items assess six dimensions of implementation climate including selection for openness, recognition for EBP, selection for EBP, focus on EBP, educational support for EBP, and rewards for EBP. The ICS has shown good to excellent reliability, construct validity, and has revealed a six-factor structure (Ehrhart et al., 2014; Ehrhart, Torres, Wright, Martinez, \& Aarons, 2016). Internal consistency for our study ranged from good to excellent: Focus on EBP $(\alpha=.94)$, Educational Support for EBP $(\alpha=.92)$, Recognition for EBP Scale $(\alpha=.85)$, Rewards for EBP $(\alpha=0.90)$, Selection for EBP $(\alpha=.92)$, and Selection for Openness $(\alpha=.94)$. Only MH providers who work within a team or agency completed this measure.

\section{Knowledge of Evidence-Based Services Questionnaire (KEBSQ; Stumpf,}

Higa-Mcmillan, \& Chorpita, 2009). KEBSQ is a 40 -item test that assesses a provider's knowledge of discrete treatment techniques for anxious/avoidant, depression/withdrawn, disruptive behavior, and attention/hyperactivity problem areas. Providers indicate 
whether an item, or discrete treatment technique, is derived from the evidence base for each problem area (yes/no). The provider receives a point for each treatment technique correctly indicated as being derived or not derived from the evidence base for each problem area, and thus, each item is scored on a scale from 0 to 4 , with a possible total score range of 0 to 160 . Of note, the KEBSQ does not assess knowledge of practices derived from research for youth trauma. The KEBSQ has demonstrated acceptable testretest reliability, sensitivity to training, and discriminant validity (Stumpf et al., 2009) and support for three factors: high extent and coverage, low extent and coverage, and high extent and low coverage (Okamura, Nakamura, Mueller, Hayashi, \& McMillan, 2016). All providers were administered the KEBSQ.

\section{Training Participation Measures}

Data regarding workshop registration was collected through the web-based registration survey. Workshop attendance data (i.e., presence at workshop, number of hours) were collected in person at the workshops. Participation in individual consultation (i.e., presence at a consultation session and number of hours) and supervision (i.e., presence at a supervision session and number of hours) was tracked by the consultant or supervisor following a consultation or supervision session. Attendance and number of hours at the biweekly LCs was collected in person at the LCs. Registration for the online clinical feedback system was tracked through creating an account for the feedback system and use of the feedback system was tracked through submission of a session report in the online system. 


\section{Qualitative Interviews}

The semi-structured interview questions were developed based on prior literature (Beidas et al., 2016; Herschell, Reed, et al., 2014; Wiltsey Stirman et al., 2013). The interview guide had specific questions exploring providers' experiences with the training initiative, determinants of both their participation in training activities and their implementation of EBPs in practice, and finally, their experiences with the voterapproved sales tax that funded the training initiative. The interview guide can be found in the Appendix. 


\section{CHAPTER 3: STATISTICAL ANALYSIS PLAN}

\section{Quantitative Data Analysis}

Aim 1: Training Initiative Reach and Participation. We ran descriptives and frequencies to investigate participation in training activities and the reach, or number of agencies who participated in the initiative compared to the number of agencies in the county (Glasgow, Vogt, \& Boles, 1999), of the initiative. The number of agencies in the county was based on a larger database of individual and agency-based providers who serve Boone County youths ages 0-19 years. This database was developed based on the initial county-level report (e.g., Schumacher et al., 2014) and further developed by the Family Access Center of Excellence, a cross-sector implementation center in the county (Herman et al., 2019).

Aim 2: Predictors of Training Engagement. Due to overdispersion, we used negative binomial regressions to predict a count of hours of engagement in training activities (i.e., number of hours attending workshops, biweekly learning community, consultation, and/or supervision). Negative binomial models provide a better fit over other count models (e.g., Poisson) for overdispersion. The inclusion of provider and organizational factor variables was guided by previous literature and theory (e.g., JensenDoss et al., 2019; McMillen et al., 2016; Skriner, Benjamin Wolk, et al., 2018) and based on statistically significant correlation analyses conducted between predictor variables and the outcome variable. Predictor variables examined included pre-training EBP attitudes, EBP knowledge, common EB strategy use, specific EB strategy use, other therapy strategy use, provider mental health discipline (i.e., psychology discipline), trainee status, 
provider age, years of experience, number of years at current employer, work setting (i.e., agency setting or not), and organizational implementation climate.

Aim 3: Specific Workshop Interest and Engagement. We performed zero-inflated Poisson and negative binomial regression models to predict workshop registration and attendance at anxiety, disruptive behavior, and depression workshops. Zero-inflated models are useful for when an excess of zero counts are present; these models predict both excess zero counts using a logit model and count scores using a Poisson or negative binomial count model. We determined the best model for each analysis based on the distribution, dispersion, and excess zeros of the dependent variable and by testing the fit of the different models (i.e., AIC). Predictor variables included self-reported pre-training confidence in treating the applicable problem type (e.g., confidence in treating anxiety for predicting anxiety workshop registration and attendance), pre-training knowledge of EB treatment techniques for the applicable problem type, the primary and secondary presenting problems of the case selected for the therapy strategy use survey (e.g., whether or not the provider reported on an anxiety case for predicting anxiety workshop registration and attendance), pre-training common EB strategy use, specific EB strategy use, and other therapy strategy use.

Aim 4: Effectiveness of Training Initiative. We used a longitudinal multi-level modeling (MLM) approach to examine changes in training outcomes over time both between- and within-providers. The two-level models included surveys nested within providers. Analyses examined the relationship between time, number of hours of training completed, ongoing support training activity participation $(1=$ participation, $0=$ no participation $)$, trainee status $(1=$ trainee, $0=$ non-trainee $)$, and training outcomes. To 
determine the most parsimonious model, all models began with the maximal model and then a model-selection strategy was conducted (Barr, Levy, Scheepers, \& Tily, 2013; Matuschek, Kliegl, Vasishth, Baayen, \& Bates, 2017).

\section{Qualitative Data Analysis}

Aim 5: Qualitative Interviews with Providers. Qualitative interviews were audio recorded and transcribed verbatim. Rapid qualitative analysis of transcripts was conducted to compare with and expand upon quantitative findings (Gale et al., 2019; Hamilton, 2013). Rapid qualitative analysis has been shown to be a feasible and reasonable alternative to in-depth qualitive analysis (Gale et al., 2019). First, we developed a summary template based on the interview guide to summarize each transcript. After the initial development of the summary template, the template was tested on one transcript by the entire summarizing team (four doctoral graduate students). The team subsequently met to compare their summaries and modify the template. The template was then tested on a second transcript using the modified template summary (see Appendix). The team met again to compare their summaries and establish consistency across coders. After establishing consistency, the remaining transcripts were divided up among the team, with each template summarized by two members of the summarizing team. Lastly, all of the completed transcript summaries were consolidated into a matrix. The matrix was collaboratively and iteratively reviewed and discussed by the summarizing team to determine cross-cutting themes and sub-themes.

\section{Mixed Methods Analysis}

The study used a sequential collection and analysis of the data, starting with the quantitative data followed by the qualitative data (QUAN $\rightarrow$ Qual; Palinkas et al., 2011). 
The functions of the mixed methods analysis were complementarity and expansion with the purpose of connecting the two methods, with the qualitative interviews building upon the quantitative surveys. The analysis aimed to use the quantitative surveys to provide breadth of understanding and the qualitative interviews to provide depth of understanding to the quantitative findings (i.e., complementarity) and to have the qualitative interviews expand upon the quantitative findings (i.e., expansion). 


\section{CHAPTER 4: RESULTS}

\section{Participants}

MH providers were majority female $(n=615,85.77 \%)$ and Caucasian $(n=584$, $81.45 \%)$, with a mean age of 36.67 years $(S D=11.86$, range $=21$ to 84$)$. Providers were predominantly Master's level $(n=404,56.35 \%)$, representing social work $(n=238$, $39.47 \%)$ and counseling $(n=206,28.73 \%)$ disciplines, and were fully licensed mental health providers $(n=222,30.96 \%)$. Providers were most commonly employed at outpatient or community mental health centers $(n=232,32.36 \%)$ or in private practice $(n$ $=128,17.85 \%$ ). Providers on average had been providing mental services for 8.06 years $(S D=8.65$, range $=0$ to 45$)$. Some $45.19 \%$ of providers $(n=324)$ currently provided therapy or therapy supervision for youth and young adults. The most common mental or behavioral health services provided by providers were talk or behavior therapy $(n=387$, $53.97 \%)$, assessment/testing $(n=327,45.61 \%)$, and case management $(n=309,43.10 \%)$. See Table 2 for $\mathrm{MH}$ provider demographics and practice characteristics.

\section{Data Screening}

We also conducted analyses to screen the data and determine if the data were missing at random. Less than 5\% of data were missing for most of the demographic, practice, and ICS items. Greater than $5 \%$ of the data were missing for provider age $(5.5 \%)$, mental health licensure $(9.2 \%)$, items from the therapy strategy use survey $(5.0-$ 7.2\%), EBPAS items $(6.7-7.3 \%)$, and KEBSQ items $(14.8 \%)$. While some items were missing by design (e.g., only those who indicated being a part of an agency or team were administered the ICS), fatigue or interruptions while taking the survey may have also played a role given the amount of missing data increased as the survey went along (e.g., 
later KEBSQ items had more missing responses than the earlier EBPAS items). This corroborates email correspondence a few MH providers had with the training initiative indicating the survey was too long and they started the survey but could not complete it. To determine whether the data were missing completely at random, we performed Little's MCAR test. Little's MCAR test was not statistically significant $\left(\chi^{2}(6332)=6403.91, p=\right.$ .26), suggesting the data were missing at random. As such, we proceeded with planned analyses despite having somewhat more missing data for the last measures on the survey.

Data were also screened to exclude invalid responding from analyses. For example, and perhaps related to fatigue, some providers appeared to skip through the survey by "straightlining," or responding with the same response throughout a measure (i.e., answering all 1's or 2's). For the therapy strategy use survey, $20(3.73 \%)$ responses were determined to be straightlining, 54 (5.34\%) EBPAS responses, 99 (13.29\%) ICS items, and $133(14.39 \%)$ KEBSQ items. These straightlining responses were excluded from analyses. In addition, of the 717 providers, 324 (45.19\%) providers indicated they currently provide therapy or therapy supervision for children, adolescents, or young adults, 293 (40.86\%) indicated they did not, and the remaining 100 providers $(13.95 \%)$ either primarily did not provide any mental health services (e.g., student, foster parent) or a few were unknown due to missing data. Providers who did not provide therapy or therapy supervision to youth and young adults were also excluded from Aim 2, 3, and 4 analyses because they were not asked the items related to therapy and therapy supervision. 


\section{Quantitative Results}

Aim 1: Training Initiative Reach. Providers were primarily from Boone County $(n=564,78.80 \%)$; however, the initiative reached beyond the county, with $153(21.34 \%)$ providers from other counties (33 counties) participating in the initiative. Providers from 157 agencies, organizations, and private practices within the county and in primarily surrounding counties registered on the website through the web-based survey. The number of agencies, organizations, and practices who participated in the initiative (157 agencies or practices) exceeded the list of agencies and practices within and surrounding the county (106 agencies or practices) compiled by the local cross-sector implementation center in the county. While the initiative was far reaching, 36 of the 106 agencies or practices previously identified in the county did not have any providers who participated in the initiative.

Aim 1: Training Initiative Participation. Registered providers participated most frequently in formal workshops $(n=479$ providers, $66.81 \%)$ and less often in Learning Community (LC; $n=47,6.56 \%)$, individual case consultation $(n=33,5.60 \%)$, ongoing supervision $(n=19,2.65 \%)$, and the online clinical feedback system $(n=42,5.86 \%)$. Of providers who registered, 224 did not participate in any training activity $(n=224$, $31.24 \%)$. The most common pattern for providers were to attend workshops only $(n=$ $400,55.79 \%)$, the second most frequent was workshops and LC $(n=23,3.21 \%)$, and the third most was workshops, individual consultation or supervision, and use of the clinical feedback system $(n=20,2.79 \%)$. Only 6 providers $(0.84 \%)$ participated in all four training activities (See Table 3). 
For formal workshops, providers who registered for at least one workshop $(n=$ 606 providers, $84.52 \%)$ registered on average for 4.26 workshops $(S D=5.06$, range $=1$ to 39). Providers who attended at least one workshop ( $n=479$ providers, $66.81 \%)$ attended on average 2.90 workshops $(S D=3.12$, range $=1$ to 20$)$ and had 8.93 workshop continuing education hours $(S D=8.93$, range $=1.25$ to 55.80$)$. Providers who participated in consultation attended on average 2.65 hours of consultation $(S D=3.45$, range $=0.20$ to 20 ). Regarding supervision, providers attended on average 127.63 total hours of supervision $(S D=63.23$, range $=48$ to 250 ), 53.32 hours of individual supervision $(S D=26.36$, range $=16$ to 104$)$, and 81.89 hours of group supervision $(S D=$ 39.03 , range $=32$ to 148$)$ over an average of 15.95 months $(S D=8.29$, range $=5$ to 30$)$. Finally, 42 (5.86\%) providers registered for the online clinical feedback system. However, only $30(71.43 \%)$ used the online clinical feedback system at least once. Of those providers who used the system, they used it with an average of 9.63 cases $(S D=$ 7.60 , range $=1$ to 29$)$ and for 100.2 sessions $(S D=95.68$, range $=2$ to 424$)$.

Aim 2: Predictors of Training Engagement. Time (i.e., years) participating in the initiative, was included as a covariate in the model, as it was significantly, positively associated with number of training hours. We performed two negative binomial regression analyses, one without organizational implementation climate (i.e., ICS total score) as a predictor and one with organizational implementation climate as a predictor. We ran two separate models because only those providers who indicated working as part of a team or agency were administered the ICS; thus, the second model was only looking at $\mathrm{MH}$ providers within an agency or team. 
The analysis without organizational climate as a predictor included both agency and non-agency $\mathrm{MH}$ providers. For this model, the covariate time $(B=0.55, S E=0.07, p$ $<.01, \mathrm{IRR}=1.73,95 \% \mathrm{CI}: 1.50-1.99)$ remained predictive of engaging in more training. In addition, provider's baseline knowledge of EB services $(B=0.03, S E=0.01$, $p<.01$, Incidence Rate Ratio [IRR] $=1.03,95 \%$ CI: $1.02-1.04$ ), less use of other therapy strategies $(B=-0.27, S E=0.11, p<.05$, IRR $=0.76,95 \%$ CI: $0.60-0.95)$, more use of common EB strategies $(B=0.25, S E=0.10, p<.01$, IRR $=1.29,95 \%$ CI: $1.06-$ 1.57), and being a trainee $(B=0.89, S E=0.20, p<.01, \mathrm{IRR}=2.44,95 \%$ CI: $1.61-3.76)$ were also predictive of engaging in more training (see Table 4). There was a 3\% increase in incident rate of training engagement for every one-unit increase in provider knowledge of EB practices and 29\% increase in incident rate of training engagement for every oneunit increase in provider's use of common EB strategies; thus, providers with greater knowledge of EB services and who more extensively used common EB strategies had greater training engagement. Being a pre-service trainee (i.e., a provider enrolled in a $\mathrm{MH}$ graduate program) was associated with a $144 \%$ increase in incident rate of training engagement compared to post-graduate $\mathrm{MH}$ providers. Moreover, a one-unit increase in provider use of other therapy strategies was associated with a $24 \%$ decrease in the incident rate of training engagement.

For the analysis including the organizational implementation climate variable, we found similar results. Being a trainee $(B=1.03, S E=0.23, p<.01$, IRR $=2.81,95 \% \mathrm{CI}$ : $1.72-4.68)$, provider's baseline knowledge of EB services $(B=0.03, S E=0.01, p<.01$, $\mathrm{IRR}=1.03,95 \% \mathrm{CI}: 1.01-1.05)$, and the covariate time $(B=0.52, S E=0.08, p<.01$, $\mathrm{IRR}=1.67,95 \%$ CI: $1.42-1.97)$ were statistically significant predictors of hours of 
training engagement (see Table 4). Being a pre-service trainee was associated with a $181 \%$ increase in the incident rate of training engagement compared to post-graduate providers. For every one-unit increase in knowledge score, there was a 3\% increase in the incident rate of training engagement. Additionally, provider's use of common EB strategies $(B=0.21, S E=0.11, p=0.06, \mathrm{IRR}=1.24,95 \% \mathrm{CI}: 0.98-1.56)$ was trending towards significance. Organizational implementation climate was not a statistically significant predictor of engagement in training.

Aim 3: Specific Workshop Interest and Engagement. Similar to Aim 2, we included time, (i.e., years) participating in the initiative, as a covariate in the model, due to significant, positive associations between time and number of workshops registered and attended. Three types of EBP knowledge scores were calculated to examine specific EBP knowledge for anxiety, depression, and disruptive behavior disorders. Using similar scoring as the KEBSQ total score, providers received a point if they correctly indicated a treatment technique as being derived or not derived from the evidence base for a problem area. Unlike the KEBSQ total, these specific scale scores only included the items for that specific problem area. ${ }^{1}$

Anxiety Workshop Registration. A zero-inflated negative binomial regression was determined to be the best fit for predicting anxiety workshop registration, due to excess zeros (64.20\%) and overdispersion. Results of the zero-inflated portion of the regression showed provider's use of other therapy strategies $(B=-1.12, S E=0.50, p<.05$, Odds ratio $[\mathrm{OR}]=0.33,95 \% \mathrm{CI}: 0.12-0.86)$ and the covariate time $(B=1.79, S E=0.85, p<$

\footnotetext{
${ }^{1}$ To the best of my knowledge, this exact scoring has not been used in the literature, but similar scoring for specific EBP knowledge has been used (Lim et al., 2012).
} 
$.05, \mathrm{OR}=5.98,95 \% \mathrm{CI}: 1.13-31.71)$ to be predictive of no or any anxiety workshop registration (see Table 5). As hypothesized, providers who used other therapy strategies more extensively were less likely to register for an anxiety workshop, with a $67 \%$ decrease in the odds of registering for an anxiety workshop with every one-unit increase in other therapy strategy use. In the negative binomial part of the regression, only the covariate time $(B=0.97, S E=0.13, p<.01, \mathrm{IRR}=2.65,95 \% \mathrm{CI}: 2.07-3.39)$ was predictive of more anxiety workshop registration, though provider's use of other therapy strategies was trending towards significance $(B=-0.28, S E=0.17, p=.09, \operatorname{IRR}=0.75$, $95 \%$ CI: $0.54-1.04)$.

Anxiety Workshop Attendance. For predicting anxiety workshop attendance, we ran a zero-inflated negative binomial regression because of excess zeros $(71.60 \%)$ and overdispersion. For predicting no or any anxiety workshop attendance, results from the zero-inflated part revealed provider's use of other therapy strategies $(B=-0.82, S E=$ $0.41, p<.05, \mathrm{OR}=0.44,95 \%$ CI: $0.20-0.99)$ and the covariate time $(B=-1.11, S E=$ $0.47, p<.05, \mathrm{OR}=0.33,95 \% \mathrm{CI}: 0.13-0.83$ ) to be statistically significant (see Table 6 ). Similar to anxiety workshop registration and as hypothesized, providers who use other therapy strategies more extensively were less likely to attend an anxiety workshop, a $56 \%$ decrease in the odds of attending an anxiety workshop with each unit increase in other therapy strategy use. Results of the negative binomial portion found baseline knowledge of EB techniques for youth anxiety $(B=0.07, S E=0.03, p<.05$, IRR $=1.08,95 \% \mathrm{CI}$ : $1.01-1.15)$ to be predictive of anxiety workshop attendance count. Consistent with our hypothesis, providers were more likely to attend more anxiety workshops if they had greater knowledge of EB techniques for youth anxiety; a one-unit increase in knowledge 
score was associated with an $8 \%$ increase in the incident rate of attending anxiety workshops.

Depression Workshop Registration. Due to excess zeros (65.12\%) but no overdispersion, a zero-inflated Poisson regression was performed to predict depression workshop registration. Results showed provider's confidence in treating depression $(B=-$ $1.95, S E=0.73, p<.01, \mathrm{OR}=0.14,95 \% \mathrm{CI}: 0.03-0.60)$ to be predictive of no or any depression workshop registration. Similarly, provider's confidence in treating depression $(B=-0.30, S E=0.12, p<.05, \mathrm{IRR}=0.74,95 \% \mathrm{CI}: 0.59-0.94)$ and the covariate time $(B=0.51, S E=0.11, p<.01, \mathrm{IRR}=1.66,95 \% \mathrm{CI}: 1.34-2.05)$ were found to be statistically significant in predicting registering for more depression workshops (see Table 7). Inconsistent with our hypothesis, providers who felt more confident about their effectiveness in treating children and adolescents with depression were less likely to register for depression workshops, with an $86 \%$ decrease in the odds of registering for any depression workshop and 16\% decrease in the incident rate of registering for a number of depression workshops for every one-unit increase in confidence.

Depression Workshop Attendance. To predict depression workshop attendance, we also used a zero-inflated Poisson regression (see Table 8). In the zero-inflation portion of the model, provider's confidence in treating depression $(B=2.72, S E=0.89, p<.01$, OR $=15.17,95 \% \mathrm{CI}: 2.68-85.95)$ and the covariate time $(B=-1.88, S E=0.67, p<.01, \mathrm{OR}$ $=0.15,95 \%$ CI: $0.04-0.57)$ significantly predicted no attendance or any attendance at a depression workshop. As hypothesized and unlike the depression workshop registration findings, providers who felt more confident about their effectiveness in treating youth with depression were more likely to attend a depression workshop. For the Poisson 
portion of the model, provider's confidence in treating depression $(B=0.43, S E=0.18, p$ $<.05, \mathrm{IRR}=1.54,95 \%$ CI: $1.09-2.18)$ and knowledge of EB techniques for treating youth depression $(B=0.10, S E=0.04, p<.05, \mathrm{IRR}=1.10,95 \% \mathrm{CI}: 1.01-1.20)$ significantly predicted attending more depression workshops. Also, as expected, providers who already felt more confident about their effectiveness in treating youth with depression and had greater baseline knowledge of EB techniques for treating youth depression were more likely to attend depression workshops; there was a $54 \%$ and $10 \%$ increase in incident rate for attending more depression workshops for every one-unit increase confidence and knowledge score, respectively .

Disruptive Behavior Workshop Registration. A zero-inflated negative binomial regression was determined to be the best fit for predicting registration for disruptive behavior workshops because of overdispersion and excess zeros (61.11\%). Contrary to what was hypothesized, none of the variables in the zero-inflated part of the model were statistically significant in predicting no or any disruptive behavior workshop registration (see Table 9). For predicting disruptive behavior workshop registration count, provider's use of other therapy strategies $(B=0.33, S E=0.12, p<.01$, IRR $=1.40,95 \%$ CI: $1.09-$ $1.78)$ and the covariate time $(B=0.45, S E=0.12, p<.01, \mathrm{IRR}=1.56,95 \% \mathrm{CI}: 1.23-$ 1.98) were statistically significant. Interestingly, and in contrast with anxiety and depression findings, for every one-unit increase in other therapy strategy use, there was a $40 \%$ increase in the incident rate of registering for more disruptive behavior workshops.

Disruptive Behavior Workshop Attendance. We ran a zero-inflated Poisson regression analysis to predict disruptive behavior workshop attendance due to excess zeros $(70.68 \%)$. In the zero-inflated part of the model, provider's use of common EB 
strategies $(B=-1.72, S E=0.79, p<.05$, IRR $=0.18,95 \%$ CI: $0.04-0.84)$, use of other therapy strategies $(B=1.82, S E=0.74, p<.05$, IRR $=6.14,95 \% \mathrm{CI}: 1.45-26.13)$, and the covariate time $(B=-1.54, S E=0.46, p<.01, \mathrm{IRR}=0.21,95 \% \mathrm{CI}: 0.09-0.53)$ significantly predicted no attendance or any attendance at a disruptive behavior workshop (see Table 10). Contrary to what was expected, providers who were using common EB strategies less extensively and using other therapy strategies more extensively were actually more likely to attend a disruptive behavior workshop. For every one-unit increase in common EB strategy use and other therapy strategy use, there was an $82 \%$ decrease and 514\% increase, respectively, in incident rate of attending any disruptive behavior workshop. Also, not as hypothesized, none of the variables in the Poisson regression portion of the model were found to be statistically significant in predicting disruptive behavior workshop attendance count.

Aim 4: Change in Training Outcomes. Six multilevel models with varying intercepts were performed to predict the following training outcomes: (a) provider knowledge of EBPs, (b) attitudes regarding the efficacy and feasibility of EBPs, (c) confidence in their own efficacy in treating youths, (d) use of specific EB strategies (e.g., exposure for anxiety), (e) use of common EB strategies (e.g., relaxation), and (f) use of other therapy strategies (e.g., gaining insight, exposure for disruptive behavior). When a significant interaction was found, post hoc Tukey-adjusted pairwise comparisons of predicted means from regression estimates were conducted.

Knowledge of EB Services. In the model (Model 1: lmer(Knowledge $\sim$ Time + Trainee*OngoingSupport + TrainingHours $+(1 \mid$ id $))$ predicting knowledge of EB services (i.e., KEBSQ Total Score), we found being a pre-service trainee was associated 
with a higher KEBSQ score $(\mathrm{B}=3.16, S E=1.58, t=2.01, p<.05$; see Table 11$)$. We also found a statistically significant interaction between trainee status and ongoing support activity participation $(\mathrm{B}=9.47, S E=3.67, t=2.58, p<.05$; see Figure 1$)$. Post hoc Tukey-adjusted pairwise comparisons indicated three significant differences. As hypothesized, trainee providers who participated in ongoing support activities had greater KEBSQ scores than trainee providers who did not participate in ongoing support training activities $(t(291)=-3.77, p<0.01)$. Similarly, among providers who participated in ongoing support activities, trainees had greater KEBSQ scores than post-graduate providers $(t(393)=-3.57 p<0.01)$, and trainees who participated in ongoing support activities also had greater KEBSQ scores than post-graduate providers who did not participate $(t(350)=-4.83, p<0.05)$.

Specific EB Strategy Use. For the model for predicting specific EB strategy use (Model 2: Imer(SpecificEBStrategyUse $\sim$ Time + Trainee + OngoingSupport + TrainingHours $+(1 \mid \mathrm{id}))$, in contrast to hypotheses, none of the variables were significant (see Table 12). Being a trainee $(\mathrm{B}=-0.52, S E=0.28, t=-1.85, p=.06)$ was trending towards significance, with trainees having a lower specific EB strategy use score than post-graduate providers.

Common EB Strategy Use. For the model (Model 3: $\operatorname{lmer}($ CommonEBStrategyUse $\sim$ Time + Trainee*OngoingSupport*TrainingHours $+(1 \mid$ id)) predicting common EB strategy use, we found one main effect and three interactions to be statistically significant (see Table 13$)$. We found trainee status $(\mathrm{B}=-0.58, S E=$ $0.14, t=-4.19, p<.01)$ to be statistically significant, with being a trainee associated with a 0.58 decrease in common EB strategy use score compared to being a post-graduate 
provider. A statistically significant interaction between trainee status, ongoing support activity participation, and number of training hours was found $(\mathrm{B}=-0.07, S E=0.02, t=-$ $2.90, p<.01)$, but post hoc Tukey-adjusted pairwise comparisons did not reveal any significant contrasts (see Figure 2). In addition, the interaction between trainee status and ongoing support activity participation was statistically significant $(\mathrm{B}=0.96, S E=0.34, t$ $=2.83, p<.01$; see Figure 3 ), but post hoc pairwise comparisons did not show any significant contrasts. The interaction between ongoing support participation and amount of training completed was also statistically significant $(\mathrm{B}=0.28, S E=0.01, t=2.33, p<$ .05 ; see Figure 4), but again post hoc comparisons did not reveal a statistically significant difference between the slopes of providers who participated in ongoing support activities and those who did not.

Other Therapy Strategy Use. The model (Model 4:

$\operatorname{lmer}($ OtherTherapyStrategyUse $\sim$ Time + Trainee*OngoingSupport + TrainingHours $+(1$ | id)) for predicting use of other therapy strategies found being a trainee $(\mathrm{B}=-0.77, S E=$ $0.12, t=-6.25, p<.01)$ to be statistically significant, with being a trainee associated with less use of other therapy strategies than post-graduate providers (see Table 14). As hypothesized, number of training hours $(\mathrm{B}=-0.004, S E=0.01, t=-2.01, p<.05)$ was also statistically significant in the model, indicating a 0.004 decrease in predicted use of other therapy strategies for every one-unit increase in number of training hours. We found a significant interaction between participation in ongoing support training activities and trainee status $(\mathrm{B}=0.60, S E=0.26, t=2.28, p<.05)$, suggesting the effect of participation in ongoing support activities may differ depending on trainee status. Further post hoc Tukey-adjusted pairwise comparisons found a significant difference among 
providers who did not participate in ongoing support training activities, with trainee providers using other therapy strategies less extensively than post-graduate providers $(t(472)=6.23, p<0.01)$. Contrary to expectations, trainee providers who did not participate in ongoing support training activities used other therapy strategies less extensively than post-graduate providers who did participate in ongoing support activities, $t(472)=-3.80, p<0.01($ see Figure 5).

Confidence. MH provider's confidence was an average of how confident a provider rated feeling about their effectiveness in treating children and adolescents with 1) Fears or Anxiety, 2) Depression or Mood, 3) Disruptive Behavior or Conduct Problems, and 4) Trauma or Abuse History or Post-Traumatic Stress. In the model (Model 5: $\operatorname{lmer}($ Confidence $\sim$ Time + OngoingSupport*Trainee + TrainingHours $+(1 \mid$ id)), we found a significant effect of trainee status ( $\mathrm{B}=-0.84, S E=0.12, t=-6.75, p<$ .01 ), with being a trainee associated with less confidence compared to being a postgraduate provider (see Table 15). The interaction between trainee status and ongoing support activity participation was also significant $(\mathrm{B}=0.76, S E=0.29, t=2.64, p<.01$; see Figure 6). Additional post hoc Tukey-adjusted pairwise comparisons revealed three significant contrasts. Consistent with hypotheses, trainee providers who did not participate in ongoing support activities had less confidence than post-graduate providers who did not participate in ongoing support $(t(516)=6.73, p<0.01)$, post-graduate providers who did participate in ongoing support $(t(505)=-4.83, p<0.01)$, and trainees who did participate in ongoing support $(t(378)=-3.00, p<0.05)$.

Attitudes towards EBPs. In the model (Model 6: 1mer(EBPAS Time + Trainee + OngoingSupport + TrainingHours + (1 | id)) for predicting attitudes towards EBPs, only 
one effect was significant. In line with our hypothesis, participation in ongoing support activities was associated with more positive attitudes towards EBPs (see Table 16).

\section{Qualitative Results}

Qualitative Participants. MH providers $(n=13)$ who participated in the qualitative interviews represented variation in the types of training activities they participated in and number of workshops they attended. Six $(46.15 \%)$ of the qualitative participants engaged in more than one training method (e.g., workshops, biweekly learning community, consultation, and/or online clinical feedback system), five $(38.46 \%)$ participated in only workshops, and two $(15.38 \%)$ did not participate in any training. Among participants who attended workshops, six (46.15\%) had attended a low number of workshops (i.e., 1-5), three $(23.08 \%)$ participated in a moderate number of workshops (i.e., 6-10), and two (15.38\%) had attended a high number of workshops (i.e., 11+).

Similar to the full sample, qualitative participants were mostly female $(n=12$, $92.31 \%)$ and Caucasian $(n=10,76.92 \%)$, with a mean age of 38.81 years $(S D=10.56$, range $=27$ to 60$).$ Participants represented social work $(n=7,53.85 \%)$ counseling $(n=2$, $15.38 \%)$, marriage and family therapy $(n=2,15.38 \%)$, psychology $(n=1,7.69 \%)$, and psychiatry $(n=1,7.69 \%)$ disciplines. Participants were primarily Master's level $(n=12$, $92.31 \%)$, fully licensed mental health providers $(n=8,61.54 \%)$, and on average had been providing mental services for 11.54 years $(S D=8.48$, range $=2$ to 26$)$. The most common mental or behavioral health services qualitative participants provided were talk or behavior therapy $(n=10,76.92 \%)$, case management $(n=8,61.54 \%)$, and assessment/testing $(n=7,53.85 \%)$. Some $84.26 \%(n=11)$ currently provided therapy or therapy supervision for youth and young adults. Additionally, participants were most 
commonly employed at outpatient or community mental health centers $(n=4,30.77 \%)$, in private practice $(n=4,30.77 \%)$, or at a college or university $(n=4,30.77 \%)$.

Overall Impressions of the Training Initiative. When asked about their overall experience with the training initiative, many $\mathrm{MH}$ providers noted the acceptability (e.g., satisfaction) of the initiative and the different training activities, with one provider saying:

Just uh kind of a general observation that I think it's a really great um service that you guys are making available for professionals so...it's hard to pass up free trainings and they're really quality trainings, so um, so all in all great experience. Additionally, several $\mathrm{MH}$ providers indicated they recommended the workshops to colleagues or supervisees. Table 17 lists the qualitative themes and subthemes identified through the rapid qualitative analysis.

Training Engagement Barriers and Facilitators. Several themes emerged from the questions asking providers about what drove them to attend certain trainings, what made it more likely, and what made it more difficult for them to attend or participate in training activities. Practical factors (e.g., cost, time) were frequently noted by $\mathrm{MH}$ providers. For example, many providers talked about the free cost, receiving email reminders, and convenient location of the trainings as a facilitator of engagement. Similarly, lack of awareness of training opportunities and inconvenient times (e.g., training's fit with their work schedule, scheduling conflicts) were commonly talked about as practical barriers to engagement. For example, one provider noted, "Uh it's not for lack of wanting to go, it's definitely scheduling and being able to make those." Furthermore, an outer setting factor that was frequently cited as a facilitator, and the only 
outer setting factor talked about by providers, was the opportunity to earn continuing education hours by attending the trainings.

Provider-level themes also emerged, expanding on the provider-level factors identified in the quantitative data related to training engagement. A provider's motivation to improve (e.g., wanting to become a better clinician) and having a personality that loves learning emerged as facilitators to attendance. Provider's professional role was also talked about by a few MH providers, with providers who were not currently seeing clients or in a supervisor role finding it more challenging to attend trainings. Other provider-level determinants were related to a training's fit with providers' orientation and practice caseload, with trainings that were a good fit with these factors increasing the likelihood of attendance and a poor fit decreasing the likelihood of attendance.

In contrast to the quantitative results which did not find organizational implementation climate to be a significant predictor of training engagement, organizational-level factors were commonly discussed by MH providers. A provider's organization setting, such as lack of in-house consultation or education opportunities (e.g., private practice), was identified as a facilitator to engagement, as these providers had to go outside of their practice setting to obtain these opportunities. Recommendation of the trainings by a colleague and an employer's openness and support of ongoing learning and EBP implementation emerged as facilitators to engagement. In one illustrative example, a provider stated:

Uhm, we have a [leader] that uhm is. It's refreshing. Uhm she wants to be on cutting edge and uhm if you know, there's a new evidence-based practice out there she wants uhm, she wants our staff to be informed and trained and be able 
to implement that as a tool to use with our consumers, and so having that support makes a huge difference.

An employer requiring participation was another facilitator to attendance, with a provider noting, "And that if I remember was sort of a voluntold situation, like our supervisors didn't give us much choice about whether we were going to go or not." Regarding organizational-level barriers, competing demands (e.g., productivity requirements) was cited as a barrier by $\mathrm{MH}$ providers.

Themes specific to the training activities were also discussed by $\mathrm{MH}$ providers. Providers talked about opportunities for networking, learning from others, and consultation as facilitators of engagement. Providers talked about the opportunity for ongoing support as a facilitator for attending the biweekly LC, and one provider noted the opportunity for professional support as a facilitator for attending individual consultation. For example, a provider who attended the biweekly LC shared the following: At the time I did the [learning community] I was in private practice, so I didn't really have um anybody to consult with, so it was really nice to have that opportunity to meet with other therapists and talk about cases and learn something new.

A barrier to using the online clinical feedback system talked about by one provider was that it seemed like a duplication of other required documentation. Specific to workshops, length of the workshop was identified as a determinant, with providers sharing it was more challenging to attend longer than shorter workshops, noting "it's easier to squeeze in some shorter stuff." Workshop topic was also commonly cited as both a barrier and facilitator of attendance; in particular, providers explained interesting workshop topics; 
workshop topics relevant to their cases, current practice, practice setting, and orientation; and topics that were novel and unfamiliar facilitated attendance. Moreover, the workshop presenter (e.g., knowledge, expertise, and presentation style) was a facilitator to attendance. For instance, one provider explained:

Uh I think the biggest motivator was because I knew [Presenter Name] was involved in them, um, and I have a lot of respect for her um her clinical skills her uh her teaching style, the way she delivers information, so that was very helpful.

Implementation. When asked if they have used what they have learned in any of the trainings, and what they have used, several themes of implementation were discussed by providers, providing further depth to the quantitative results. Many providers noted the implementation of materials, such as using resources (e.g. handouts) provided at the workshops, referencing workshop slides, and purchasing manuals introduced at a workshop. Providers also reported using specific techniques or skills learned in workshops (e.g., motivational interviewing skills, pleasant activities scheduling, trauma narrative); however, none of the providers mentioned implementing the entire EBP. Other providers talked about using knowledge learned in workshops to provide information and referrals to families. Providers also noted collaboration with other providers following workshops, such as sharing worksheets from the workshops with colleagues. One provider talked about using what they learned to get their employer's support and buy-in to fund providers in the organization to get additional training in an EBP. Lastly, a few providers reported using what they learned in trainings in their other roles as a clinical supervisor and educator. 
Barriers and Facilitators to Implementation. The qualitative data expanded on the quantitative training outcome results by clarifying the common barriers and facilitators encountered to implementing what they learned in the trainings into their clinical practice. Several themes emerged, including practical, provider-level, organizational-level, training-specific, and implementation factors. Practical factors (e.g., time, resources) were reported by providers as barriers to implementing what they have learned in trainings. For instance, competing demands or not having time to learn the practices covered post-workshop hindered provider's implementation post-training.

Several provider-level determinants were described by providers. Providers noted the fit or relevance of what they learned in training with their orientation, professional role, setting (e.g., clinic, school), skill level, and their cases and caseload to be related to implementation, with better fit or more relevant learnings easier to implement. One provider stated, "So, uhm, some of the trainings their practices are great, they're evidence-based, but it's not uhm realistic to my environment, so that is a challenge for me." Similar to attending a training, a provider's motivation to improve (e.g., wanting to try something new or better) was discussed as a facilitator to implementation. Lastly, providers talked about lack of comfort or familiarity with a treatment as a barrier to implementation. For example, providers found it difficult to implement something new, noting the following:

It's exciting and it creates a little anxiety and uh you know we get into, especially at my age, we you know just kind of get into our groove and so changing strategies can be like I said exciting and anxiety provoking and sometimes it's just easier to just not. Stick with what you know or what's comfortable. 
Providers also discussed employer support as an inner setting, or organizationallevel, facilitator. Collaboration and consultation with colleagues and supervisors to implement EBPs and support from their employer helped providers to be able to implement what they learned in trainings. A provider said, "Uhm I've worked in, in a realm where we didn't have that from the top down. Uhm and so it, it just makes a big difference to have that support."

In addition, providers mentioned implementation factors influencing their implementation. The timing of their implementation was identified as a facilitator, with providers indicating that being able to apply what they learned right away following training helped them to implement. Inconsistency in implementation was described as a barrier; providers who implemented the EBP for a little while immediately after the training and then stopped for a while found it challenging to start using the EBP again. One demonstrative example noted by a provider:

You'll go to a training, you'll learn about it, you'll do it for a while and then you just won't and then it's like 'okay but where do I start back' or 'where...do I get the information from'...

Themes related to the training activities were also talked about as determinants to implementation. Across the training activities, learning from others emerged as a theme that facilitated implementation, as providers from various settings allowed for different perspectives on challenges and how to implement EBPs. Concerning the biweekly LC, providers mentioned the LC helped them to reprocess information they learned and allowed them to consult with others, such as consulting on tailoring EBPs to their practice and problem solving with others. For instance, a provider reported: 
...it was meeting more clinicians within the community. And, of course, when you do the collaborative meetings it's so wonderful to have different minds together with different levels of expertise and different areas of expertise, not necessarily levels. Um, but hearing other's approaches, how they would handle it, um, also hearing their brag moments of what they've done well and what worked well for them. It's just so inspirational. Um, and it's this learning of different things. Several online clinical feedback system determinants were also identified. One facilitator included ease of use of the feedback system. One provider noted that they were not tech savvy, which was a barrier to them implementing the online clinical feedback system in their practice. A few providers indicated it was difficult to use the feedback system when they already had a system in place and it was hard to find the time to implement the feedback system because of competing demands and other pressing tasks (e.g., backed up on documentation). Indicative of this theme, one provider said the following:

....it seemed like it was uh a really promising tool but it was hard for me to learn it and uh not because I think it's especially difficult but you know just learning a new thing when you already have a system in place and um I'm forever um behind on my documentation just what brings me in earlier today, um so it was really a time factor like just not feeling like I had the time to devote to it. Specific to workshops, providers often thought workshops alone were not adequate for translating knowledge to practice, providers indicated that: Uhm even if you're fully engaged, even if you want to, it's just a lot, so, unless you're taping it and you're listening to it several times, uhm, being able to 
implement it halfway successfully just isn't necessarily a thing. Uhm, so uh not just being able to hear it one time and then going out and being able to do something with it.

Length of the workshop and absence of active learning strategies were also noted as barriers to implementation, with providers indicating shorter workshops and a lack of opportunities to practice skills in workshops made it more difficult for them to implement EBPs. Providers discussed that:

No, I would say the only thing that maybe makes it difficult is just if we don't like practice it in our training then it is hard to practice it in your practice. Umm, I'm kind of a like do-one see-one teach-one mentality and sometimes we just talk about it in the trainings rather than actually working on it.

The take home materials (e.g., handouts) provided at workshops were frequently cited as a facilitator to implementation following a workshop. Providers viewed trainings provided by more expert presenters as a facilitator to implementation; for example, one provider reported: "I think the trainings I attended with, that [Presenter Name] led were uh a little more richer and I found I could take that and apply it a little bit more um more in real time." 


\section{CHAPTER 5: DISCUSSION}

The current study describes the reach and impact of a training initiative aimed to improve youths' and families' access to effective youth MH services by providing free EBP training and implementation support to MH service providers. We evaluated the training initiative using a mixed methods approach within a naturalistic, longitudinal design. The training initiative reached over $700(N=717)$ providers who were part of over 150 different organizations and private practices. Moreover, the initiative reached beyond its intended goal with about a fifth of the providers working in other counties.

However, fewer providers ultimately engaged in training. A sizable minority, approximately $30 \%$ of providers, never participated in any training activities following registration ( $n=224,31.24 \%$ ). This is puzzling, but not uncommon in EBP training initiatives where initial enthusiasm leads to enrollment but day-to-day workload and the "tyranny of the urgent" can interfere with follow-through (e.g., McMillen et al., 2016). In addition, another sizable group of providers $(n=92,28.40 \%)$ participated in just a single training activity - almost always a formal workshop.

Of the training activities, formal workshops were by far the most utilized by providers. Providers most frequently participated in formal workshops $(n=479,66.81 \%)$, followed by the ongoing biweekly learning community $(n=47,6.56 \%)$, online clinical feedback system $(n=42,5.86 \%)$, individual consultation $(n=33,5.60 \%)$, and individual and group supervision $(n=19,2.65 \%)$. This is consistent with prior literature where workshops have been the most common method to train providers (e.g., Davis et al., 1995; Herschell et al., 2010) and the most common format of continuing education (Beidas \& Kendall, 2010). This pattern also aligns with previous studies that found 
higher participation in in-person workshops and learning sessions, web-based training, and web-based webinars, and lower participation in ongoing consultation calls, completing training cases, partnered in-person practice of clinical skills, and an online discussion board (Jensen-Doss et al., 2019; McMillen et al., 2016).

Interestingly, in other research, providers have endorsed more positive attitudes towards EBPs that require consultation and they have noted difficulties implementing EBPs without the added support of consultation (Barnett et al., 2017). Yet, we see low participation in the ongoing support training activities (e.g., biweekly learning community, consultation, supervision) - both in our current study and in prior research (e.g., Jensen-Doss et al., 2019; McMillen et al., 2016). One possibility may be that workshops are typically larger, more passive and anonymous, requiring very little of the provider, whereas ongoing support training activities (e.g., consultation) are commonly smaller, more intimate and active, requiring much more of the provider. For example, in ongoing support activities, providers often have to interact, be engaged, try to perform skills in front of others, and may be judged or evaluated for feedback purposes. Providing some support for this notion, a prior qualitative study that inquired about low rates of engagement in partnered in-person practice of clinical skills found clinicians reported hesitancy and discomfort around performing or displaying skills in front of other clinicians (McMillen et al., 2016). Further research is needed to understand this discrepancy between positive attitudes and need for ongoing support but low engagement in these activities, even when it is freely and locally available. In addition, future work should identify strategies for increasing engagement in ongoing support training activities. 
To better understand provider training engagement, we examined provider characteristics and organizational factors as predictors of training engagement. Quantitative findings found providers who showed greater engagement in training, (a) had higher baseline knowledge of EBPs, (b) were pre-service trainees, (c) used other therapy strategies (e.g., gaining insight) less extensively, and (d) used common EB strategies (e.g., relaxation) more extensively. Consistent with prior research, providers engaging in our initiative had more prior knowledge of EB services and were already using more EB strategies (Jensen-Doss et al., 2019), suggesting that our initiative may be "preaching to the choir" rather than successfully engaging EBP-naïve providers.

Pre-service trainee providers (i.e., those enrolled in MH graduate programs) also participated in more training than post-graduate providers. One reason for this difference could be that post-graduate providers may have more work duties than trainees (McMillen et al., 2016). In addition, trainees are already in a period of their career in which training is exactly what they are supposed to be doing. Trainees are also accustomed to receiving feedback and undergoing judgment and evaluation, as they are primarily in supervisee roles; whereas post-graduate providers may have more reservations about being in an evaluative role and appearing unskilled to a small group or professional consultant (e.g., McMillen et al., 2016). Further, previous research found trainees more often endorsed cost and lack of funds to pay for trainings as a barrier than practitioners or clinical educators (Meyer et al., 2019). Therefore, the free cost of the training initiative may matter more to trainees than post-graduate providers, and postgraduate providers may have more options available than our initiative's free options. Indeed, we did have a few post-graduate providers describe other paid trainings and 
certifications (e.g., Eye Movement Desensitization and Reprocessing) they attended. Unfortunately, we do not have quantitative data on outside training activities to test this hypothesis.

Qualitative data expanded on these findings by identifying additional providerlevel factors related to training engagement (e.g., having a personality that loves learning). Interestingly, organizational implementation climate did not emerge as a significant predictor of training engagement in the quantitative analyses; however, within the qualitative results, several organizational-level factors (e.g., employer's openness and support of ongoing learning and EBP implementation) were indicated as facilitators and barriers to training engagement. In addition, the qualitative data expanded upon the quantitative findings by illuminating barriers and facilitators not captured in the quantitative data, including practical, system-level, and training activity-specific determinants. Consistent with prior studies, providers commonly endorsed time as a practical barrier to training engagement (Herschell, Reed, et al., 2014; McMillen et al., 2016; Meyer et al., 2019). In contrast to previous research, however, cost and location were not identified as barriers to engagement, but rather free cost and convenient location emerged as facilitators in the current study, suggesting the training initiative helped address these barriers (Herschell, Reed, et al., 2014; Meyer et al., 2019).

We also explored providers' interest and engagement in specific workshops. Quantitative findings found no common predictors that held across anxiety, depression, and disruptive behavior workshop registration and attendance. Greater problem-specific baseline knowledge was predictive of attending more anxiety and depression workshops but not disruptive behavior workshops. Greater confidence in treating the specific 
problem was predictive of depression workshop attendance but not anxiety or disruptive behavior workshops. Thus, for anxiety and depression workshops, our findings were mainly in line with our hypothesis that providers would register for and attend workshops that advanced their existing skill set (Jensen-Doss et al., 2019; Powell et al., 2013). However, contrary to what was expected, more extensive other therapy strategy use was predictive of disruptive behavior workshop registration, and less extensive common EB strategy use and more extensive other therapy strategy use was predictive of disruptive behavior workshop attendance. This latter finding suggests providers may have been attending a disruptive behavior workshop to learn new skills rather than to advance an existing skill set.

Notably, there may be a distinction between provider's motivation for attending internalizing versus externalizing workshops. In general, providers may stick with workshops that are consistent with their current practices and skills (Jensen-Doss et al., 2019). However, if a provider receives negative information (e.g., client dissatisfaction, poor alliance, no reduction in client symptoms), this may cause cognitive dissonance and compel the provider to want to try something different (Riemer, Rosof-Williams, \& Bickman, 2005). Externalizing cases characterize the majority of youth who present to usual care (e.g., Garland et al., 2001), and symptoms and impairment are often more overt for externalizing cases than internalizing cases (Pearcy, Clopton, \& Pope, 1993). Moreover, alliance for youth with an anxiety diagnosis tends to be higher than those without an anxiety diagnosis (e.g., Accurso \& Garland, 2015). Thus, providers treating youth with disruptive behavior problems may be more likely to receive negative information that would motivate them to learn new strategies. Further research is needed 
to better understand this discrepancy between internalizing and externalizing workshops and what motivates a provider to attend a specific workshop.

Qualitative findings elaborated on these results and revealed factors not denoted in the quantitative findings. In accordance with previous research (Herschell, Reed, et al., 2014; McMillen et al., 2016), workshop length, topic, attendees, and presenter emerged as facilitators of engagement in specific workshops in the qualitative data. More specifically, the workshop topic being interesting; relevant to a provider's caseload, current practice, orientation, and practice setting; and not duplicative, such as being a novel topic or area in which a provider needs growth, were facilitators of attending a specific workshop.

Lastly, we examined the impact of the training initiative on providers' knowledge, attitudes, confidence, and therapy strategy use. In particular, we explored the influence of training quantity (i.e., number of training hours), training method (i.e., participation in ongoing support training activities), and stage of career (e.g., pre-service trainee vs. postgraduate provider) on change in training outcomes. Regarding training quantity, we found more training hours to be predictive of less extensive use of other therapy strategies. This finding provided some support to the influence of quantity of training hours, but quantity was not significant for the other training outcomes: knowledge of EB services, specific EB strategy use, common EB strategy use, confidence, or attitudes.

Regarding training method, participation in ongoing support training activities was associated with more positive attitudes towards EBPs. We also found significant interactions between trainee status and ongoing support activity participation for predicting knowledge of EB services and self-reported confidence. Trainee providers 
who participated in ongoing support activities had higher knowledge scores than trainees who did not. We also found trainee providers who did not participate in ongoing support activities had less confidence than trainees who did participate. These findings align with other training studies that have found improved knowledge and confidence following trainings that included support components (Harned et al., 2014; Herschell, Lindhiem, Kogan, Celedonia, \& Stein, 2014; Kolko et al., 2012).

While post hoc analyses did not reveal as many differences for post-graduate providers, trainee providers participated in significantly more hours of ongoing support training than post-graduate providers in the initiative. ${ }^{2}$ Thus, if post-graduate providers had more variability in hours participating in ongoing support training, we may have found similar findings among post-graduate providers. Even though ongoing support is thought to be essential to changing provider behavior, the optimal dosage of and which ongoing support training activities a provider should participate in to achieve optimal outcomes is unknown (Frank et al., 2020). Future research should explore how much and which ongoing support training activities are needed to change behaviors, in order to inform future training and implementation efforts and improve provider and client outcomes.

We also explored the influence of stage of career, being a pre-service trainee provider vs. post-graduate provider, on the effectiveness of the training initiative, as few studies have directly explored this factor. In our study, being a trainee was associated with more knowledge of EB services and less extensive use of other therapy strategies. This difference may be due to trainee providers likely receiving more support in general

\footnotetext{
${ }^{2}$ Trainee providers were significantly more likely to participate in ongoing support training activities than post-graduate providers $\left(\chi^{2}(1)=5.98, p=.02\right)$.
} 
during the initiative because they were in graduate programs. Further, more recent graduate training is likely more EBP-focused than it used to be, as there has been increasing efforts to make graduate programs more focused on training in EBPs (e.g., Bearman, Wadkins, Bailin, Graduate, \& Doctoroff, 2015; Bell, Seager, Shader, \& Fristad, 2018).

However, trainee providers used common EB strategies less extensively than postgraduate providers, with the same finding for specific EB strategy use trending towards significance. One possibility for this finding is that post-graduate providers may report a higher use of all therapy strategies than trainees. Indeed, previous research has found providers to overestimate their use of evidence-based interventions (Herschell, Quetsch, \& Kolko, 2019; Hogue, Dauber, Lichvar, Bobek, \& Henderson, 2015). Of course, trainee providers have also been found to rate their CBT competency higher than independent objective raters (Rozek et al., 2018). Thus, more research is needed to understand this difference between trainees and post-graduate providers.

Trainees, regardless of ongoing support participation, used other therapy strategies less extensively than post-graduate providers who did participate in ongoing support activities. One possibility for this finding is that trainees likely do not have a set practice yet because they are still learning, while post-graduate providers likely do have a set practice, or strategies they have adopted and typically use in their clinical practice. Thus, it may be more challenging for post-graduate providers to change their behavior than for trainees. Moreover, the focus of the training initiative was on the implementation of specific and common EB strategies, not on the de-implementation of other therapy strategies. Post-graduate providers may be more likely to implement specific and 
common EB strategies following participation in the training initiative than deimplementing their adopted other therapy strategies.

Trainees also had less self-reported confidence in their effectiveness in treating youths compared to post-graduate providers, indicating that less experienced trainee providers felt less confident about their effectiveness. Importantly, the current study assessed provider's self-reported confidence in their own effectiveness in treating youth with specific problems, not their self-reported confidence in using EBPs. Thus, postgraduate providers' confidence may be due to their years of experience and not necessarily their confidence in using EBPs. Indeed, years of clinical experience has been shown to be positively related to confidence, though experience is not consistently related to client outcomes (Dawson, 2018). Additional research is needed to disentangle these types of confidence from one another and illuminate how training impacts a provider's confidence and how a provider's confidence may influence the training and implementation process (McLeod et al., 2018).

The qualitative data complemented the quantitative findings examining the impact of the training initiative by providing more depth to these quantitative results, as providers gave examples of how they applied what they learned in trainings. Providers noted gaining knowledge through the workshops and described how they used the knowledge they learned, such as providing psychoeducation to clients or referrals. Similarly, providers discussed using the resources provided at workshops (e.g., handouts, slides). Providers also talked about implementing specific techniques or skills learned in trainings, though providers did not mention implementing entire EBPs. Additionally, the qualitative data also expanded upon the quantitative findings by highlighting common 
barriers and facilitators to implementation following training, including practical, provider-level, organizational-level, implementation-related, and training-specific factors. Consistent with previous findings (Herschell, Reed, et al., 2014), providers endorsed take home materials as a facilitator to implementation following workshops, while time restraints due to competing demands or not having time to learn more about the practices covered post-training were barriers to implementation.

\section{Strengths \& Limitations}

The current study has several strengths. One strength is that the study consisted of multiple follow-up assessments and had a longer-term follow-up than other training studies. In addition, the study was a naturalistic study of a voluntary, community-based, EBP implementation initiative. Findings provide insight into which training activities providers engage in when free and locally available, the extent to which a voluntary initiative can impact training outcomes, and potential areas of improvement for these types of training initiatives. Another strength is that we administered several psychometrically sound measures (e.g., EBPAS, KEBSQ, ICS), which can allow us to compare our results to those of other studies that have used these measures. Moreover, the current study's sample included a diverse range of MH providers and disciplines, including various licensure statuses (e.g., trainees, licensed providers), supervisors, and providers who do and do not belong to professional organizations, with many of these providers often not included in other studies (e.g., Meyer et al., 2019).

Several limitations to the current study exist. First, only self-report measures were used in the current study. Self-report measures are subject to known biases, including response bias and social desirability (Dillman, 2000; Hurlburt, Garland, Nguyen, \& 
Brookman-Frazee, 2010). Additionally, previous studies have found providers to over report their use of therapy strategies in practice (Hogue et al., 2015; Hurlburt et al., 2010). To reduce potential social desirability bias, we included a wide range of treatment strategies and did not label which strategies had an evidence base. Second, because this is a naturalistic, observational study, $\mathrm{MH}$ providers were not randomly assigned to receive a specific amount of training. In addition, we had different amounts of data points at differing time intervals for each provider. Because of this, we used MLM, which has several advantages over repeated measures (M)ANOVA (Gibbons, Hedeker, \& DuToit, 2010). MLM allows intercepts and/or slopes to vary from person to person, and participants are not assumed to have been assessed on the same number of time-points or at the same time-points. Moreover, a participant can be included in analyses even with incomplete or missing data. Third, providers were primarily from a county in Central Missouri, so the results may not be generalizable to all $\mathrm{MH}$ providers. Fourth, we did not collect client or other service outcomes. We provided the online clinical feedback system, which would have allowed for tracking client progress, but very few providers used the free system. Future studies should collect client outcomes in addition to implementation outcomes to ensure training strategies and initiatives are resulting in improved client outcomes. Lastly, another limitation is we did not conduct qualitative interviews with any pre-service trainee providers and cannot compare the qualitative themes identified in the interviews with post-graduate providers to themes from trainees.

\section{Conclusions}

While the training initiative had high reach, far fewer providers ultimately engaged in training, with providers who were trainees, had higher baseline knowledge of EB 
services, used other therapy strategies less extensively, and used common EB strategies more extensively having more training engagement. Despite all activities being free and locally available, providers primarily participated in workshops and considerably less participated in the ongoing support training activities. Providers seemed to attend anxiety and depression workshops to advance their existing skill set, while providers appeared to attend disruptive behavior workshops to learn new skills. Stage of career (i.e., pre-service trainee provider vs. post-graduate provider) was related to differences in several training outcomes, while training quantity and method were less consistently associated with change in training outcomes. Qualitative interviews both complemented and expanded on the quantitative findings, highlighting common determinants to engagement in the training initiative and implementation of EBPs post-training. Future research should concentrate on identifying strategies for improving provider training engagement, particularly engagement in ongoing support training activities, and on illuminating the impact of training quantity, training methods, and stage of career on training, implementation, and client outcomes. 


\section{REFERENCES}

Aarons, G. A. (2004). Mental Health Provider Attitudes Toward Adoption of EvidenceBased Practice: The Evidence-Based Practice Attitude Scale (EBPAS). Mental Health Services Research, 6(2), 61-74. https://doi.org/10.1023/B:MHSR.0000024351.12294.65

Aarons, G. A., Cafri, G., Lugo, L., \& Sawitzky, A. (2012). Expanding the Domains of Attitudes Towards Evidence-Based Practice: The Evidence Based Practice Attitude Scale-50. Administration and Policy in Mental Health and Mental Health Services Research, 39(5), 331-340. https://doi.org/10.1007/s10488-010-0302-3

Accurso, E. C., \& Garland, A. F. (2015). Child, caregiver, and therapist perspectives on therapeutic alliance in usual care child psychotherapy. Psychological Assessment, 27(1), 347-352. https://doi.org/10.1037/pas0000031

Bandura, A. (1986). Social foundations of thought and action. Englewood Cliffs, NJ: Prentice Hall.

Barr, D. J., Levy, R., Scheepers, C., \& Tily, H. J. (2013). Random effects structure for confirmatory hypothesis testing: Keep it maximal. Journal of Memory and Language, 68(3), 255-278. https://doi.org/10.1016/J.JML.2012.11.001

Bearman, S. K., Schneiderman, R. L., \& Zoloth, E. (2017). Building an Evidence Base for Effective Supervision Practices: An Analogue Experiment of Supervision to Increase EBT Fidelity. Administration and Policy in Mental Health and Mental Health Services Research, 44(2), 293-307. https://doi.org/10.1007/s10488-0160723-8

Bearman, S. K., Wadkins, M., Bailin, A., Graduate, F., \& Doctoroff, G. (2015). Pre- 
Practicum Training in Professional Psychology to Close the Research-Practice Gap: Changing Attitudes Towards Evidence-Based Practice HHS Public Access. Train Educ Prof Psychol, 9(1), 13-20. https://doi.org/10.1037/tep0000052

Becker-Haimes, E. M., Okamura, K. H., Baldwin, C. D., Wahesh, E., Schmidt, C., \& Beidas, R. S. (2019). Understanding the Landscape of Behavioral Health Pre-service Training to Inform Evidence-Based Intervention Implementation. Psychiatric Services, 70(1), 68-70. https://doi.org/10.1176/appi.ps.201800220

Becker-Haimes, E. M., Williams, N. J., Okamura, K. H., \& Beidas, R. S. (2019). Interactions Between Clinician and Organizational Characteristics to Predict Cognitive-Behavioral and Psychodynamic Therapy Use. Administration and Policy in Mental Health and Mental Health Services Research, 46(6), 701-712. https://doi.org/10.1007/s10488-019-00959-6

Becker, E. M., Smith, A. M., \& Jensen-Doss, A. (2013). Who's using treatment manuals? A national survey of practicing therapists. Behaviour Research and Therapy, 51(10), 706-710. https://doi.org/10.1016/J.BRAT.2013.07.008

Beidas, R. S., \& Kendall, P. C. (2010). Training Therapists in Evidence-Based Practice: A Critical Review of Studies From a Systems-Contextual Perspective. Clinical Psychology: A Publication of the Division of Clinical Psychology of the American Psychological Association, 17(1), 1-30. https://doi.org/10.1111/j.14682850.2009.01187.x

Beidas, R. S., Stewart, R. E., Adams, D. R., Fernandez, T., Lustbader, S., Powell, B. J., ... Barg, F. (2016). A Multi-Level Examination of Stakeholder Perspectives of Implementation of Evidence-Based Practices in a Large Urban Publicly-Funded 
Mental Health System HHS Public Access. Adm Policy Ment Health, 43(6), 893908. https://doi.org/10.1007/s10488-015-0705-2

Beidas, R. S., Williams, N. J., Becker-Haimes, E. M., Aarons, G. A., Barg, F. K., Evans, A. C., ... Mandell, D. S. (2019). A repeated cross-sectional study of clinicians' use of psychotherapy techniques during 5 years of a system-wide effort to implement evidence-based practices in Philadelphia. Implementation Science, 14(1), 67. https://doi.org/10.1186/s13012-019-0912-4

Bell, Z., Seager, I., Shader, T., \& Fristad, M. A. (2018). Updating the Textbook: A Novel Approach to Training Graduate Students in Evidence-Based Youth Practices. Cognitive and Behavioral Practice, 25(1), 1-6. https://doi.org/10.1016/j.cbpra.2017.04.003

Bickman, L., Athay, M. M., Riemer, M., Lambert, E. W., Kelley, S. D., Breda, C., ... Vides de Andrade, A. R. (2010). Peabody Treatment Progress Battery. In Manual of the Peabody Treatment Progress Battery, 2nd ed. (2nd ed). Retrieved from http://peabody.vanderbilt.edu/ptpb $\% 5 \mathrm{C}$

Borduin, C. M., \& Dopp, A. R. (2015). Economic impact of multisystemic therapy with juvenile sexual offenders. Journal of Family Psychology, 29(5), 687-696. https://doi.org/10.1037/fam0000113

Brookman-Frazee, L., Haine, R. A., Baker-Ericzén, M., Zoffness, R., \& Garland, A. F. (2010). Factors Associated with Use of Evidence-Based Practice Strategies in Usual Care Youth Psychotherapy. Administration and Policy in Mental Health and Mental Health Services Research, 37(3), 254-269. https://doi.org/10.1007/s10488-0090244-9 
Brookman-Frazee, L. I., Drahota, A., \& Stadnick, N. (2012). Training community mental health therapists to deliver a package of evidence based practice strategies for school-age children with ASD. J Autism Dev Disord, 42(8), 1651-1661. https://doi.org/10.1007/s10803-011-1406-7.Training

Campos-Melady, M., Smith, J. E., Meyers, R. J., Godley, S. H., \& Godley, M. D. (2017). The effect of therapists' adherence and competence in delivering the adolescent community reinforcement approach on client outcomes. Psychology of Addictive Behaviors, 31(1), 117-129. https://doi.org/10.1037/adb0000216

Chaffe, S. H., \& Roser, C. (1986). Involvement and the Consistency of Knowledge, Attitudes, and Behaviors. Communication Research, 13(3), 373-399.

Cho, E., Wood, P. K., Taylor, E. K., Hausman, E. M., Andrews, J. H., \& Hawley, K. M. (2019). Evidence-Based Treatment Strategies in Youth Mental Health Services: Results from a National Survey of Providers. Administration and Policy in Mental Health and Mental Health Services Research, 46(1), 71-81. https://doi.org/10.1007/s10488-018-0896-4

Cook, J. M., Biyanova, T., \& Coyne, J. C. (2009). Barriers to adoption of new treatments: An internet study of practicing community psychotherapists. Administration and Policy in Mental Health and Mental Health Services Research, 36(2), 83-90. https://doi.org/10.1007/s10488-008-0198-3

Damschroder, L. J., Aron, D. C., Keith, R. E., Kirsh, S. R., Alexander, J. A., \& Lowery, J. C. (2009). Fostering implementation of health services research findings into practice: a consolidated framework for advancing implementation science. Implementation Science, 4(1), 50. https://doi.org/10.1186/1748-5908-4-50 
Davis, DA, Thomson, M., Oxman, A., \& Haynes, R. (1992). Evidence for the effectiveness of CME. A review of 50 randomized controlled trials. Journal of the American Medical Association, 268(9), 1111-1117.

Davis, DA, Thomson, M., Oxman, A., \& Haynes, R. (1995). Changing physician performance. A systematic review of the effect of continuing medical education strategies. Jama, 274(9), 700-705.

Davis, Dave, O’Brien, M. A. T., Freemantle, N., Wolf, F. M., Mazmanian, P., \& TaylorVaisey, A. (1999). Impact of Formal Continuing Medical Education. JAMA, 282(9), 867. https://doi.org/10.1001/jama.282.9.867

Dawson, G. C. (2018). Years of Clinical Experience and Therapist Professional Development: A Literature Review. Journal of Contemporary Psychotherapy, 48(2), 89-97. https://doi.org/10.1007/s10879-017-9373-8

Dillman, D. (2000). Procedures for conducting government-sponsored establishment surveys: Comparisons of the total design method (TDM), a traditional costcompensation. Proceedings of American Statistical Association, Second International Conference on Establishment Surveys, 343-352.

Dopp, A. R., Borduin, C. M., Wagner, D. V., \& Sawyer, A. M. (2014). The economic impact of multisystemic therapy through midlife: A cost-benefit analysis with serious juvenile offenders and their siblings. Journal of Consulting and Clinical Psychology, 82(4), 694-705. https://doi.org/10.1037/a0036415

Dopp, A. R., Schaeffer, C. M., Swenson, C. C., \& Powell, J. S. (2018). Economic Impact of Multisystemic Therapy for Child Abuse and Neglect. Administration and Policy in Mental Health and Mental Health Services Research, 45(6), 876-887. 
https://doi.org/10.1007/s10488-018-0870-1

Eccles, M. P., \& Mittman, B. S. (2006). Implementation Science Welcome to Implementation Science Implementation Science. https://doi.org/10.1186/1748$5908-1-1$

Ehrhart, M. G., Aarons, G. A., \& Farahnak, L. R. (2014). Assessing the organizational context for EBP implementation: the development and validity testing of the Implementation Climate Scale (ICS). Implementation Science, 9(1), 157. https://doi.org/10.1186/s13012-014-0157-1

Ehrhart, M. G., Schneider, B., \& Macey, W. H. (2013). Organizational climate and culture: An introduction to theory, research, and practice. In Organizational Climate and Culture: An Introduction to Theory, Research, and Practice. https://doi.org/10.4324/9781315857664

Ehrhart, M. G., Torres, E. M., Wright, L. A., Martinez, S. Y., \& Aarons, G. A. (2016). Validating the Implementation Climate Scale (ICS) in child welfare organizations. Child Abuse \& Neglect, 53, 17-26. https://doi.org/10.1016/J.CHIABU.2015.10.017

Falender, C. A., Cornish, J. A. E., Goodyear, R., Hatcher, R., Kaslow, N. J., Leventhal, G., ... Grus, C. (2004). Defining competencies in psychology supervision: A consensus statement. Journal of Clinical Psychology, 60(7), 771-785. https://doi.org/10.1002/jclp.20013

Frank, H. E., Becker-Haimes, E. M., \& Kendall, P. C. (2020). Therapist training in evidence-based interventions for mental health: A systematic review of training approaches and outcomes. Clinical Psychology: Science and Practice, (January 2019), 1-30. https://doi.org/10.1111/cpsp.12330 
Frazier, S., Bearman, S., Garland, A., \& Atkins, M. (2014). Dissemination and implementation in children's mental health: Closing the research to training gap. In R. S. Beidas \& P. C. Kendall (Eds.), Dissemination and implementation of evidencebased practices in child and adolescent mental health (pp. 98-132). Oxford University Press.

Gale, R. C., Wu, J., Erhardt, T., Bounthavong, M., Reardon, C. M., Damschroder, L. J., \& Midboe, A. M. (2019). Comparison of rapid vs in-depth qualitative analytic methods from a process evaluation of academic detailing in the Veterans Health Administration. Implementation Science, 14(1), 1-12. https://doi.org/10.1186/s13012-019-0853-y

Garland, Ann F., Bickman, L., \& Chorpita, B. F. (2010). Change What? Identifying Quality Improvement Targets by Investigating Usual Mental Health Care. Administration and Policy in Mental Health and Mental Health Services Research, 37(1-2), 15-26. https://doi.org/10.1007/s10488-010-0279-y

Garland, ANN F., Hough, R. L., McCabe, K. M., Yeh, M., Wood, P. A., \& Aarons, G. A. (2001). Prevalence of Psychiatric Disorders in Youths Across Five Sectors of Care. Journal of the American Academy of Child \& Adolescent Psychiatry, 40(4), 409418. https://doi.org/10.1097/00004583-200104000-00009

Glasgow R E, Vogt T M, \& Boles S M. (1999). Evaluating the public health impact of health promotion interventions: the RE-AIM framework. American Journal of Public Health, 89(9), 1322-1327.

Glisson, C., \& Schoenwald, S. K. (2005). The ARC Organizational and Community Intervention Strategy for Implementing Evidence-Based Children's Mental Health 
Treatments. Mental Health Services Research, 7(4). https://doi.org/10.1007/s11020005-7456-1

Glisson, C., Schoenwald, S. K., Kelleher, K., Landsverk, J., Hoagwood, K. E., Mayberg, S., ... Health, T. R. N. on Y. M. (2008). Therapist Turnover and New Program Sustainability in Mental Health Clinics as a Function of Organizational Culture, Climate, and Service Structure. Administration and Policy in Mental Health and Mental Health Services Research, 35(1-2), 124-133.

https://doi.org/10.1007/s10488-007-0152-9

Greenhalgh, T., Robert, G., Macfarlane, F., Bate, P., \& Kyriakidou, O. (2004). Diffusion of innovations in service organizations: Systematic review and recommendations. Milbank Quarterly, Vol. 82, pp. 581-629. https://doi.org/10.1111/j.0887378X.2004.00325.X

Hamilton, A. (2013). Qualitative methods in rapid turn-around health services research. Retrieved April 3, 2020, from http://www.hsrd.research.va.gov/for_researchers/cyber_seminars/archives/780notes.pdf

Harned, M. S., Dimeff, L. A., Woodcock, E. A., Kelly, T., Zavertnik, J., Contreras, I., \& Danner, S. M. (2014). Exposing Clinicians to Exposure: A Randomized Controlled Dissemination Trial of Exposure Therapy for Anxiety Disorders. Behavior Therapy, 45(6), 731-744. https://doi.org/10.1016/j.beth.2014.04.005

Hawley, K. (2019). Cognitive Behavioral Therapy Adherence Measure. Manuscript in Preparation.

Heck, N. C., Saunders, B. E., \& Smith, D. W. (2015). Web-based training for an 
evidence-supported treatment: Training completion and knowledge acquisition in a global sample of learners. Child Maltreatment, 20(3), 183-192.

https://doi.org/10.1177/1077559515586569

Herman, K. C., Reinke, W. M., Thompson, A. M., \& Hawley, K. M. (2019). The Missouri Prevention Center: A multidisciplinary approach to reducing the societal prevalence and burden of youth mental health problems. American Psychologist, 74(3), 315-328. https://doi.org/10.1037/amp0000433

Herschell, A. D., Kolko, D. J., Baumann, B. L., \& Davis, A. C. (2010). The role of therapist training in the implementation of psychosocial treatments: A review and critique with recommendations. Clinical Psychology Review, 30(4), 448-466. https://doi.org/10.1016/j.cpr.2010.02.005

Herschell, A. D., Lindhiem, O. J., Kogan, J. N., Celedonia, K. L., \& Stein, B. D. (2014). Evaluation of an implementation initiative for embedding Dialectical Behavior Therapy in community settings. Evaluation and Program Planning, 43, 55-63. https://doi.org/10.1016/j.evalprogplan.2013.10.007

Herschell, A. D., Quetsch, L. B., \& Kolko, D. J. (2019). Measuring Adherence to Key Teaching Techniques in an Evidence-Based Treatment: A Comparison of Caregiver, Therapist, and Behavior Observation Ratings. Journal of Emotional and Behavioral Disorders, 106342661882190. https://doi.org/10.1177/1063426618821901

Herschell, A. D., Reed, A. J., Mecca, L. P., \& Kolko, D. J. (2014). Community-based clinicians' preferences for training in evidence-based practices: A mixed-method study. Professional Psychology: Research and Practice, 45(3), 188-199. https://doi.org/10.1037/a0036488 
Higa-McMillan, C. K., Nakamura, B. J., Morris, A., Jackson, D. S., \& Slavin, L. (2015).

Predictors of Use of Evidence-Based Practices for Children and Adolescents in Usual Care. Administration and Policy in Mental Health and Mental Health Services Research, 42(4), 373-383. https://doi.org/10.1007/s10488-014-0578-9

Hogue, A., Dauber, S., Lichvar, E., Bobek, M., \& Henderson, C. E. (2015). Validity of Therapist Self-Report Ratings of Fidelity to Evidence-Based Practices for Adolescent Behavior Problems: Correspondence between Therapists and Observers. Administration and Policy in Mental Health and Mental Health Services Research, 42(2), 229-243. https://doi.org/10.1007/s10488-014-0548-2

Hogue, A., Henderson, C. E., Dauber, S., Barajas, P. C., Fried, A., \& Liddle, H. A. (2008). Treatment adherence, competence, and outcome in individual and family therapy for adolescent behavior problems. Journal of Consulting and Clinical Psychology, 76(4), 544-555. https://doi.org/10.1037/0022-006X.76.4.544

Hukkelberg, S. S., \& Ogden, T. (2013). Working alliance and treatment fidelity as predictors of externalizing problem behaviors in parent management training. Journal of Consulting and Clinical Psychology, 81(6), 1010-1020. https://doi.org/10.1037/a0033825

Hurlburt, M. S., Garland, A. F., Nguyen, K., \& Brookman-Frazee, L. (2010). Child and Family Therapy Process: Concordance of Therapist and Observational Perspectives. Administration and Policy in Mental Health and Mental Health Services Research, 37(3), 230-244. https://doi.org/10.1007/s10488-009-0251-X

Jensen-Doss, A., \& Hawley, K. M. (2011). Understanding Clinicians’ Diagnostic Practices: Attitudes Toward the Utility of Diagnosis and Standardized Diagnostic 
Tools. Administration and Policy in Mental Health and Mental Health Services Research, 38(6), 476-485. https://doi.org/10.1007/s10488-011-0334-3

Jensen-Doss, A., Smith, A. M., Walsh, L. M., Mora Ringle, V., Casline, E., Patel, Z., ... Webster, R. (2019). Preaching to the Choir? Predictors of Engagement in a Community-Based Learning Collaborative. Administration and Policy in Mental Health and Mental Health Services Research, 1-12. https://doi.org/10.1007/s10488019-00985-4

Jones, E., Manassis, K., Arnold, P., Ickowicz, A., Mendlowitz, S., Nowrouzi, B., ... Schmidt, F. (2015). Translating Cognitive Behavioral Therapy for Anxious Youth to Rural-Community Settings via Tele-Psychiatry. Community Mental Health Journal, 51(7), 852-856. https://doi.org/10.1007/s10597-015-9882-4

Karlin, B. E., Brown, G. K., Trockel, M., Cunning, D., Zeiss, A. M., \& Barr Taylor, C. (2012). National dissemination of cognitive behavioral therapy for depression in the department of veterans affairs health care system: Therapist and patient-level outcomes. Journal of Consulting and Clinical Psychology, 80(5), 707-718. https://doi.org/10.1037/a0029328

Knotek, S. E., \& Hylander, I. (2014). Research issues in mental health consultation and consultee-centered approaches. Handbook of Research in School Consultation, 2, $153-179$.

Kobak, K. A., Wolitzky-Taylor, K., Craske, M. G., \& Rose, R. D. (2017). Therapist Training on Cognitive Behavior Therapy for Anxiety Disorders Using InternetBased Technologies. Cognitive Therapy and Research, 41(2), 252-265. https://doi.org/10.1007/s10608-016-9819-4 
Kolko, D. J., Baumann, B. L., Herschell, A. D., Hart, J. A., Holden, E. A., \& Wisniewski, S. R. (2012). Implementation of AF-CBT by Community Practitioners Serving Child Welfare and Mental Health. Child Maltreatment, 17(1), 32-46. https://doi.org/10.1177/1077559511427346

Lim, A., Nakamura, B. J., Higa-McMillan, C. K., Shimabukuro, S., \& Slavin, L. (2012). Effects of workshop trainings on evidence-based practice knowledge and attitudes among youth community mental health providers. Behaviour Research and Therapy, 50(6), 397-406. https://doi.org/10.1016/j.brat.2012.03.008

Locke, J., Beidas, R. S., Marcus, S., Stahmer, A., Aarons, G. A., Lyon, A. R., ... Mandell, D. S. (2019). A mixed methods study of individual and organizational factors that affect implementation of interventions for children with autism in public schools. Implementation Science, 11(1), 135. https://doi.org/10.1186/s13012-016$0501-8$

Lu, W., Yanos, P. T., Gottlieb, J. D., Duva, S. M., Silverstein, S. M., Xie, H., ... Mueser, K. T. (2012). Use of Fidelity Assessments to Train Clinicians in the CBT for PTSD Program for Clients With Serious Mental Illness. Psychiatric Services, 63(8), 785792. https://doi.org/10.1176/appi.ps.201000458

Lyon, A. R., Stirman, S. W., Kerns, S. E. U., \& Bruns, E. J. (2011). Application of training approaches from multiple disciplines. Administration and Policy in Mental Health, 38(4), 238-253. https://doi.org/10.1007/s10488-010-0331-y.Developing Marques, L., Dixon, L., Valentine, S. E., Borba, C. P. C., Simon, N. M., \& Stirman, S. W. (2016). Providers' Perspectives of Factors Influencing Implementation of Evidence-Based Treatments in a Community Mental Health Setting: A Qualitative 
Investigation of the Training-Practice Gap. Psychol Serv, 13(3), 322-331.

https://doi.org/10.1037/ser0000087

Marques, L., Dixon, L., Valentine, S. E., Borba, C. P. C., Simon, N. M., \& Wiltsey

Stirman, S. (2016). Providers' perspectives of factors influencing implementation of evidence-based treatments in a community mental health setting: A qualitative investigation of the training-practice gap. Psychological Services, 13(3), 322-331. https://doi.org/10.1037/ser0000087

Marriott, B., Cho, E., Tugendrajch, S., \& Hawley, K. (2020). Training as Usual in Community Mental Health Care: Influence on Practice and Time for Training. Manuscript in Preparation.

Martino, S., Paris, M., Añez, L., Nich, C., Canning-Ball, M., Hunkele, K., ... Carroll, K. M. (2016). The Effectiveness and Cost of Clinical Supervision for Motivational Interviewing: A Randomized Controlled Trial. Journal of Substance Abuse Treatment, 68, 11-23. https://doi.org/10.1016/j.jsat.2016.04.005

Matuschek, H., Kliegl, R., Vasishth, S., Baayen, H., \& Bates, D. (2017). Balancing Type I error and power in linear mixed models. Journal of Memory and Language, 94, 305-315. https://doi.org/10.1016/J.JML.2017.01.001

McLeod, B. D., Cox, J. R., Jensen-Doss, A., Herschell, A., Ehrenreich-May, J., \& Wood, J. J. (2018). Proposing a mechanistic model of clinician training and consultation. Clinical Psychology: Science and Practice, 25(3), 1-19. https://doi.org/10.1111/cpsp.12260

McMillen, J. C., Hawley, K. M., \& Proctor, E. K. (2016). Mental Health Clinicians' Participation in Web-Based Training for an Evidence Supported Intervention: Signs 
of Encouragement and Trouble Ahead. Administration and Policy in Mental Health and Mental Health Services Research, 43(4), 592-603.

https://doi.org/10.1007/s10488-015-0645-x

Mendel, P., Meredith, L. S., Schoenbaum, M., Sherbourne, C. D., \& Wells, K. B. (2008). Interventions in organizational and community context: A framework for building evidence on dissemination and implementation in health services research. Administration and Policy in Mental Health and Mental Health Services Research, 35(1-2), 21-37. https://doi.org/10.1007/s10488-007-0144-9

Meyer, A. E., Reilly, E. E., Daniel, K. E., Hollon, S. D., Jensen-Doss, A., Mennin, D. S., ... Teachman, B. A. (2019). Characterizing Evidence-Based Practice and Training Resource Barriers: A Needs Assessment. Training and Education in Professional Psychology. https://doi.org/10.1037/tep0000261

Nadeem, E., Gleacher, A., \& Beidas, R. S. (2013). Consultation as an implementation strategy for evidence-based practices across multiple contexts: Unpacking the black box. Administration and Policy in Mental Health and Mental Health Services Research, 40(6), 439-450. https://doi.org/10.1007/s10488-013-0502-8

Nelson, T. D., \& Steele, R. G. (2007). Predictors of Practitioner Self-reported Use of Evidence-Based Practices: Practitioner Training, Clinical Setting, and Attitudes Toward Research. Administration and Policy in Mental Health and Mental Health Services Research, 34(4), 319-330. https://doi.org/10.1007/s10488-006-0111-x Okamura, K. H., Benjamin Wolk, C. L., Kang-Yi, C. D., Stewart, R., Rubin, R. M., Weaver, S., ... Mandell, D. S. (2018). The Price per Prospective Consumer of Providing Therapist Training and Consultation in Seven Evidence-Based Treatments 
within a Large Public Behavioral Health System: An Example Cost-Analysis Metric. Frontiers in Public Health, 5(January), 1-8.

https://doi.org/10.3389/fpubh.2017.00356

Okamura, K. H., Nakamura, B. J., Mueller, C., Hayashi, K., \& McMillan, C. K. H. (2016). An Exploratory Factor Analysis of the Knowledge of Evidence-Based Services Questionnaire. Journal of Behavioral Health Services and Research, 43(2), 214-232. https://doi.org/10.1007/s11414-013-9384-5

Palinkas, L. A., Aarons, G. A., Horwitz, S., Chamberlain, P., Hurlburt, M., \& Landsverk, J. (2011). Mixed method designs in implementation research. Administration and Policy in Mental Health and Mental Health Services Research, 38(1), 44-53. https://doi.org/10.1007/s10488-010-0314-z

Palinkas, L. A., Horwitz, S. M., Green, C. A., Wisdom, J. P., Duan, N., \& Hoagwood, K. (2015). Purposeful Sampling for Qualitative Data Collection and Analysis in Mixed Method Implementation Research. Administration and Policy in Mental Health and Mental Health Services Research, 42(5), 533-544. https://doi.org/10.1007/s10488013-0528-y

PEARCY, M. T., CLOPTON, J. R., \& POPE, A. W. (1993). Influences on Teacher Referral of Children to Mental Health Services. Journal of Emotional and Behavioral Disorders, 1(3), 165-169. https://doi.org/10.1177/106342669300100304

Powell, B. J., McMillen, J. C., Hawley, K. M., \& Proctor, E. K. (2013). Mental Health Clinicians' Motivation to Invest in Training: Results From a Practice-Based Research Network Survey. Psychiatric Services, 64(8), 816-818. https://doi.org/10.1176/appi.ps.003602012 
Powell, B. J., Waltz, T. J., Chinman, M. J., Damschroder, L. J., Smith, J. L., Matthieu, M. M., ... Kirchner, J. A. E. (2015). A refined compilation of implementation strategies: Results from the Expert Recommendations for Implementing Change (ERIC) project. Implementation Science, 10(1), 1-14.

https://doi.org/10.1186/s13012-015-0209-1

Proctor, E., Silmere, H., Raghavan, R., Hovmand, P., Aarons, G., Bunger, A., ... Hensley, M. (2011). Outcomes for implementation research: Conceptual distinctions, measurement challenges, and research agenda. Administration and Policy in Mental Health and Mental Health Services Research, 38(2), 65-76. https://doi.org/10.1007/s10488-010-0319-7

Rav-Marathe, K., Wan, T. T. H., \& Marathe, S. (2016). A Systematic Review on the Kap-O Framework for Diabetes Education and Research. Medical Research Archives, 4(1), 1-21.

Riemer, M., Rosof-Williams, J., \& Bickman, L. (2005). Theories Related to Changing Clinician Practice. Child and Adolescent Psychiatric Clinics of North America, 14(2), 241-254. https://doi.org/10.1016/j.chc.2004.05.002

Rogers, E. M. (2003). Diffusion of Innovations. New York: Free Press.

Rozek, D. C., Serrano, J. L., Marriott, B. R., Scott, K. S., Hickman, L. B., Brothers, B. M., ... Simons, A. D. (2018). Cognitive Behavioural Therapy Competency: Pilot Data from a Comparison of Multiple Perspectives. Behavioural and Cognitive Psychotherapy, 46(2), 244-250. https://doi.org/10.1017/S1352465817000662

Schoenwald, S. K., Carter, R. E., Chapman, J. E., \& Sheidow, A. J. (2008). Therapist Adherence and Organizational Effects on Change in Youth Behavior Problems One 
Year After Multisystemic Therapy. Administration and Policy in Mental Health and Mental Health Services Research, 35(5), 379-394. https://doi.org/10.1007/s10488008-0181-z

Schoenwald, S. K., Sheidow, A. J., \& Letourneau, E. J. (2004). Toward Effective Quality Assurance in Evidence-Based Practice: Links Between Expert Consultation, Therapist Fidelity, and Child Outcomes. Journal of Clinical Child \& Adolescent Psychology, 33(1), 94-104. https://doi.org/10.1207/S15374424JCCP3301_10

Schumacher, J., Arment, C., \& Meyers, E. (2014). Community Input Report. Columbia, MO.

Sholomskas, D. E., Syracuse-Siewert, G., Rounsaville, B. J., Ball, S. A., Nuro, K. F., \& Carroll, K. M. (2005). We don't train in vain: a dissemination trial of three strategies of training clinicians in cognitive-behavioral therapy. Journal of Consulting and Clinical Psychology, 73(1), 106-115. https://doi.org/10.1037/0022-006X.73.1.106

Simons, A. D., Padesky, C. A., Montemarano, J., Lewis, C. C., Murakami, J., Lamb, K., ... Beck, A. T. (2010). Training and dissemination of cognitive behavior therapy for depression in adults: A preliminary examination of therapist competence and client outcomes. Journal of Consulting and Clinical Psychology, 78(5), 751-756. https://doi.org/10.1037/a0020569

Skriner, L. C., Benjamin Wolk, C., Stewart, R. E., Adams, D. R., Rubin, R. M., Evans, A. C., \& Beidas, R. S. (2018). Therapist and organizational factors associated with participation in evidence-based practice initiatives in a large urban publicly-funded mental health system HHS Public Access. J Behav Health Serv Res, 45(2), 174-186. https://doi.org/10.1007/s11414-017-9552-0 
Skriner, L. C., Wolk, C. B., Stewart, R. E., Adams, D. R., Rubin, R. M., Evans, A. C., \& Beidas, R. S. (2018). Therapist and Organizational Factors Associated with Participation in Evidence-Based Practice Initiatives in a Large Urban PubliclyFunded Mental Health System. Journal of Behavioral Health Services and Research, 45(2), 174-186. https://doi.org/10.1007/s11414-017-9552-0

Smith, T. L., Landes, S. J., Lester-Williams, K., Day, K. T., Batdorf, W., Brown, G. K., ... Weingardt, K. R. (2017). Developing alternative training delivery methods to improve Psychotherapy implementation in the U.S. department of Veterans affairs. Training and Education in Professional Psychology, 11(4), 266-275. https://doi.org/10.1037/tep0000156

Southam-Gerow, M. A., Daleiden, E. L., Chorpita, B. F., Bae, C., Mitchell, C., Faye, M., \& Alba, M. (2014). MAPping Los Angeles County: Taking an Evidence-Informed Model of Mental Health Care to Scale. Journal of Clinical Child and Adolescent Psychology, 43(2), 190-200. https://doi.org/10.1080/15374416.2013.833098

Stewart, R. E., Chambless, D. L., \& Baron, J. (2012). Theoretical and practical barriers to practitioners' willingness to seek training in empirically supported treatments. Journal of Clinical Psychology, 68(1), 8-23. https://doi.org/10.1002/jclp.20832

Stumpf, R. E., Higa-Mcmillan, C. K., \& Chorpita, B. F. (2009). Implementation of Evidence-Based Services for Youth Assessing Provider Knowledge. https://doi.org/10.1177/0145445508322625

Tugendrajch, S. K., Cho, E., Proctor, E. K., McMillen, J. C., \& Hawley, K. M. (2019). Implementation of EBPs within Publicly-Funded Youth Mental Health Services: Comparing EBP in TAU against States Following Mandates and Incentives. 


\section{Manuscript in Preparation.}

Valente, T. W., \& Rogers, E. M. (1995). The Origins and Development of the Diffusion of Innovations Paradigm as an Example of Scientific Growth. In Science Communication (Vol. 16). https://doi.org/10.1177/1075547095016003002

Valente, T. W., \& Saba, W. P. (1998). Mass Media and Interpersonal Influence in a Reproductive Health Communication Campaign in Bolivia. Communication Research, 25(1), 96-124. Retrieved from https://journals.sagepub.com/doi/pdf/10.1177/009365098025001004?casa_token=k KmFctXfzRkAAAAA:wxfyMVewL2b3jYbQjGJguoTCRCLTxtVyGLCtxvIYyc2tV ZNJxsbseN9R-NNIEGW6zvNdIBtxKVitJ5k

Walser, R. D., Karlin, B. E., Trockel, M., Mazina, B., \& Barr Taylor, C. (2013). Training in and implementation of Acceptance and Commitment Therapy for depression in the Veterans Health Administration: Therapist and patient outcomes. Behaviour Research and Therapy, 51(9), 555-563. https://doi.org/10.1016/j.brat.2013.05.009

Weersing, V. R., Weisz \& Geri, J. R., \& Donenberg, R. R. (2002). Development of the Therapy Procedures Checklist: A Therapist-Report Measure of Technique Use in Child and Adolescent Treatment. Journal of Clinical Child and Adolescent Psychology, 31(2), 168-180. https://doi.org/10.1207/S15374424JCCP3102_03

Weisz, J. R., Chorpita, B. F., Frye, A., Ng, M. Y., Lau, N., Bearman, S. K., ... Hoagwood, K. E. (2011). Youth top problems: Using idiographic, consumer-guided assessment to identify treatment needs and to track change during psychotherapy. Journal of Consulting and Clinical Psychology, 79(3), 369-380. https://doi.org/10.1037/a0023307 
Weisz, J. R., Kuppens, S., Eckshtain, D., Ugueto, A. M., Hawley, K. M., \& Jensen-Doss, A. (2013). Performance of evidence-based youth psychotherapies compared with usual clinical care a multilevelmeta-analysis. JAMA Psychiatry, 70(7), 750-761. https://doi.org/10.1001/jamapsychiatry.2013.1176

Weisz, J. R., Ng, M. Y., Ugueto, A. M., Jensen-Doss, A., Marchette, L. S. K., Weersing, V. R., ... Fordwood, S. R. (2017). What five decades of research tells us about the effects of youth psychological therapy: A multilevel meta-analysis and implications for science and practice. American Psychologist, 72(2), 79-117. https://doi.org/10.1037/a0040360

Williams, N. J. (2016). Multilevel Mechanisms of Implementation Strategies in Mental Health: Integrating Theory, Research, and Practice. Administration and Policy in Mental Health and Mental Health Services Research, 43(5), 783-798. https://doi.org/10.1007/s10488-015-0693-2

Williams, N. J., Wolk, C. B., Becker-Haimes, E. M., \& Beidas, R. S. (2020). Testing a theory of strategic implementation leadership, implementation climate, and clinicians' use of evidence-based practice: a 5-year panel analysis. Implementation Science, 15(1), 10. https://doi.org/10.1186/s13012-020-0970-7

Wiltsey-Stirman, S., Kimberly, J., Cook, N., Calloway, A., Castro, F., \& Charns, M. (2012). The sustainability of new programs and innovations: a review of the empirical literature and recommendations for future research. Implementation Science, 7(1), 17. https://doi.org/10.1186/1748-5908-7-17

Wiltsey Stirman, S., Gutiérrez-Colina, A., Toder, K., Esposito, G., Barg, F., Castro, F., ... Crits-Christoph, P. (2013). Clinicians' Perspectives on Cognitive Therapy in 
Community Mental Health Settings: Implications for Training and Implementation NIH Public Access. Adm Policy Ment Health, 40(4), 274-285.

https://doi.org/10.1007/s10488-012-0418-8 


\section{APPENDIX}

Table 1

Workshops and Topics $(N=62)$

Training Topic

N (\%)

Anxiety

$16(25.81 \%)$

Disruptive Behavior

$10(16.13 \%)$

Depression

$7(11.29 \%)$

Trauma

$5(8.06 \%)$

Eating Disorders

$4(6.45 \%)$

ADHD

$1(1.62 \%)$

Obsessive-Compulsive Disorder

$3(4.84 \%)$

Motivational Enhancement

$4(6.45 \%)$

Assessment

$3(4.84 \%)$

Other (e.g., Substance Use, Medications, Tics)

$13(20.97 \%)$

Age Focus

$N(\%)$

Youth-Focused

$40(64.52 \%)$

Adolescent and Adult-Focused

$20(32.26 \%)$

Both

$2(3.23 \%)$ 
Table 2

Mental Health Provider Demographic and Practice Characteristics $(N=717)$

Demographic Variables $N(\%)$

$M(S D)$ years of age $36.67(11.86)$

Female $615(85.8 \%)$

Race

Caucasian $584(81.5 \%)$

Black or African American

$63(8.8 \%)$

Asian/Pacific Islander

$27(3.77 \%)$

Biracial or Multiracial

$25(3.5 \%)$

Decline to State

$20(2.8 \%)$

Native American

$6(0.08 \%)$

Other

$9(1.3 \%)$

Latinx

$27(3.8 \%)$

Practice Characteristics

$N(\%)$

Professional discipline

Social work

$238(33.2 \%)$

Counseling

$206(28.7 \%)$

Psychology

$88(12.3 \%)$

Psychiatry

$13(1.8 \%)$

Marriage and family therapy

$8(1.1 \%)$

Other Mental Health Specialty

$83(11.6 \%)$

N/A - not in Mental Health field

$81(11.3 \%)$

Highest degree

Master's

$404(56.3 \%)$

Bachelor's

$191(26.6 \%)$

Doctoral

$64(8.9 \%)$

Some College

$22(3.1 \%)$

Specialist

$14(2.0 \%)$

Associate's

$12(1.7 \%)$ 
Other

$10(1.39 \%)$

Mental Health Licensure Status

Trainee (e.g., student, intern)

$180(25.1 \%)$

Post-Masters/Post-Doctorate (e.g., provisionally licensed)

$92(12.8 \%)$

Missouri Licensed Mental Health Provider

$222(31.0 \%)$

Other

$142(19.8 \%)$

N/A - not in Mental Health field

$81(11.3 \%)$

Employment setting ${ }^{\mathrm{a}}$

Private Practice

$128(17.9 \%)$

Outpatient or Community mental health center

$232(32.4 \%)$

Elementary, middle, high school

$96(13.4 \%)$

College or university

$87(12.1 \%)$

Inpatient hospital or medical clinic

$36(5.0 \%)$

Residential treatment facility or group home

$53(7.4 \%)$

Day treatment or partial day hospital

$12(1.7 \%)$

HMO, PPO, or other managed care organization

$9(1.3 \%)$

Jail or Correctional Facility

$9(1.3 \%)$

Other

$116(16.2 \%)$

$M(S D)$ \# of Years with Current Employer ${ }^{\mathrm{a}}$

$4.14(5.71)$

Mental or Behavioral Health Services Provided

Talk or Behavior Therapy

$387(54.0 \%)$

Assessment/Testing

$327(45.6 \%)$

Case Management

$309(43.1 \%)$

Other

$135(18.8 \%)$

Supervision of Providers

$118(16.5 \%)$

None

$93(13.0 \%)$

Medication Management

$36(5.0 \%)$

Provide Therapy or Therapy Supervision for Youth and Young Adults ${ }^{\mathrm{a}} 324$ (45.2\%)

$M(S D)$ \# of Years Providing Mental Health Services

$8.06(8.65)$

Note. ${ }^{\text {a }} N=100$ were missing this data. 
Table 3

Training Activity Participation $(N=717)$

\begin{tabular}{|c|c|c|}
\hline Training Activity & $\begin{array}{c}N(\% \text { total sample, } \% \\
\text { who completed any } \\
\text { training })\end{array}$ & $\begin{array}{c}\text { Number of Hours of } \\
\text { Participation } \\
M(S D), \text { Range }\end{array}$ \\
\hline EBP Workshops & $479(66.81 \%, 97.16 \%)$ & $8.93(8.93), 1.25-55.80^{a}$ \\
\hline Individual Consultation & $39(5.44 \%, 7.91 \%)$ & $2.78(3.59), 0.20-22^{a}$ \\
\hline $\begin{array}{l}\text { Weekly Individual and } \\
\text { Group Supervision }\end{array}$ & $19(2.65 \%, 3.85 \%)$ & $127.63(63.23), 48-250^{a}$ \\
\hline $\begin{array}{l}\text { Ongoing Biweekly } \\
\text { Learning Community }\end{array}$ & $47(6.56 \%, 9.53 \%)$ & $4.46(7.48), 1-49.50^{a}$ \\
\hline $\begin{array}{l}\text { Online Clinical Feedback } \\
\text { System }\end{array}$ & $42(5.85 \%, 8.52 \%)$ & $9.63(7.60), 1-29^{a c}$ \\
\hline Any Training Activity & $493(68.76 \%)$ & $6.41(9.23), 0-67.60^{b}$ \\
\hline \multicolumn{2}{|l|}{ Training Combinations } & $N(\%$ total sample $)$ \\
\hline \multicolumn{2}{|l|}{ None } & $224(31.24 \%)$ \\
\hline \multicolumn{2}{|l|}{ EBP Workshops Only } & $400(55.79 \%)$ \\
\hline \multicolumn{2}{|c|}{ Consultation or Supervision Only } & $1(0.14 \%)$ \\
\hline \multicolumn{2}{|l|}{ Learning Community Only } & $8(1.12 \%)$ \\
\hline \multicolumn{2}{|c|}{ Online Clinical Feedback System Only } & $1(0.14 \%)$ \\
\hline \multicolumn{2}{|c|}{$\begin{array}{l}\text { 1) EBP Workshops and 2) Consultation or } \\
\text { Supervision }\end{array}$} & $11(1.53 \%)$ \\
\hline \multicolumn{2}{|c|}{$\begin{array}{l}\text { 1) EBP Workshops and 2) Online Clinical } \\
\text { Feedback System }\end{array}$} & $9(1.26 \%)$ \\
\hline \multicolumn{2}{|c|}{ 1) EBP Workshops and 2) Learning Community } & $23(3.21 \%)$ \\
\hline \multicolumn{2}{|c|}{$\begin{array}{l}\text { 1) Consultation or Supervision and 2) Online } \\
\text { Clinical Feedback System }\end{array}$} & $4(0.56 \%)$ \\
\hline
\end{tabular}


1) Workshop, 2) Consultation or Supervision, and

3) Online Clinical Feedback System

1) Workshop, 2) Consultation or Supervision, and

3) Learning Community

$8(1.12 \%)$

1) Workshop, 2) Online Clinical Feedback System, and 3) Learning Community

$2(0.28 \%)$

All Four Activities: 1) Workshop, 2) Consultation

or Supervision, 3) Online Clinical Feedback

$6(0.84 \%)$

System, and 4) Learning Community

Note. ${ }^{a}$ Mean, SD, and Range only included those who had participated in that

training activity. ${ }^{b}$ Mean, SD, and Range included the whole sample. ${ }^{\mathrm{c}}$ Mean, SD,

and Range is for number of cases providers used the online clinical feedback

system with. 
Table 4

Negative Binomial Regression Variables Associated with Training Engagement among Mental Health Providers

\begin{tabular}{|c|c|c|c|c|c|c|c|c|}
\hline \multirow[b]{2}{*}{ Variable } & \multicolumn{4}{|c|}{ All Providers } & \multicolumn{4}{|c|}{ Agency Providers Only } \\
\hline & IRR & $\begin{array}{c}95 \% \\
\mathrm{CI}\end{array}$ & $B$ & $S E$ & IRR & $\begin{array}{l}95 \% \\
\mathrm{CI}\end{array}$ & $B$ & $S E$ \\
\hline Trainee Status & 2.44 & $\begin{array}{l}1.61- \\
3.76\end{array}$ & $0.89 * *$ & 0.20 & 2.81 & $\begin{array}{l}1.72- \\
4.68\end{array}$ & $1.03 * *$ & 0.23 \\
\hline $\begin{array}{l}\text { Time at } \\
\text { Employer }\end{array}$ & 0.98 & $\begin{array}{c}0.95- \\
1.01\end{array}$ & -0.02 & 0.02 & 0.99 & $\begin{array}{c}0.95- \\
1.03\end{array}$ & -0.01 & 0.02 \\
\hline $\begin{array}{l}\text { Years of } \\
\text { Experience }\end{array}$ & 1.01 & $\begin{array}{c}0.99- \\
1.03\end{array}$ & 0.01 & 0.01 & 1.01 & $\begin{array}{c}0.99- \\
1.04\end{array}$ & 0.01 & 0.01 \\
\hline $\begin{array}{l}\text { Knowledge of } \\
\text { EB Treatment } \\
\text { Techniques }\end{array}$ & 1.03 & $\begin{array}{l}1.02- \\
1.04\end{array}$ & $0.03 * *$ & 0.01 & 1.03 & $\begin{array}{l}1.01- \\
1.05\end{array}$ & $0.03 * *$ & 0.01 \\
\hline $\begin{array}{l}\text { Other Therapy } \\
\text { Strategy Use }\end{array}$ & 0.76 & $\begin{array}{l}0.60- \\
0.95\end{array}$ & $-0.27 *$ & 0.11 & 0.84 & $\begin{array}{c}0.63- \\
1.11\end{array}$ & -0.17 & 0.13 \\
\hline $\begin{array}{l}\text { Common EB } \\
\text { Strategy Use }\end{array}$ & 1.29 & $\begin{array}{l}1.06- \\
1.57\end{array}$ & $0.25 * *$ & 0.10 & 1.24 & $\begin{array}{c}0.98- \\
1.56\end{array}$ & $0.21+$ & 0.11 \\
\hline $\begin{array}{l}\text { Years in the } \\
\text { Initiative }\end{array}$ & 1.73 & $\begin{array}{c}1.50- \\
1.99\end{array}$ & $0.55 * *$ & 0.07 & 1.15 & $\begin{array}{c}0.91- \\
1.45\end{array}$ & $0.14 * *$ & 0.11 \\
\hline \multicolumn{9}{|c|}{ Note. IRR = Incidence Rate Ratios; CI = Confidence Interval; EB = Evidence-based; } \\
\hline Reference Grou & or Trai & Statu & is $0=\mathrm{N}$ & -Trai & +Der & tes $p<$ & $.10, * D$ & lotes $p$ \\
\hline
\end{tabular}


Table 5

Zero-Inflated Negative Binomial Regression Variables Associated with Anxiety Workshop Registration among Mental Health Providers

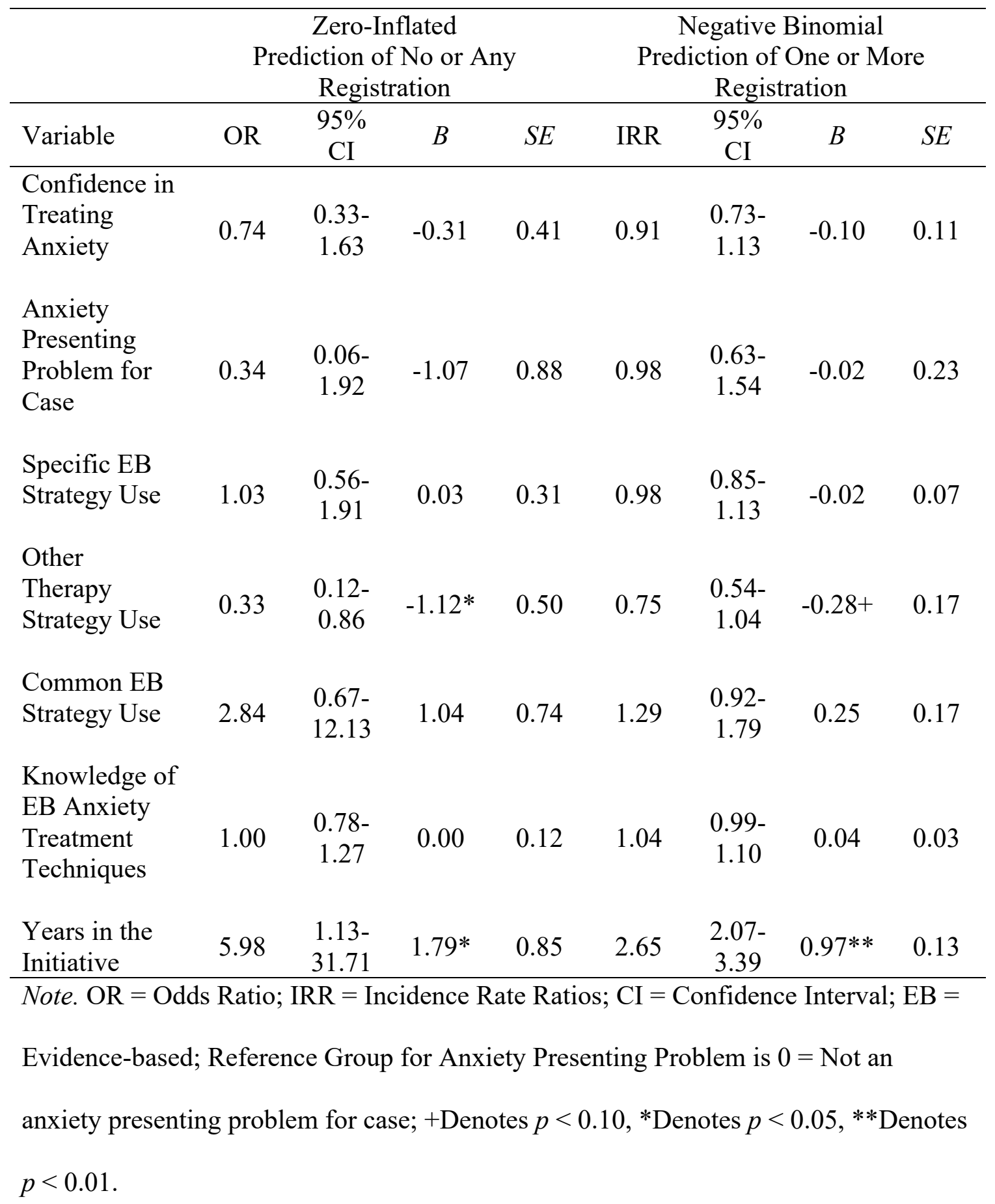


Table 6

Zero-Inflated Negative Binomial Regression Variables Associated with Anxiety Workshop Attendance among Mental Health Providers

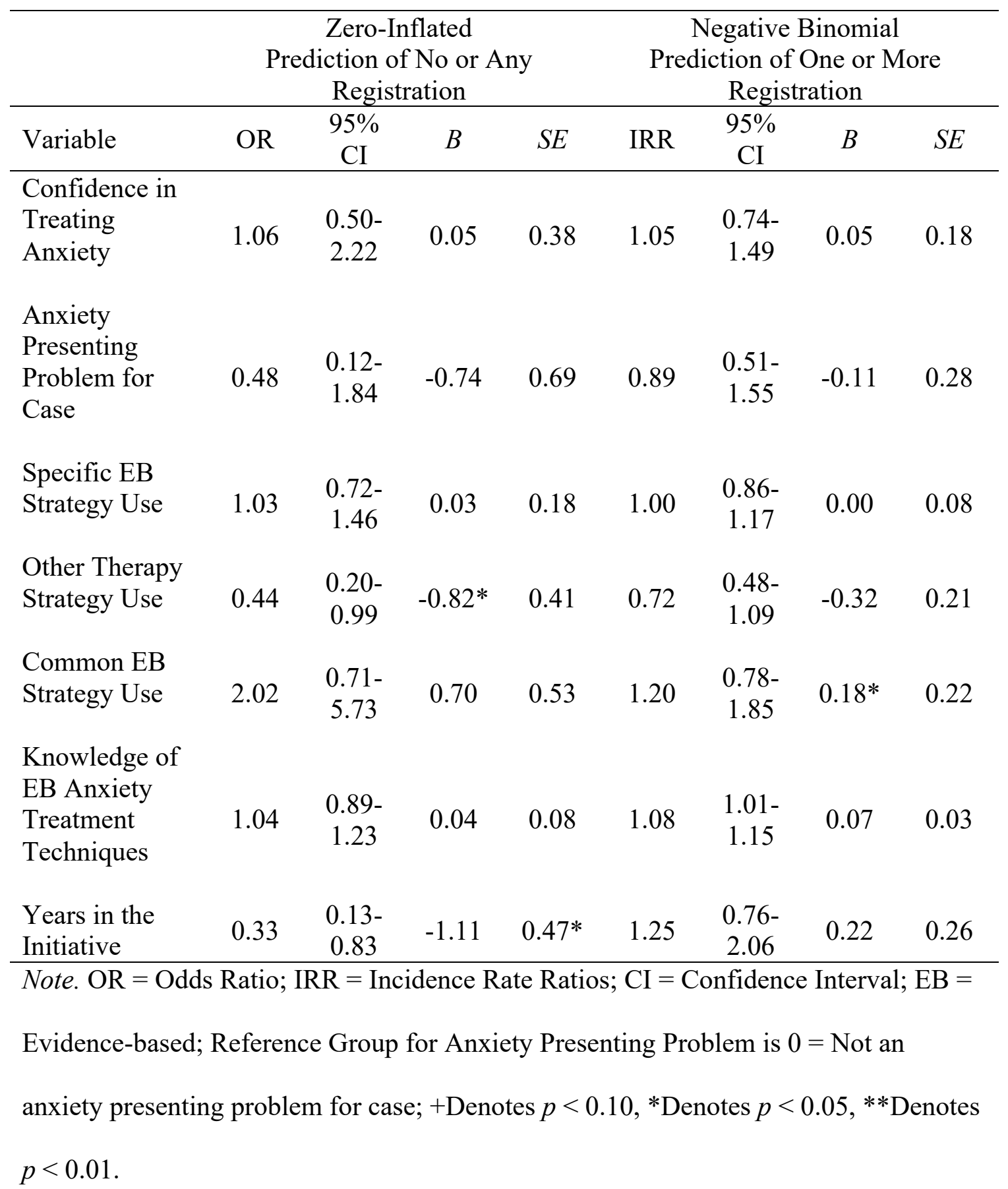


Table 7

Zero-Inflated Poisson Regression Variables Associated with Depression Workshop Registration among Mental Health Providers

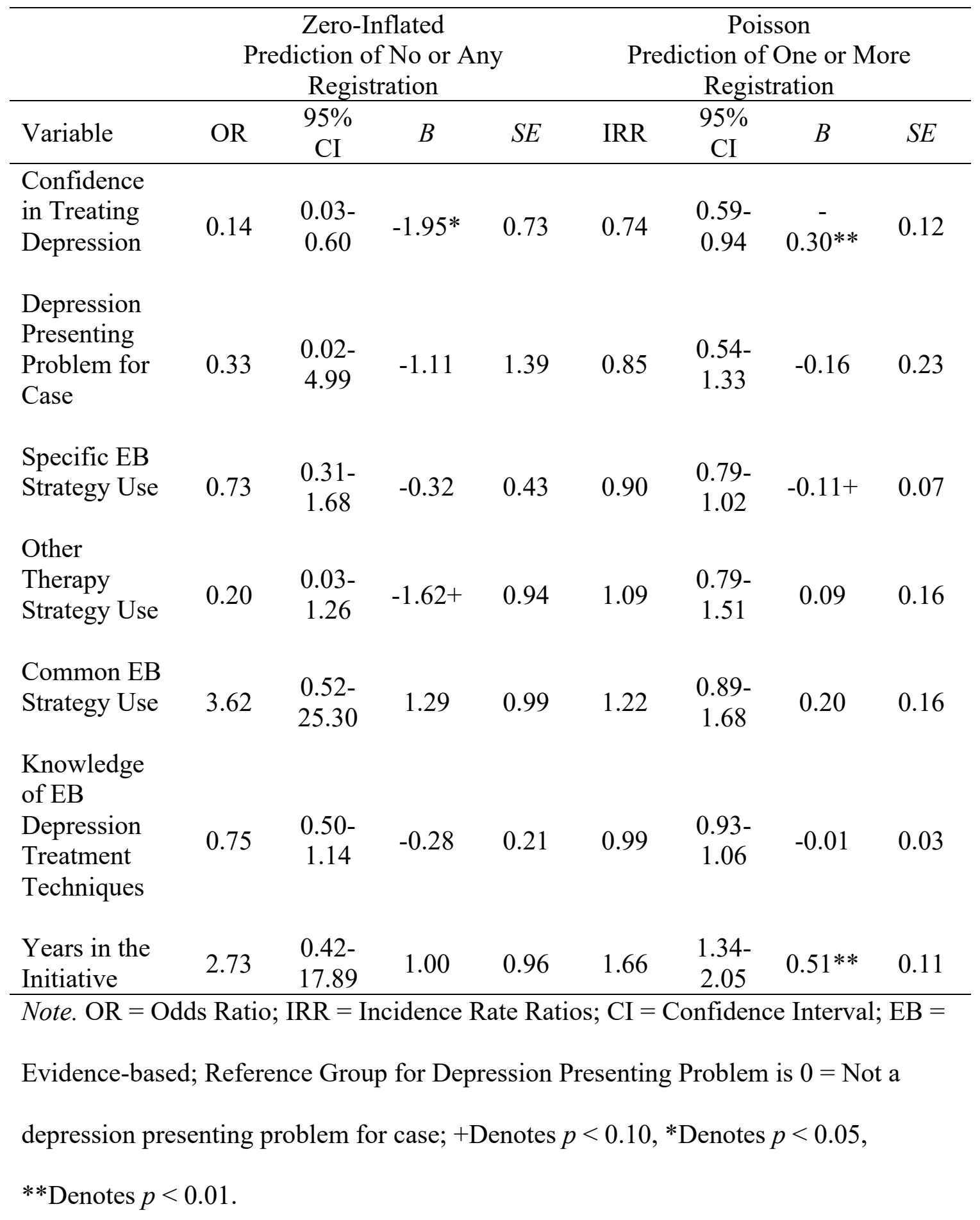


Table 8

Zero-Inflated Poisson Regression Variables Associated with Depression Workshop Attendance among Mental Health Providers

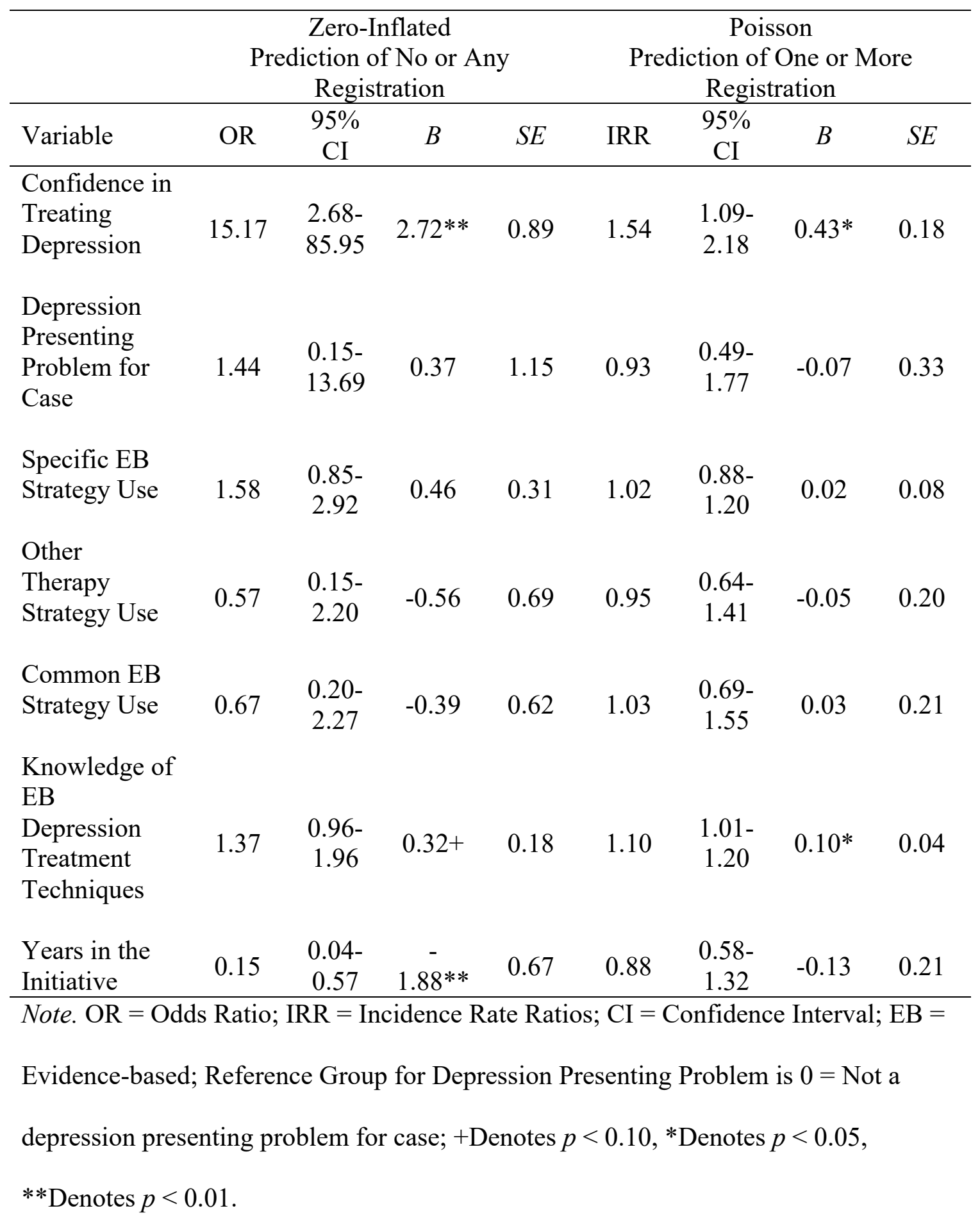


Table 9

Zero-Inflated Negative Binomial Regression Variables Associated with Disruptive Behavior Workshop Registration among Mental Health Providers

\begin{tabular}{|c|c|c|c|c|c|c|c|c|}
\hline \multirow[b]{2}{*}{ Variable } & \multicolumn{4}{|c|}{$\begin{array}{c}\text { Zero-Inflated } \\
\text { Prediction of No or Any } \\
\text { Registration }\end{array}$} & \multicolumn{4}{|c|}{$\begin{array}{c}\text { Negative Binomial } \\
\text { Prediction of One or More } \\
\text { Registration }\end{array}$} \\
\hline & OR & $\begin{array}{c}95 \% \\
\mathrm{CI} \\
\end{array}$ & $B$ & $S E$ & IRR & $\begin{array}{c}95 \% \\
\text { CI }\end{array}$ & $B$ & $S E$ \\
\hline $\begin{array}{l}\text { Confidence in } \\
\text { Treating } \\
\text { Disruptive } \\
\text { Behavior }\end{array}$ & 0.33 & $\begin{array}{l}0.06- \\
1.83\end{array}$ & -1.10 & 0.87 & 0.91 & $\begin{array}{l}0.77- \\
1.07\end{array}$ & -0.10 & 0.08 \\
\hline $\begin{array}{l}\text { Disruptive } \\
\text { Behavior } \\
\text { Presenting } \\
\text { Problem for Case }\end{array}$ & 0.02 & $\begin{array}{l}0.00- \\
4.95\end{array}$ & -4.18 & 2.95 & 0.92 & $\begin{array}{l}0.61- \\
1.39\end{array}$ & -0.09 & 0.21 \\
\hline $\begin{array}{l}\text { Specific EB } \\
\text { Strategy Use }\end{array}$ & 0.94 & $\begin{array}{l}0.39- \\
2.30\end{array}$ & -0.06 & 0.46 & 1.00 & $\begin{array}{l}0.90- \\
1.12\end{array}$ & 0.007 & 0.05 \\
\hline $\begin{array}{l}\text { Other Therapy } \\
\text { Strategy Use }\end{array}$ & 4.27 & $\begin{array}{l}0.86- \\
21.30\end{array}$ & $1.45+$ & 0.82 & 1.40 & $\begin{array}{l}1.09- \\
1.78\end{array}$ & $0.33 * *$ & 0.12 \\
\hline $\begin{array}{l}\text { Common EB } \\
\text { Strategy Use }\end{array}$ & 0.36 & $\begin{array}{c}0.07- \\
1.86\end{array}$ & -1.03 & 0.84 & 0.77 & $\begin{array}{l}0.60- \\
1.01\end{array}$ & $-0.26+$ & 0.13 \\
\hline $\begin{array}{l}\text { Knowledge of EB } \\
\text { Disruptive } \\
\text { Behavior } \\
\text { Treatment } \\
\text { Techniques }\end{array}$ & 0.76 & $\begin{array}{l}0.49- \\
1.20\end{array}$ & -0.27 & 0.23 & 1.00 & $\begin{array}{c}0.94- \\
1.05\end{array}$ & 0.00 & 0.03 \\
\hline $\begin{array}{l}\text { Years in the } \\
\text { Initiative }\end{array}$ & 0.26 & $\begin{array}{c}0.07- \\
1.00 \\
\end{array}$ & $-1.33+$ & 0.68 & 1.56 & $\begin{array}{l}1.23- \\
1.98 \\
\end{array}$ & $0.45^{* *}$ & 0.12 \\
\hline \multicolumn{9}{|c|}{ Note. $\mathrm{OR}=$ Odds Ratio; IRR = Incidence Rate Ratios; $\mathrm{CI}=$ Confidence Interval; EB = } \\
\hline \multicolumn{9}{|c|}{ Evidence-based; Reference Group for Disruptive Behavior Presenting Problem is $0=$} \\
\hline Not a disruptive be & avior 1 & esentin & problem & or cas & + Denc & s $p<0$ & $10, *$ Den & tes $p$ \\
\hline$<0.05, * *$ Denotes & 0. & & & & & & & \\
\hline
\end{tabular}


Table 10

Zero-Inflated Negative Binomial Regression Variables Associated with Disruptive Behavior Workshop Attendance among Mental Health Providers

\begin{tabular}{|c|c|c|c|c|c|c|c|c|}
\hline \multirow[b]{2}{*}{ Variable } & \multicolumn{4}{|c|}{$\begin{array}{c}\text { Zero-Inflated } \\
\text { Prediction of No or Any } \\
\text { Registration }\end{array}$} & \multicolumn{4}{|c|}{$\begin{array}{c}\text { Negative Binomial } \\
\text { Prediction of One or More } \\
\text { Registration }\end{array}$} \\
\hline & OR & $\begin{array}{c}95 \% \\
\mathrm{CI} \\
\end{array}$ & $B$ & $S E$ & IRR & $\begin{array}{c}95 \% \\
\mathrm{CI} \\
\end{array}$ & $B$ & $S E$ \\
\hline $\begin{array}{l}\text { Confidence in } \\
\text { Treating } \\
\text { Disruptive } \\
\text { Behavior }\end{array}$ & 0.75 & $\begin{array}{l}0.35- \\
1.61\end{array}$ & -0.29 & 0.39 & 0.97 & $\begin{array}{l}0.78- \\
1.20\end{array}$ & -0.03 & 0.11 \\
\hline $\begin{array}{l}\text { Disruptive } \\
\text { Behavior } \\
\text { Presenting } \\
\text { Problem for Case }\end{array}$ & 0.21 & $\begin{array}{l}0.02- \\
2.16\end{array}$ & -1.55 & 1.18 & 0.91 & $\begin{array}{c}0.52- \\
1.59\end{array}$ & -0.10 & 0.29 \\
\hline $\begin{array}{l}\text { Specific EB } \\
\text { Strategy Use }\end{array}$ & 1.06 & $\begin{array}{c}0.65- \\
1.72\end{array}$ & 0.06 & 0.25 & 0.95 & $\begin{array}{c}0.84- \\
1.09\end{array}$ & -0.05 & 0.07 \\
\hline $\begin{array}{l}\text { Other Therapy } \\
\text { Strategy Use }\end{array}$ & 6.14 & $\begin{array}{l}1.45- \\
26.13\end{array}$ & $1.82 *$ & 0.74 & 1.17 & $\begin{array}{c}0.88- \\
1.57\end{array}$ & 0.16 & 0.15 \\
\hline $\begin{array}{l}\text { Common EB } \\
\text { Strategy Use }\end{array}$ & 0.18 & $\begin{array}{c}0.04- \\
0.84\end{array}$ & $-1.72 *$ & 0.79 & 0.82 & $\begin{array}{c}0.59- \\
1.14\end{array}$ & -0.20 & 0.17 \\
\hline $\begin{array}{l}\text { Knowledge of EB } \\
\text { Disruptive } \\
\text { Behavior } \\
\text { Treatment } \\
\text { Techniques }\end{array}$ & 0.84 & $\begin{array}{l}0.65- \\
1.08\end{array}$ & -0.18 & 0.13 & 0.99 & $\begin{array}{c}0.92- \\
1.06\end{array}$ & -0.01 & 0.04 \\
\hline $\begin{array}{l}\text { Years in the } \\
\text { Initiative }\end{array}$ & 0.21 & $\begin{array}{c}0.09- \\
0.53 \\
\end{array}$ & $1.55^{-} *$ & 0.46 & 1.13 & $\begin{array}{c}0.79- \\
1.62 \\
\end{array}$ & 0.12 & 0.18 \\
\hline \multicolumn{9}{|c|}{ Note. $\mathrm{OR}=$ Odds Ratio; IRR = Incidence Rate Ratios; $\mathrm{CI}=$ Confidence Interval; $\mathrm{EB}=$} \\
\hline \multicolumn{9}{|c|}{ Evidence-based; Reference Group for Disruptive Behavior Presenting Problem is $0=$} \\
\hline \multicolumn{9}{|c|}{ Not a disruptive behavior presenting problem for case; +Denotes $p<0.10$, ${ }^{*}$ Denotes $p$} \\
\hline$<0.05, * *$ Denotes & 0.0 & & & & & & & \\
\hline
\end{tabular}


Table 11

Model 1: Multilevel Model for Knowledge of Evidence-Based Services $(n=285)$

\begin{tabular}{|c|c|c|c|c|}
\hline & $\mathrm{B}$ & $S E$ & $t$ & $p$ \\
\hline Intercept & 88.95 & 0.72 & 122.77 & $<.001 * *$ \\
\hline Time & 0.38 & 0.57 & 0.67 & 0.50 \\
\hline Trainee Status & 3.16 & 1.58 & 2.01 & $0.046 *$ \\
\hline Ongoing Support Participation & 2.78 & 1.93 & 1.44 & 0.15 \\
\hline Number of Training Hours & 0.02 & 0.02 & 0.68 & 0.50 \\
\hline $\begin{array}{l}\text { Trainee Status: Ongoing Support } \\
\text { Participation }\end{array}$ & 9.47 & 3.67 & 2.58 & $0.01 *$ \\
\hline Variance Components & Variance & $S D$ & & \\
\hline Residual & 45.50 & 6.75 & & \\
\hline Intercept & 69.67 & 8.35 & & \\
\hline
\end{tabular}

Note. Reference group for Trainee Status was Non-trainee (=0), for Ongoing Support

Participation was no ongoing participation $(=0) .+p<.10,{ }^{*} p<.05, * * p<.01$ 
Table 12

Model 2: Multilevel Model for Specific Evidence-Based Strategy Use ( $n=317)$

\begin{tabular}{lcccc}
\hline & $\mathrm{B}$ & $S E$ & $t$ & $p$ \\
\hline Intercept & 3.37 & 0.21 & 15.90 & $<.001^{* *}$ \\
Time & 0.12 & 0.13 & 0.94 & 0.35 \\
Trainee Status & -0.54 & 0.28 & -1.94 & $0.053+$ \\
Ongoing Support Participation & 0.20 & 0.31 & 0.64 & 0.52 \\
Number of Training Hours & 0.01 & 0.004 & 1.42 & 0.16 \\
\hline Variance Components & Variance & $S D$ & & \\
\hline Residual & 3.10 & 1.76 & & \\
Intercept & 1.20 & 1.10 & & \\
\hline
\end{tabular}

Note. Reference group for Trainee Status was $0=$ Non-trainee, for Ongoing Support

Training Activity Participation was $0=$ no ongoing support training activity

participation. $+p<.10, * p<.05, * * p<.01$ 
Table 13

Model 3: Multilevel Model for Common Evidence-Based Strategy Use ( $n=317)$

\begin{tabular}{|c|c|c|c|c|}
\hline & $\mathrm{B}$ & $S E$ & $t$ & $p$ \\
\hline Intercept & 4.41 & 0.06 & 71.66 & $<.001 * *$ \\
\hline Time & 0.02 & 0.06 & 0.28 & 0.78 \\
\hline Trainee Status & -0.58 & 0.14 & -4.19 & $<.001 * *$ \\
\hline Ongoing Support Participation & -0.25 & 0.20 & -1.28 & 0.20 \\
\hline Number of Training Hours & -0.001 & 0.008 & -0.09 & 0.93 \\
\hline $\begin{array}{l}\text { Trainee Status: Ongoing Support } \\
\text { Participation }\end{array}$ & 0.96 & 0.34 & 2.83 & $0.005 * *$ \\
\hline Trainee Status: Number of Training Hours & 0.04 & 0.02 & 1.94 & $0.054+$ \\
\hline $\begin{array}{l}\text { Ongoing Support Participation: Number } \\
\text { of Training Hours }\end{array}$ & 0.03 & 0.01 & 2.33 & $0.02 *$ \\
\hline $\begin{array}{l}\text { Trainee Status: Ongoing Support } \\
\text { Participation: Number of Training Hours }\end{array}$ & -0.07 & 0.02 & -2.90 & $0.004 * *$ \\
\hline Variance Components & Variance & $S D$ & & \\
\hline Residual & 0.37 & 0.61 & & \\
\hline Intercept & 0.53 & 0.73 & & \\
\hline
\end{tabular}

Note. Reference group for Trainee Status was $0=$ Non-trainee, for Ongoing Support

Training Activity Participation was $0=$ no ongoing support training activity

participation. $+p<.10, * p<.05, * * p<.01$ 
Table 14

Model 4: Multilevel Model for Other Therapy Strategy Use $(n=319)$

\begin{tabular}{lcccc}
\hline & $\mathrm{B}$ & $S E$ & $t$ & $p$ \\
\hline Intercept & 4.39 & 0.06 & 76.53 & $<.001^{* *}$ \\
Time & -0.02 & 0.04 & -0.53 & 0.60 \\
Trainee Status & $\mathbf{- 0 . 7 7}$ & $\mathbf{0 . 1 2}$ & $\mathbf{- 6 . 2 5}$ & $<.001 * *$ \\
Ongoing Support Participation & -0.09 & 0.14 & -0.66 & 0.51 \\
Number of Training Hours & $\mathbf{- 0 . 0 0 4}$ & $\mathbf{0 . 0 0 2}$ & $\mathbf{- 2 . 0 1}$ & $\mathbf{0 . 0 4 5 *}$ \\
Trainee Status: Ongoing Support & $\mathbf{0 . 6 0}$ & $\mathbf{0 . 2 6}$ & $\mathbf{2 . 2 8}$ & $\mathbf{0 . 0 2 *}$ \\
Participation & Variance & $S D$ & & \\
\hline Variance Components & 0.27 & 0.52 & & \\
\hline Residual & 0.56 & 0.75 & & \\
Intercept & 0.56 &
\end{tabular}

Note. Reference group for Trainee Status was $0=$ Non-trainee, for Ongoing Support

Training Activity Participation was $0=$ no ongoing support training activity

participation. $+p<.10, * p<.05, * * p<.01$ 
Table 15

Model 5: Multilevel Model for Confidence in One's Effectiveness in Treating Youth with Anxiety, Depression, Disruptive Behavior, and Trauma $(n=319)$

\begin{tabular}{|c|c|c|c|c|}
\hline & B & $S E$ & $t$ & $p$ \\
\hline Intercept & 4.10 & 0.06 & 72.19 & $<.001 * *$ \\
\hline Time & 0.07 & 0.05 & 1.44 & 0.15 \\
\hline Trainee Status & -0.84 & 0.12 & -6.75 & $<.001 * *$ \\
\hline Ongoing Support Participation & 0.04 & 0.15 & 0.26 & 0.79 \\
\hline Number of Training Hours & 0.003 & 0.002 & 1.45 & 0.15 \\
\hline $\begin{array}{l}\text { Trainee Status: Ongoing Support } \\
\text { Participation }\end{array}$ & 0.76 & 0.29 & 2.64 & $0.009 * *$ \\
\hline Variance Components & Variance & $S D$ & & \\
\hline Residual & 0.38 & 0.61 & & \\
\hline Intercept & 0.51 & 0.71 & & \\
\hline \multicolumn{5}{|c|}{ Note. Reference group for Trainee Status was $0=$ Non-trainee, for Ongoing Support } \\
\hline \multicolumn{5}{|c|}{ Training Activity Participation was $0=$ no ongoing support training activity } \\
\hline
\end{tabular}


Table 16

Model 6: Multilevel Model for Attitudes towards Evidence-Based Practices $(n=317)$

\begin{tabular}{lcccc}
\hline & $\mathrm{B}$ & $S E$ & $t$ & $p$ \\
\hline Intercept & 3.05 & 0.03 & 105.021 & $<.001^{* *}$ \\
Time & -0.04 & 0.02 & -1.82 & 0.07 \\
Trainee Status & 0.04 & 0.06 & 0.61 & 0.54 \\
Ongoing Support Participation & $\mathbf{0 . 1 4}$ & $\mathbf{0 . 0 7}$ & $\mathbf{2 . 1 2}$ & $\mathbf{0 . 0 3 *}$ \\
Number of Training Hours & 0.0003 & 0.001 & 0.37 & 0.71 \\
\hline Variance Components & Variance & $S D$ & & \\
\hline Residual & 0.09 & 0.30 & & \\
Intercept & 0.12 & 0.35 & & \\
\hline
\end{tabular}

Note. Reference group for Trainee Status was $0=$ Non-trainee, for Ongoing Support

Training Activity Participation was $0=$ no ongoing support training activity

participation. $+p<.10, * p<.05, * * p<.01$ 
Table 17

Qualitative Questions and Themes

\begin{tabular}{ll}
\hline \multicolumn{1}{c}{ Question(s) } & \multicolumn{1}{c}{ Themes \& Subtheme(s) } \\
\hline Overall Impressions of Training Initiative \\
$\begin{array}{ll}\text { Tell me briefly about your } & \text { Providers found the training activities to be acceptable } \\
\text { experience with the } & \text { (i.e., satisfactory) and recommended workshops to } \\
\text { training activities offered } & \text { colleagues and/or supervisees and trainees. } \\
\text { through the initiative } & \end{array}$
\end{tabular}

Facilitators and Barriers to Training Engagement

What motivated or drove

Practical Factors

you to attend those

training activities?

- Cost

- Time restraints

How did you decide to attend those specific trainings?

- Location

- Email reminders

- Awareness of training opportunities

System-Level Factors - "Outer Setting"

Can you tell us why you did not end up participating in any training activities or in the PLC and/or consultation activities?

What made it more likely for you to attend a training?

- Continue education

Provider-Level Factors - "Characteristics of individuals"

- Motivation to Improve

- Personality

- Fit with orientation

- Practice caseload

- Professional Role

Organizational-Level Factors - "Inner setting"

- Employer Openness and Support

- Employer Requirement

What made it more

- Recommendation by Colleague

difficult for you to attend a training?

- Competing Demands

- Organizational Setting

Training-Related Factors

- Networking opportunities

- Opportunities to learn from other providers

- Opportunities to consult

- Opportunities for support (e.g., professional, as a resource)

- Workshop-specific Factors

- Length of workshop

○ Workshop topic

- Relevance

- Interest

- Not duplicative

○ Attendees 
○ Presenter

- Online Clinical Feedback System-Specific Factors

○ Duplication of other required documentation

\section{Implementation following Training}

Have you used what you've learned in any of the trainings?

What have you used?
Implementation

Materials

- Used resources provided at workshops

- Referenced slides

- Purchased manuals introduced at workshops

Techniques and skills

- Used specific techniques or skills learned

Knowledge

- Used knowledge learned

Collaboration

- Collaborated with presenter following training

- Shared resources provided at workshops with colleagues

Other Implementation

- Organization support/buy-in

- Used what learned in supervision

- Applied knowledge of EBP in work as college instructor

\section{Facilitators and Barriers to Implementation}

\section{What has made it}

hard/difficult to

implement what you've

learned in the trainings?

What has helped you to implement what you've learned in the trainings?
Practical Factors

- Time restraints

- Resources

Provider-Level Factors - "Characteristics of individuals"

- Motivation to Improve

- Fit with orientation

- Practice caseload

- Professional Role

- Professional setting

- Comfort Level or Prior Training

Organizational-Level Factors - "Inner setting"

- Employer Support

Implementation Factors

- Timing

- Consistency

Training-Related Factors

- Learning from other providers

- Workshop-specific Factors

○ Length of workshop 
- Active Learning Strategies

- Presenter

- Inadequate for translating knowledge to practice

- Take home materials

- Online clinical feedback system-specific Factors

○ Not being tech savvy

- Difficult to use when already have system

- Time restraints

- Ease of use

- Biweekly Learning Community-Specific Factors

- Helps to reprocess information

○ Opportunities to consult with other providers 
Figure 1

Interaction Effect between Trainee Status and Ongoing Support Activity Participation in Model 1: Predicting Impact of the Training Initiative on Knowledge

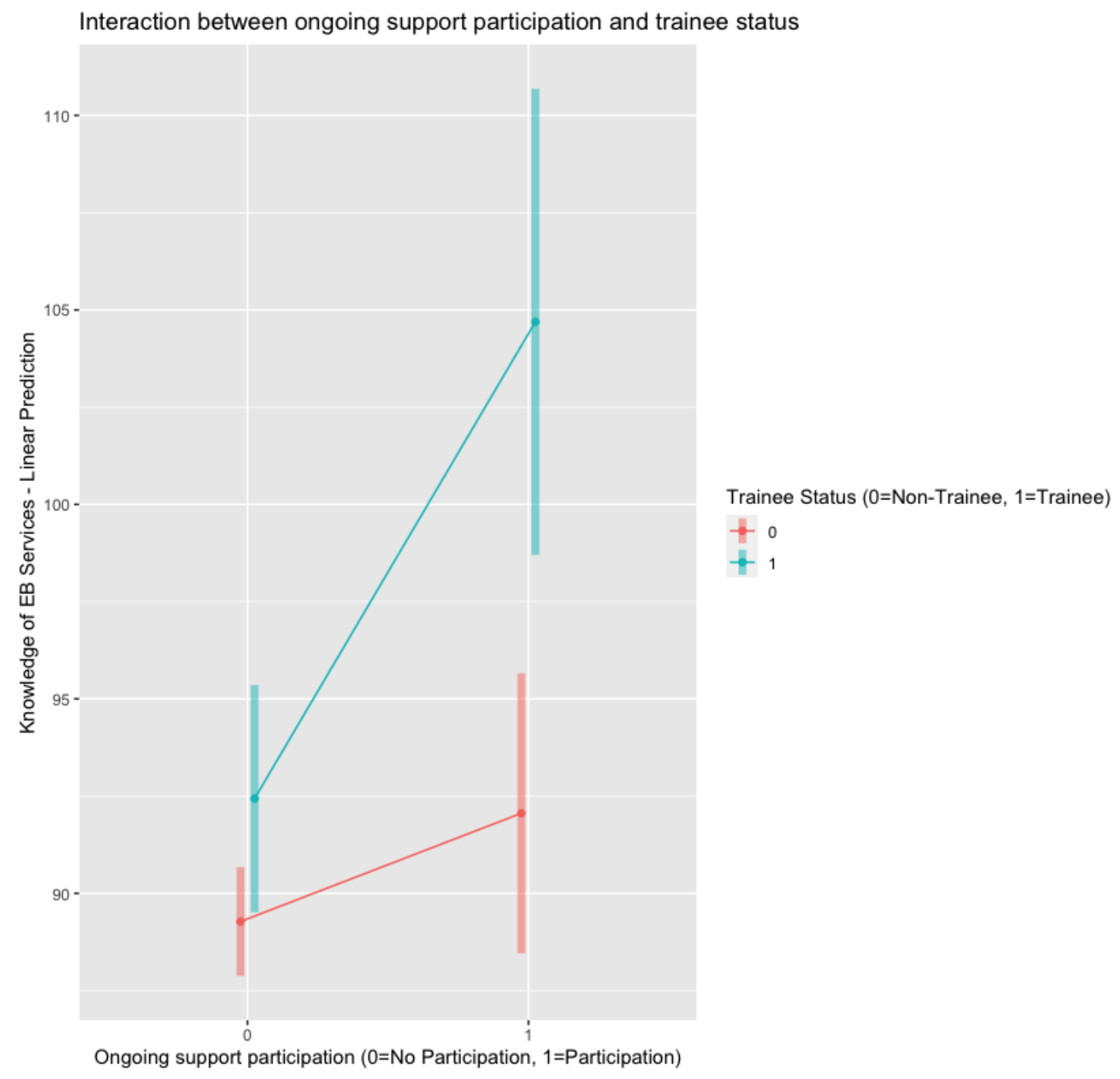


Figure 2

Interaction Effect between Number of Training Hours, Ongoing Support Activity

Participation, and Trainee Status in Model 3: Predicting Impact of the Training Initiative on Common EB Therapy Strategy Use

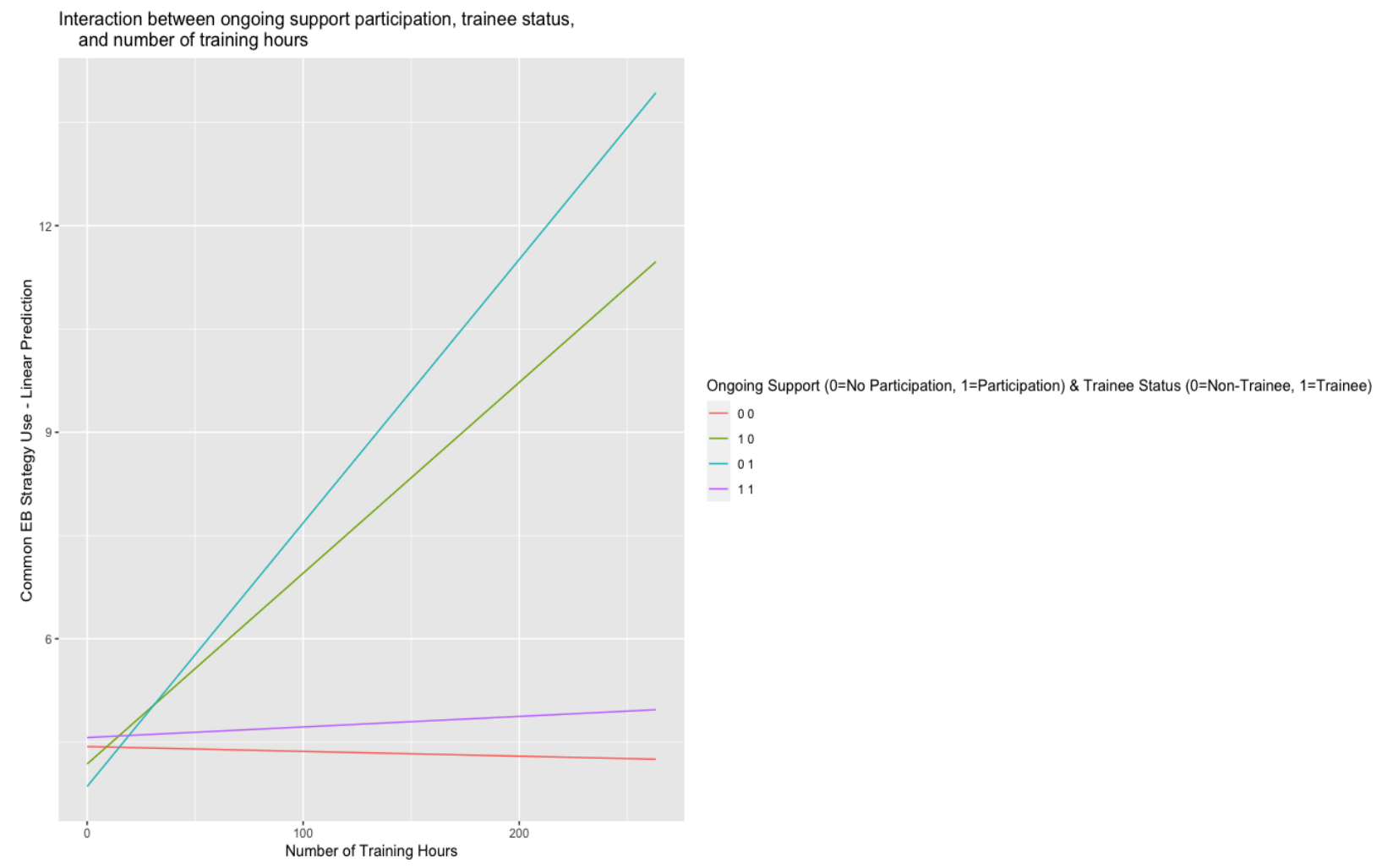


Figure 3

Interaction Effect between Trainee Status and Ongoing Support Activity Participation in Model 3: Predicting Impact of the Training Initiative on Common Evidence-Based Therapy Strategy Use

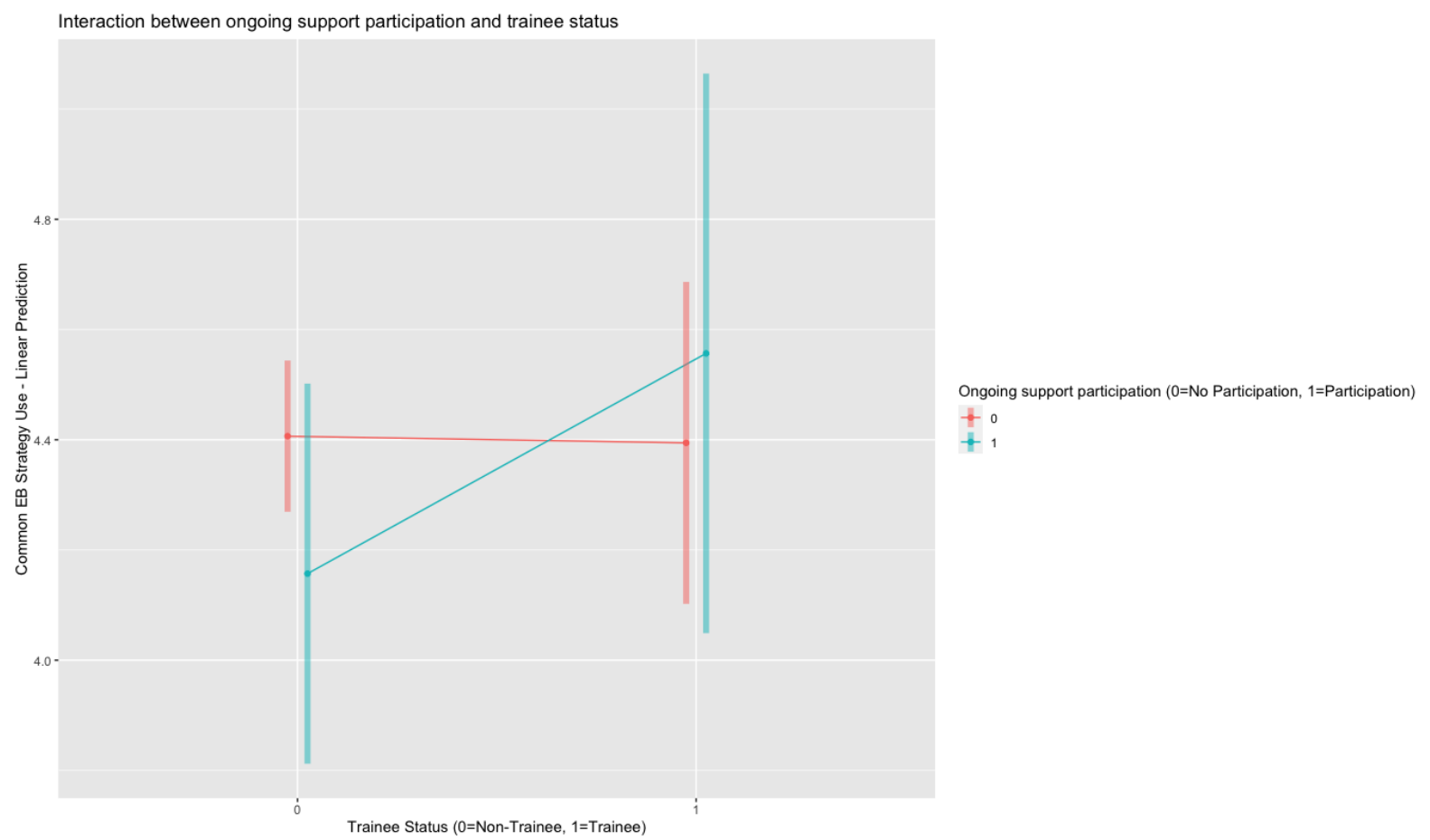


Figure 4

Interaction Effect between Number of Training Hours and Ongoing Support Activity

Participation in Model 3: Predicting Impact of the Training Initiative on Common

Evidence-Based Therapy Strategy Use

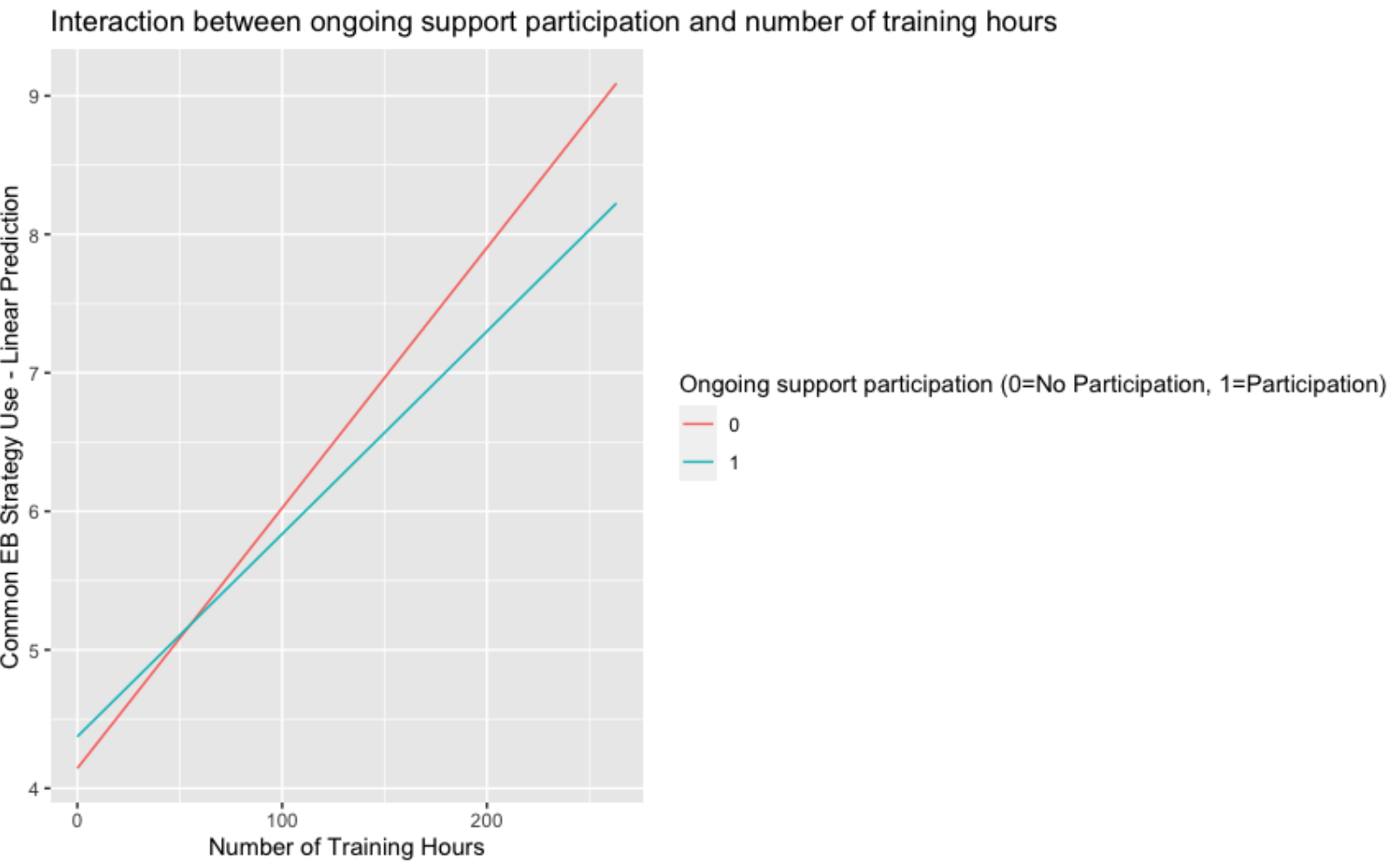


Figure 5

Interaction Effect between Number of Training Hours and Ongoing Support Activity

Participation in Model 4: Predicting Impact of the Training Initiative on Other Therapy

Strategy Use

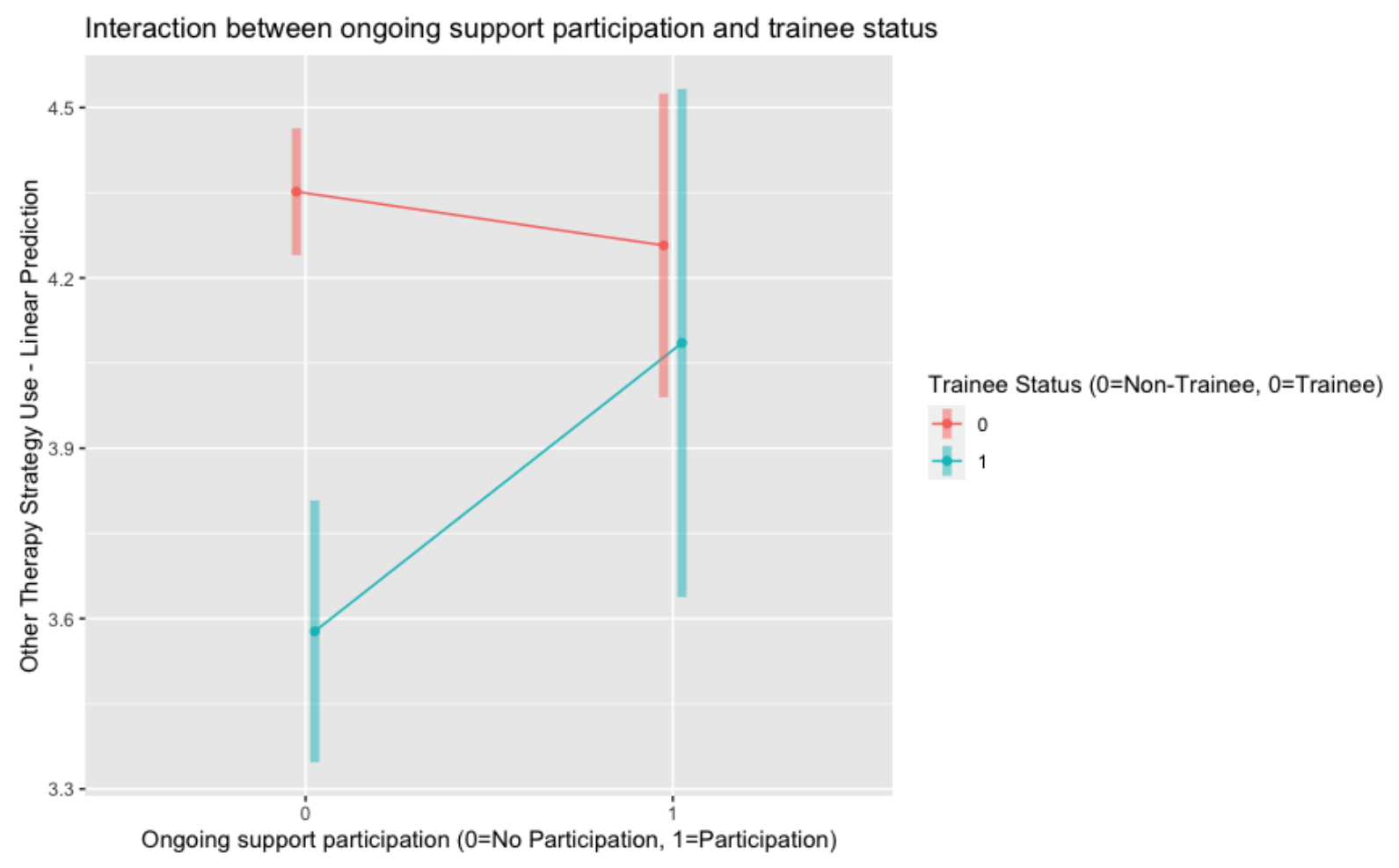


Figure 6

Interaction Effect between Trainee Status and Ongoing Support Activity Participation in Model 5: Predicting Impact of the Training Initiative on Provider Self-Reported

Confidence

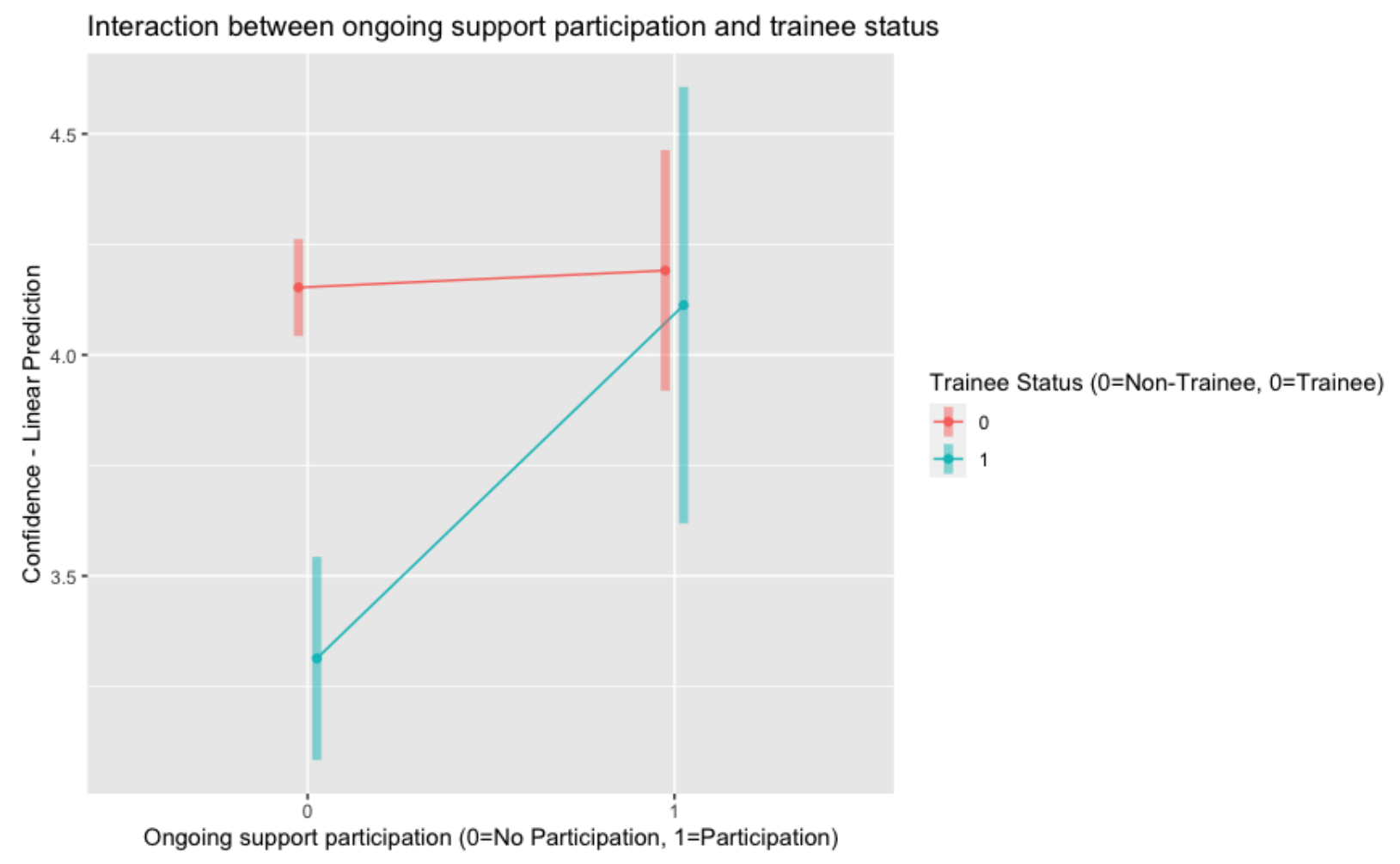




\section{Individual Interview Questions}

Thank you for participating in the Center for Evidence-Based Youth Mental Health's training initiative. Through this initiative, we were able to provide free training, consultation, and support to mental health providers and allied professionals in researchsupported assessment and treatment practices for children, adolescents, young adults and families. We offered four types of training opportunities: workshops, learning community, one-on-one consultation, and online individualized feedback. We are interviewing you to assess the usefulness of the training activities provided and determine further areas we could make improvements.

\section{Overall Impressions of Training Initiative}

Tell me briefly about your experience with the training activities offered through the Center for Evidence-Based Youth Mental Health.

\section{Deciding on and Investing in Training}

Which training activities did you attend? We offered four types of training opportunities: workshops, learning community, one-on-one consultation, and online individualized feedback.

[If participated in any training activities]

- What motivated or drove you to attend those training activities?

- How did you decide to attend those specific trainings?

[If did NOT participate in any training activities]

- Can you tell us why you did not end up participating in any training activities?

[If only participated in workshops only, not PLC or consultation]

- We know that everyone didn't complete all of the training activities. Can you talk about why you did not participate in the PLC and/or consultation activities?

What made it more likely for you to attend a training? Anything about your background, education, personality, or anything about your work or practice, anything with your job or organization?

- Which is the most important factor that helps you be able attend or participate in training activities?

What made it more difficult for you to attend a training? Again, it can be anything about you, about the nature of your work, or about your organization?

- Which of these is the greatest barrier or challenge to being able attend or participate in the training activities?

\section{Implementation Following Training}


Have you used what you've learned in any of the trainings?

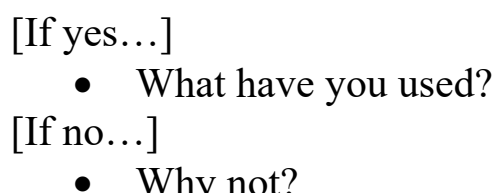

What has made it hard/difficult to implement what you've learned in the trainings? [anything about you, the nature of your work, anything within your job or organization?]

What has helped you to implement what you've learned in the trainings? [anything about you, the nature of your work, anything within your job or organization?]

\section{County Mental Health Tax}

We were able to provide these free training opportunities through funding and support from the Boone County Children's Services Fund. This fund exists because of a voterapproved sales tax that was created to support youth mental health.

Were you a part of this grass-roots effort? If so, tell me more about your experiences and thoughts.

[if not] Are you aware of this sales tax? If so, tell me about your experiences or thoughts on the tax.

What were your initial impressions of the tax? Have these impressions changed over time? If so, what prompted the change?

Have you participated in other services or programs funded through this tax besides this training initiative?

\section{Closing}

What else would you like to tell me that I haven't asked about? Or anything you were expecting to talk about today that we haven't?

\section{$\underline{\text { Training Topics Interested }}$}

How about clinical topics for which you would be most interested in receiving training? 


\section{Transcript Summary}

Prepared By: [NAME]

ID \#: [ID0\#\#]

Respondent Info: [e.g., types and amount of training completed, discipline, licensure status]

\begin{tabular}{|c|c|}
\hline Domains & Key Points \& Exemplar Quotes \\
\hline \multicolumn{2}{|c|}{ Deciding on and Investing in Training } \\
\hline $\begin{array}{l}\text { Overall Impressions \& Other } \\
\text { Thoughts } \\
\text { (themes related to the provider's } \\
\text { overall impressions or thoughts on } \\
\text { the training initiative that did not fit } \\
\text { under another domain) }\end{array}$ & \\
\hline $\begin{array}{l}\text { Training Participation } \\
\text { (which training activities the } \\
\text { provider participated in) }\end{array}$ & \\
\hline $\begin{array}{l}\text { Facilitators of Attendance } \\
\text { (themes related to the provider's } \\
\text { motivation or decision to attend } \\
\text { training activities and what made it } \\
\text { more likely for the provider to } \\
\text { attend/participate) }\end{array}$ & \\
\hline $\begin{array}{l}\text { Barriers to Attendance } \\
\text { (themes related to the provider's lack } \\
\text { of participation in training activities } \\
\text { and what made it more difficult for } \\
\text { the provider to attend/participate) }\end{array}$ & \\
\hline $\begin{array}{l}\text { Future Training Topics } \\
\text { (clinical topics for which the } \\
\text { provider would be interested in } \\
\text { receiving training) } \\
\text { Note. This was typically asked at the } \\
\text { end of the interview, though it could } \\
\text { have come up at any point in the } \\
\text { interview. }\end{array}$ & \\
\hline \multicolumn{2}{|c|}{ Implementation Following Training } \\
\hline $\begin{array}{l}\text { Implementation } \\
\text { (themes related to implementation } \\
\text { [or lack of] and what the provider } \\
\text { implemented) }\end{array}$ & \\
\hline $\begin{array}{l}\text { Barriers to Implementation } \\
\text { (themes related to what made it } \\
\text { difficult for the provider to } \\
\text { implement what they've learned in } \\
\text { trainings into their practice) }\end{array}$ & \\
\hline $\begin{array}{l}\text { Facilitators of } \\
\text { Implementation }\end{array}$ & \\
\hline
\end{tabular}




\begin{tabular}{|l|l|}
\hline $\begin{array}{l}\text { (themes related to what helped the } \\
\text { provider to implement what they've } \\
\text { learned in trainings into their } \\
\text { practice) }\end{array}$ \\
\hline \\
\hline $\begin{array}{l}\text { Grass-roots effort } \\
\text { (the provider's participation [or lack } \\
\text { off in the grass-roots effort for the } \\
\text { tax) }\end{array}$ \\
\hline $\begin{array}{l}\text { Thoughts on Tax } \\
\text { (themes related to the provider's } \\
\text { views of and experiences with the } \\
\text { tax) }\end{array}$ \\
\hline $\begin{array}{l}\text { Tax Funded Programs } \\
\text { (the provider's collaboration with } \\
\text { other tax-funded services and } \\
\text { programs) }\end{array}$ \\
\hline \multicolumn{2}{|c|}{ Suggestions/Improvements Tax } \\
\hline $\begin{array}{l}\text { Suggestions for } \\
\text { Improvement } \\
\text { (the provider's specific suggestions } \\
\text { for improvement for our trainings } \\
\text { and training initiative) }\end{array}$ \\
\hline
\end{tabular}

\section{Other Notes:}


VITA

Brigid Marriott was born in Harvey, Illinois and was raised with her two younger sisters in Munster, Indiana. She graduated from Munster High School in Munster, Indiana. She received a Bachelor of Science in Psychology from Indiana University in Bloomington, IN in 2014. During undergrad, she worked in Dr. Cara Lewis' research lab, which introduced her to the field implementation science, and completed an honors thesis focused on examining the correlates, consequences, and context surrounding the disclosure of traumatic experiences. After working as a postbaccalaureate researcher at Indiana University, she was accepted into the clinical child psychology doctoral program at the University of Missouri. She received a Master of Arts degree in Clinical Psychology from the University of Missouri in 2018. Under the mentorship of Dr. Kristin Hawley, her master's thesis evaluated a low-cost, multi-component, web-based training for Trauma-Focused Cognitive Behavioral Therapy for mental health providers. Brigid will be completing her predoctoral Clinical Psychology internship at the Medical University of South Carolina in Charleston, South Carolina and will receive a Ph.D. in Clinical Psychology from the University of Missouri in August 2021. Her long-term career goal is to have a position that combines translational science and applied clinical research to improve mental health services for youth and families. 